NBER WORKING PAPER SERIES

\title{
SPILLOVER EFFECTS OF INTELLECTUAL PROPERTY PROTECTION IN THE INTERWAR AIRCRAFT INDUSTRY
}

\author{
Walker Hanlon \\ Taylor Jaworski \\ Working Paper 26490 \\ http://www.nber.org/papers/w26490 \\ NATIONAL BUREAU OF ECONOMIC RESEARCH \\ 1050 Massachusetts Avenue \\ Cambridge, MA 02138 \\ November 2019, Revised September 2021
}

We thank Sascha Becker, Luis Cabral, Ann Carlos, Yongmin Chen, Jose Espin-Sanchez, Andy Ferrara, Dan Gross, Stephan Heblich, Shawn Kantor, Naomi Lamoreaux, Petra Moser, Steve Nafziger, Tom Nicholas, Paul Rhode, Paul Scott, Carol Shiue, Vaidyanathan Venkateswaran, Chris Vickers, Fabian Waldinger, John Wallis, Alex Whalley, Larry White, Mark Wilson and seminar participants at Bristol, ITAM, Oxford, LSE, Michigan, NYU Stern, Colorado, Warwick, Williams, Yale, the Mountain West Economic History Conference, the NBER Summer Institute, and the Washington Area Economic History Seminar for helpful comments. We thank Enrico Berkes for sharing his patent data. The views expressed herein are those of the authors and do not necessarily reflect the views of the National Bureau of Economic Research.

NBER working papers are circulated for discussion and comment purposes. They have not been peer-reviewed or been subject to the review by the NBER Board of Directors that accompanies official NBER publications.

(C) 2019 by Walker Hanlon and Taylor Jaworski. All rights reserved. Short sections of text, not to exceed two paragraphs, may be quoted without explicit permission provided that full credit, including $(\odot$ notice, is given to the source. 
Spillover Effects of Intellectual Property Protection in the Interwar Aircraft Industry

Walker Hanlon and Taylor Jaworski

NBER Working Paper No. 26490

November 2019, Revised September 2021

JEL No. N72,O34

\title{
ABSTRACT
}

Can strengthening intellectual property (IP) protection for producers of one good affect innovation in other related goods? To answer this question, we exploit a unique policy experiment in the interwar military aircraft industry. Airframe designs had little IP protection before 1926, but changes passed by Congress in 1926 provided airframe manufacturers with enhanced property rights over new designs. We show that granting property rights to air-frame producers increased innovation in airframes, but slowed innovation in aero-engines, a complementary good where there was no change in the availability of IP protection. We propose and test a simple theory that explains these patterns.

\author{
Walker Hanlon \\ Department of Economics \\ NYU Stern School of Business \\ Henry Kaufman Management Center \\ 44 West Fourth Street \\ New York, NY 10012 \\ and NBER \\ walker.hanlon@gmail.com \\ Taylor Jaworski \\ Department of Economics, UCB 256 \\ University of Colorado at Boulder \\ Boulder, CO 80309 \\ and NBER \\ taylor.jaworski@colorado.edu
}




\section{Introduction}

Granting property rights for new inventions is a central feature of innovation systems. Standard theories of innovation emphasize how intellectual property (IP) rights incentivize innovation by providing market power that allows firms to extract rents to compensate for investment. Theory also predicts that granting market power to producers of one type of good will impact the rents available to firms producing either complementary or substitute goods. A direct implication is that granting IP to one group of producers will change the rents available-and the incentives to innovate-for producers of related goods. This suggests there may be important spillovers from granting IP protection to goods on innovation activity in complement or substitute goods through market power channels. ${ }^{1}$

However, there is little empirical evidence on the spillovers of IP protection offered to producers of one type of good on innovation in related (e.g. complement or substitute) goods. Instead, existing research focuses on the impact of IP protection within classes of similar products. For example, Williams (2013) and Sampat and Williams (2019) study the impact of IP rights on follow-on innovation in human genes and Gilchrist (2016) considers the impact within classes of competing pharmaceutical drugs. ${ }^{2}$ In this paper, we quantify the spillover effects of IP protection that arise between markets linked by complementary goods produced by different firms.

Quantifying the direct and spillover effects of IP protection on innovation presents three challenges. The first is to find a setting where IP protection changes for producers of one good, but not for producers of related goods. We focus on a setting-the US aircraft industry in the interwar period-with this vital feature. A functional powered aircraft requires both an airframe and one or more aero-engines. In this period-and continuing to today-these two elements are typically produced by different companies and purchased separately (e.g., Boeing produces airframes, Pratt \& Whitney produces engines). At the end of World War I, allegations of war profiteering led Congress to limit IP protection available to airframe producers of military designs, which represented the majority of the aircraft market. Companies that produced a new military airframe did not have an exclusive right to their design. Rather, it was put out for competitive

\footnotetext{
${ }^{1}$ Several recent debates highlight the connection between access to IP protection, market power, and innovation. For example, numerous commentators have argued that the market power of the largest tech companies, which is in part due to the IP portfolios they hold, may be reducing innovation in complementary products, such as smartphones and smartphone apps (see, e.g., "Big tech has too much monopoly power - it's right to take it on," Kenneth Rogoff, The Guardian, April 2, 2019 and "How the Frightful Five Put Start-Ups in a Lose-Lose Situation," Farhad Manjoo, New York Times, Oct. 18, 2017).

${ }^{2}$ See Williams (2017) for a survey of this literature. Green and Scotchmer (1995) is a key theory reference looking at the impact of competition within a product category on innovation incentives. In addition, a number of papers examine how changes in IP protection affect the price and availability of existing products (e.g., see recent work by Chaudhuri, Goldberg and Jia (2006) and Duggan, Garthwaite and Goyal (2016)). This line of research is different from our study, which focuses on the impact of IP protection on innovation.
} 
bidding. For example, when the Glenn L. Martin Company designed the MB-3 bomber and the War Department decided to purchase 200 versions of this plane through a competitive bidding process, the production contract was eventually won by Curtiss, Martin's competitor. The IP regime changed in 1926 when Congress altered the policy to give firms producing new designs accepted by the military exclusivity in the production contract. Importantly, the change in IP protection only applied to airframe producers; engine producers had access to IP protection over the entire period. We use this policy change to understand the impact of IP protectionby which we mean property rights over a new idea or design-on innovation in airframes and complementary aero-engines.

To be clear, the setting we study reflects a strengthening of a particular type of IP protection through a change in procurement policy. This type of IP protection differs in a number of ways from other forms of IP protection, including patents, copyright, laws that help firms protect their IP through secrecy, and regulations that determine when governments can override IP rights. ${ }^{3}$ The policy we study effectively granted firms an exclusive right to produce a new design, but not the right to license or sell the design. Despite these differences, when interpreted with care, the policy change we study can be used to shed light on aspects of IP that are often difficult to study in other ways.

A second challenge in studying the spillover effects of IP protection is that standard measures of innovation used in the literature (e.g., patents) critically depend on the IP regime. These cannot be used to track the impact of changes in the IP regime on innovation. Our setting allows us to get around this issue by measuring innovation directly using data on the performance characteristics of airframes and engines. We draw on several sources to construct standard performance measures for airframes (e.g., wing load, calculated as the gross weight divided by wing area) in distinct market segments (e.g., fighters, bombers) as well as aero-engines (e.g., horsepower relative to engine weight, piston displacement, or frontal area). In addition to these direct performance measures, we examine other aspects of technological progress, such as the pace of development in high-performance engine types, and the lag between the vintage of engines and the vintage of the airframes they are used with.

The third challenge is that changes in airframe or aero-engine innovation in the United States may not be the result of IP policy, but instead reflect changes in the world technology frontier that ultimately diffused to the United States. However, in the interwar period, countries operated as mostly isolated markets for military aircraft. In each country, the military purchased airframes and engines almost exclusively from domestic producers. While firms in each coun-

\footnotetext{
${ }^{3}$ The latter have recently been studied by Moser and Voena (2012) and Baten et al. (2017).
} 
try were aware of the broader technological trends, they were exposed to different institutional environments. This allows us to compare airframe and aero-engine innovation in the United States before and after the change in IP policy with other countries that did not experience the same change.

We formalize the incentive to innovate in a theoretical model that emphasizes the profit mechanism central to theories of economic growth and innovation (e.g., Romer, 1990; Grossman and Helpman, 1991; Aghion and Howitt, 1992). In the model, the motivation for airframe producers to innovate are the expected profits associated with new invention. When airframe producers do not have access to IP protection, the price of airframes is the perfectly competitive price. This is consistent with the competitive bidding regime we observe. With IP protection, airframe producers with the best designs can extract additional rents. However, when airframe producers extract more rents, this reduces the profits for engine producers and their incentive to innovate.

Our main empirical analysis documents two patterns consistent with the theory. First, after IP protection became available to American airframe producers, the rate of improvement for key performance measures accelerated. This is apparent either when focusing only on changes within the United States over time or comparing the United States to other countries. Prior to 1926, innovation in airframes was typically slower in the United States than in comparison countries; after 1926, the rate of innovation was faster. This suggests that providing IP protection had a positive effect on technological progress in airframes, as predicted by the theory.

Second, we provide evidence that the rate of innovation in aero-engines slowed after 1926, particularly in the high-performance types used by the military. The clearest example of this change was the sharp reduction in the development of new liquid-cooled engine designs, a type that was particularly important for high-performance fighters. In addition, we show that the difference between the vintage of engines and that of the airframes they were used with increased in the United States, relative to other countries, after 1926, consistent with a slowdown in the pace of engine development. Finally, we document slower performance growth across some dimensions of engine performance, most importantly the rate at which the ratio of engine horsepower to weight was improving. This slowdown is apparent when looking in the United States over time, as well as when comparing to other countries. Because there was no change in the availability of IP protection for engine technology, we attribute this slowdown in engine performance improvements in the United States after 1926 to the spillover effects of granting IP protection to airframe producers.

We also find evidence for a third prediction from the theory: granting IP protection to air- 
frame producers generates incentivizes for mergers between airframe and aero-engine producers, which we refer to as "vertical-complement" mergers. ${ }^{4}$ This occurs because, when IP protection allows airframe producers to extract rents for new designs, it gives rise to a doublemarginalization problem, generating incentives for airframe and aero-engine producers to merge. In the absence of IP protection for airframes, no such incentives exist. Our setting offers a particularly useful environment for testing this prediction because the permissive antitrust regime meant that firms that wanted to merge faced few regulatory barriers. An analysis of firm histories shows merger patterns matching the predictions of the theory.

These findings are interesting for several reasons. First, we provide evidence for spillovers from IP protection. Currently, evidence of how the effects of IP protection can spillover across complementary goods is very limited. ${ }^{5}$ Our results indicate that spillovers arise through a link between market power and innovation decisions across markets. These findings help us understand the interaction between IP and antitrust policy and, ultimately, the direction of innovation and economic growth. In addition, there is a large literature that quantifies the effect of IP protection by comparing similar goods. Our results indicate that this approach may overstate (understate) the total amount of additional innovation generated by IP protection if these goods are complements (substitutes). We also provide the first quantitative assessment of this particular change in IP protection, which has been the subject of debate (Vander Meulen, 1991; Patillo, 1998).

Second, we contribute to research on the effect of market size on innovation (Schmookler, 1966; Acemoglu and Linn, 2004; Finkelstein, 2004). In our setting, IP protection for airframes reduces innovation in aero-engines by reducing residual demand. There is also closely related work beginning with Schumpeter (1942) and Arrow (1962) on the relationship between competition and innovation. Existing empirical evidence frequently takes competition or market concentration as given and estimates the effect on innovative activity (e.g., Blundell, Griffith and Van Reenen, 1999; Aghion, Bloom, Blundell, Griffith and Howitt, 2005; Aghion, Blundell, Griffith, Howitt and Prantl, 2009). Our focus on the effect of IP protection on firms producing complementary goods is novel and in this context our results provide evidence for the endogenous response of market structure to IP protection through vertical-complement mergers. ${ }^{6}$

\footnotetext{
${ }^{4}$ We use this terminology because, while mergers between aero-engine and airframe producers do not fit the classic definition of a vertical merger, since these inputs were typically purchased separately, they are similar to classic vertical mergers in important ways.

${ }^{5}$ One recent related paper is Moscona (2019), which studies the impact of a change in patent protection applying to US agriculture and provides evidence of spillover effects on complementary goods. One difference in our study is that we investigate the mechanisms behind the spillover effects we observe, both theoretically and empirically. Interestingly, the spillovers we document for the aircraft industry are the opposite of those that Moscona documents in agriculture, which suggests that understanding the mechanisms is crucial.

${ }^{6}$ See Loury (1979), Vives (2008), and Chen and Sappington (2010) for related theory and Sanyal and Ghosh (2013)
} 
The remainder of this paper is organized as follows. In Section 2 we provide historical background relevant for understanding the setting of the aircraft industry during the interwar period. In Section 3 we present our theory and the predictions we take to the data. Section 4 describes the data and Section 5 describes the empirical analysis and results. We also discuss the evidence for alternative mechanisms. Section 6 concludes.

\section{Empirical Setting}

Military procurement was the primary source of demand for the early aircraft industry, starting with the Wright Brother's first sale to the US Army in 1908. The onset of the First World War increased the demand for aircraft, first in Europe and later in the United States. ${ }^{7}$ The increase in military aircraft purchases during World War I created enormous profits among companies involved in aircraft production (Holley, 1964, p. 83). In the United States, public disclosure of these profits generated a backlash that led to a Congressional investigation. Anxious to avoid charges of waste, Congress forced military procurement officers to use competitive bidding to allocate aircraft production contracts in the years from the end of the war to 1926. Under this regime, a company that produced a design was paid a small design fee and the production order was put up for competitive bidding. ${ }^{8}$ As a result, the vast majority of expenditure on aircraft before 1926 was done through competitive bidding. Specifically, of the $\$ 22$ million spent by the military on aircraft from 1920 to 1924 , all but $\$ 3$ million was allocated through competitive bidding (Holley, 1964, p. 84).

World War I also led to the formation of a patent pool, the Manufacturers' Aircraft Association. Most major airframe producers eventually joined the pool, but even those that did not had free access to the patents included in the pool when working on military orders (Bittlingmayer, 1988). ${ }^{9}$ The presence of the patent pool essentially eliminated the ability of airframe manufacturers to protect their designs using patents. However, an important feature for our purposes is the fact that the pool did not cover aero-engines. For further discussion of the patent pool, see Appendix B.2

for related empirical work. In addition, Klepper (1996), Klepper and Simons (2000), and Buenstorf and Klepper (2009) study innovation and industry evolution in a dynamic framework. Finally, Shapiro (2012), Cohen (2010), and Gilbert (2006) provide overviews of this literature.

${ }^{7}$ See Bryan (2016) for a study of aircraft innovation in the period before 1918.

${ }^{8}$ When one company won the bid for another company's design, the designing company was forced to provide the producer with a prototype together with a set of designs. This ensured that designs could not be protected through secrecy. However, firms could still benefit from process improvements under this regime, so the policy changes we study were unlikely to have substantially altered the benefits of innovations in the production process.

${ }^{9}$ This patent pool differed from those considered by Lampe and Moser $(2010,2014,2016)$. The formation of the pool was compelled by the government largely against the will of the main patent holders. New airframe patents were required to be added to the pool, patent holders received limited remuneration, and firms outside the pool had free access to pool patents when working on government (including military) contracts. See Gilbert (2017) for additional discussion of the impact of patent pools on innovation. 
The combination of procurement by competitive bidding and inability to seek patent protection meant that in the early 1920s airframe producers often failed to win the production orders for their own designs. An illustration of this is provided by the MB-3 bomber designed by the Glenn L. Martin company towards the end of World War I. Having bought the design rights for a modest sum that did not cover development costs, the War Department decided to purchase 200 versions of the plane. The contract was put up for competitive bidding. Martin's bid for the production order, which was calculated to include the cost of developing the original design, came in higher than rival companies. As a result, the contract was won by Curtiss Aeroplane and Motor Company. As a consequence, Holley (1964, p. 85) writes,

Deprived of his airplane, Martin no longer had any incentive to improve that particular design. Worse yet, deprived of a profitable production contract as a means of reimbursing his earlier investment, Martin was soon unable to finance further development work. The statutes... retarded the pace of research and development.

This is just one of several examples of a firm failing to win the production order for an airframe that it had designed. Soon after Curtiss won the MB-3 order, Martin would turn the tables by underbidding Curtiss for the production order of a Navy scout-bomber that Curtiss lost $\$ 180,000$ designing (Vander Meulen, 1991, p. 62). ${ }^{10}$ Clement Keys, the head of Curtiss Aircraft, observed,

It is fairly obvious that no company can spend that amount of money and suffer the grief and disappointment of experimental labor-which is so often lost labor-only to have the product of that labor taken up by the Government and thrown open to competitive bidding. It is fair to say that because of these conditions over which the industry has no control, not only the Curtiss Company, but all other forward looking institutions in this art, have curtailed their efforts, economized their resources and foregone their ambitions for the art in order to adapt themselves to the policies of their Government. (Vander Meulen, 1991, p. 53).

Not surprisingly, this procurement regime provided airframe producers with little incentive to produce new designs. The military tried to compensate for the lack of innovation incentives by producing their own designs in-house at the Naval Aircraft Factory in Philadelphia and the Army's McCook Field in Ohio. In the end this proved unsatisfactory, possibly because it largely separated design work from manufacturing. ${ }^{11}$

\footnotetext{
${ }^{10}$ Vander Meulen (1991, p. 62) goes on to describe how Curtiss, "submitted a bid of \$32,000 per plane, but Glenn Martin won the contract at $\$ 23,000$ apiece. Martin complained that the plane came with no blueprints but admitted that they would have been useless in his shop anyway. His staff drew up a new set of blueprints and in the process produced an entirely new plane inferior in performance to the Curtiss design." This story, which was not unusual, highlights how the process of competitive bidding was inefficient in addition to retarding innovation.

${ }^{11}$ The military also sought to generate innovation through the purchase of high-performance racing planes, such as the Curtiss R6 and R3C, but in the end this also proved unsatisfactory and government funding of racers was abandoned by 1930 .
} 
Engines formed an important part of the cost of a complete aircraft and were also typically produced by a different company. Consider as an example Boeing's PW-9 pursuit (fighter) aircraft, one of the most successful designs of the 1920s. Army Air Corps Procurement Board records show the total price for a fully equipped PW-9 in 1928 was between $\$ 30,015$ and $\$ 31,654$. The cost of the airframe alone was quoted at $\$ 11,000$. This plane was powered by a single Curtiss D-12 engine, which cost around $\$ 9,000$ at this time. The remaining cost was due to armament, instruments, and other government furnished equipment.

A key feature for our purposes is that the lack of protection for new designs was primarily a problem for airframe manufacturers. For aero-engines, in contrast, the more specialized production process created a concentrated industry with high barriers to entry. Engines were also excluded from the airframe patent pool, which gave engine producers recourse to patent protection. By the mid-1920s, engine production was dominated by a small set of companies, including Wright, Pratt \& Whitney, Packard, Lawrence, and Curtiss (see Appendix B.7 for market share data). ${ }^{12}$ After 1926, and particularly after the mergers of 1929, Wright and Pratt \& Whitney came to dominate this group. As a result of this relatively concentrated market, together with access to patent protection, engine manufacturers were not at risk of losing production orders for an engine designed under the competitive bidding regime.

Both the military and aircraft manufacturers recognized that competitive bidding for production orders was impeding technological progress in the first half of the 1920s. Pressure from both parties led to the inclusion of changes in the procurement procedures in Section 10 of the Air Corps Act of 1926, which established the Air Corps as a wing of the Army and provided for a five-year expansion in military aircraft purchases (though the expansion in aircraft purchases envisioned by the act was never fully achieved). ${ }^{13}$ While Congress continued to insist on competitive bidding, the language of the 1926 Act included a loophole that Air Corps and Navy procurement officers exploited to avoid competitive bidding in favor of contracts negotiated with individual manufacturers. From 1926 to 1934 the air arm made \$38 million in purchases using negotiated contracts and just \$750,000 under competitive bidding (Holley, 1964, p. 117).

The 1926 Air Corps Act did not change the availability (or lack thereof) of patent protection for either airframe or aero-engine manufacturers. Both before and after the 1926 Act, airframe producers were essentially unable to take advantage of patent protection due to the existence

\footnotetext{
${ }^{12}$ Pratt \& Whitney was founded in 1925 by former Wright employees with the encouragement of the Navy. This occurred in part as a response to Wright's purchase of another engine producer Lawrence, as well as the concurrent decline of interest in aero-engine production by Packard, which left the military concerned about becoming overlyreliant on Wright. This led the military to encourage the emergence of Pratt \& Whitney in order to maintain some balance in the market.

${ }^{13}$ Further discussion of the events leading to the passage of the Air Cops Act can be found in Appendix B.1.
} 
of the patent pool, while aero-engine manufacturers always had access to patent protection. The change in IP protection was not, therefore, due to a change in access to patents. Rather, it was due to a shift in government procurement policy that effectively ensured that if airframe manufacturers managed to produce the leading design within an aircraft category then that firm would receive the purchase order for that design. In practice this change was similar to, but not the same as, gaining IP protection through patents. The main similarity was that it provided firms a monopoly over their designs; one difference was that a design could not be licensed to another producer.

To understand how the changes introduced by the 1926 Act affected aircraft and engine manufacturers it is useful to have some understanding of procurement policies during this period. Most new designs were produced by airframe manufacturers at their own expense in the hope the military would choose to adopt their new airframe (see Appendix D). These "private ventures" were sometimes based on government specifications, while in other cases aircraft companies simply aimed to produce a substantially better plane than the one currently in use. ${ }^{14}$ Other new designs were produced as collaborations between manufacturers and the military. Once a prototype was ready, a few versions would be delivered to the military for testing and evaluation. If a design proved satisfactory then the design would be recommended to the Procurement Board of each branch. Working with an essentially fixed budget each year, procurement boards would make a preliminary decision about how many planes, engines, and other pieces of equipment to purchase based on estimated costs. As actual cost figures were agreed upon, either through competitive bidding (before 1926) or direct negotiation, purchase numbers would be modified to stay within the budget, or certain items could be cancelled or purchases delayed to future years. This meant higher prices for certain aircraft had to be compensated by reducing quantity of that type or cancelling other purchases (see Appendix B.4). Purchase prices for equipment were fixed (though regularly adjusted as the military asked for modifications of the original design), unlike the cost-plus or other contracts that are commonly used today. The demand system used in our model is intended to reflect these features in a stylized way.

Congress passed other legislation affecting the aircraft industry in the middle of the 1920s. The Air Mail Act of 1925 (Kelly Act) authorized the Post Office to contract with private air carriers for the carriage of mail, effectively launching the commercial aviation industry. The Air Commerce Act of 1926 empowered the Department of Commerce to regulate and promote air

\footnotetext{
${ }^{14}$ For example, in 1930 Boeing produced a new bomber design (YB-9), the first all-metal monoplane bomber, as a private venture based on the lessons learned from the Model 200 Monomail. In response, the Glenn L. Martin Company produced their own private venture, the Martin Model 123 which would become the B-10 bomber. The Boeing Model 66 (XP-8) pursuit aircraft of 1926 was another example of a private venture design.
} 
commerce, including licensing pilots and aircraft, developing air routes and airfields, and collecting statistics.

These were important changes for civil aviation and, because of their timing, they present a potential concern for our study. However, several features of the industry suggest that the changes initiated by these laws are not likely to be behind our findings. One factor is the size of military procurement relative to civil aircraft purchases. From 1926 to 1936, military aircraft purchases totaled $\$ 88$ million while civil aircraft purchases were worth approximately $\$ 55$ million (Koistinen, 1998). ${ }^{15}$ Military procurement was particularly important for high-performance aircraft, which is critical for our study since these are the focus of our analysis. In terms of unit value, military purchases of both airframes and engines were much more expensive than civilian sales, reflecting "the exceptionally rigorous performance and quality requirements" of military aircraft, while most civilian purchases "consisted of single-engine, small planes that were relatively inexpensive to produce" (Koistinen, 1998, p. 191). ${ }^{16}$ The military also purchased much more expensive engines than the civilian market. For example, data from Holley (1964, p. 20) shows that the average unit value of military engines purchased in 1928 was $\$ 4,736$ while the average for civilian engines was just $\$ 1,551$. In 1932 the corresponding figures were $\$ 5,872$ for the military and $\$ 3,565$ for the civil market. Similar patterns appear if we focus on engine power: Holley (1964, pp. 20-21) reports that in 1937, 2,289 engines were purchased for civil aircraft, but only 88 produced over 600 horsepower and 1,393 were under 50 horsepower. Military purchases amounted to 1,800 engines, of which 1,276 were over 700 horsepower, and none below 50 .

The military's demand for frontier designs also increased the speed of product turnover and the need for R\&D. Holley (1964, p. 21) writes that,

... the necessity of turning out aircraft of progressively superior performance to meet the tactically competitive requirements of the military market involved the annual investment of large sums for research and development in contrast to the civil aircraft market, where a single basic design occasionally continued to amortize initial development costs over a period of several years.

Contemporary sources also highlight the role military orders played in innovation during the 1920s. For example, Rae (1968, p. 17) describes how the aircraft manufacturer Grover Loening,

\footnotetext{
${ }^{15}$ Data collected from the Aircraft Yearbooks published by the Aircraft Chamber of Commerce and generously provided to us by Paul Rhode provides somewhat different figures which indicate military purchases from 1925-1935 of $\$ 113$ million and civilian purchases of $\$ 109$ million. The discrepancy between these figures and those provided by Koistinen (1998) is most likely due to the specific equipment included as part of the purchase. Export sales were also important for some companies, but prior to the mid-1930s the vast majority of these sales were in older military aircraft designs. For defense purposes manufacturers were banned from exporting new designs until two years after they were introduced. This delay meant that export sales were likely to have little impact on the innovation decisions that we study.

${ }^{16}$ See figure in Appendix B.3.
} 
"complained that lack of government orders might compel him to stop commercial work, and he pointed out a feature of the aircraft business that would in time be recognized as fundamental: no private company could bear the cost of development work on commercial planes unless it had support from government contracts." Given these features, it is unlikely that changes in the civilian market substantially influenced the high-performance end of the market that we focus on, at least before the entry of the DC-3 in 1935, which marked a turning point in civilian aviation. ${ }^{17}$

Consistent with the argument that military demand played a central role in aircraft innovation in the 1920s and 1930s is the fact that the two companies that would lead American commercial aviation into the modern era in the mid-1930s, Douglas and Boeing, were primarily focused on military production. ${ }^{18}$ The fact that these firms drove innovation in the mid-1930s, rather than firms more focused on the civilian market (e.g., Lockheed and Fairchild), highlights the central role of the military market in driving civilian innovation after 1927. Later, we discuss in detail the sequence of designs that led to these breakthroughs.

The US government was also active in research in airframes, engines, and components. Most of this research took place under the aegis of the National Advisory Committee on Aeronautics (NACA), the predecessor of NASA. NACA was involved in research on a wide variety of topics and published a number of technical reports each year with their results. While the NACA budget grew across the study period, there was no break in the pace of growth around 1926 that would threaten our identification strategy (see Appendix Figure B3). Morevoer, NACA's reports were publicly available and would have been disseminated to foreign manufacturers by their governments, just as the US government was active in disseminating the reports emanating from foreign research agencies to US firms. NACA had a particularly close relationship with its British counterpart, the British Aeronautical Research Committee. ${ }^{19}$ Similar government-funded research organizations existed in each comparison country. Because of the wide dissemination of public aeronautical research, and the spread of this research across countries, comparing innovation patterns across countries helps to control for potential technological breakthroughs that affect all countries. ${ }^{20}$

\footnotetext{
${ }^{17}$ Even after this point, however, there is evidence that military contracts played an important role in driving innovation in civil aviation, particularly in the years just after World War II (Jaworski and Smyth, 2016).

${ }^{18}$ Boeing (as part of United Aircraft), which produced the first modern commercial passenger plane, the Model 247 of 1933, made two-thirds of its sales to the government between 1927 and 1933. Moreover, as we discuss below, the Model 247 was produced as a direct result of an earlier bomber design. For Douglas, which would produce the even more important DC-3 in 1935, government sales accounted for over $90 \%$ of revenues during the same period (Rae, 1968, p. 43).

${ }^{19}$ See, e.g., discussion in National Advisory Committee for Aeronautics (1923, pp. 53-54)

${ }^{20}$ We provide additional background information on the state of the aircraft industry in the United Kingdom, our main comparison country, in Appendix B. We also compare the patterns observed in the United States to other coun-
} 
Finally, our study spans a period of enormous volatility in the broader economy, from the roaring twenties through the Great Depression. It is notable that the aircraft industry fared better during the early 1930s than other sectors of the economy. Patillo (1998) describes the period from 1927 to 1935 as a "golden age" for the industry. A surge in interest in aviation came after Charles Lindbergh's flight across the Atlantic in May 1927 and was followed by a number of other record flights (Patillo, 1998, p. 65). This gave a boost to nascent airlines, attracted attention from Wall Street, and led several aircraft manufacturers to go public (e.g., Douglas in 1928 and Consolidated in 1929).

\section{Theory}

This section presents a simple theory describing how granting IP protection to one group of producers impacts innovation rates among those producers as well as for producers of a key complementary good. The mechanism in the model is general and can potentially be applied in any setting where the strength of IP protection changes for one out of a set of complementary or substitute goods. However, we tailor the details of our model to fit the aircraft industry.

The model is partial equilibrium to match our focus on a single industry. We consider a static one-period problem in which firms choose the level of investment in innovation for new designs. Firms observe the outcome of the innovation process and then produce, after which markets clear.

\subsection{Demand}

The government, the sole source of demand, purchases aircraft in a number of product categories (e.g., fighters, bombers) indexed by $m$. Each aircraft is composed of two components, airframes and engines, indexed by $j \in\{A, E\}$. Initially, firms produce only one of these products. To keep things simple, we suppose that each product market requires a different type of airframe and engine. We abstract from the possibility that different aircraft use a different number of engines and just consider a single composite "engine good" within each market, so each aircraft requires one airframe unit and one engine unit. Let $P_{m A}$ be the price of the airframe of type $m$ and $P_{m E}$ be the price of the engine unit of type $m$. Thus, the cost to the government of an aircraft of type $m$ is $P_{m}=P_{m A}+P_{m E}$.

There is variation in the quality of the product that a firm $i$ of type $j$ can produce in sector $m$. Within each product type $m$ and input type $j$ there is one leading firm, denoted by $\mathrm{L}$, that has the ability to produce the highest quality product, which we call the frontier technology. All other firms, which can only produce products that are considered obsolete, are followers (denoted by

tries (Japan, Germany, and Italy) when data are available. Other comparison countries were considered but not used for various reasons, as discussed in the data appendix. 
$F$ ) in that market and input type. The government is only interested in purchasing the frontier technology in a particularly product and input type. ${ }^{21}$ This reflects the empirical setting, where the military typically only purchased the best design available for a particularly aircraft type in a particular time period. ${ }^{22}$

The military's utility from purchasing a quantity $x$ of the frontier aircraft of a particular type is quasi-linear in money and given by:

$$
U\left(B, x_{m}\right)=B+\theta x_{m}^{\rho}
$$

where $B$ is the amount of money left over after the purchase and $\rho \in(0,1)$. Let $D$ be the amount of money initially allocated to purchases of type $m$ aircraft, a feature that is meant to reflect the appropriation process in which Congress set aside a specific amount of funds for particular uses over a particular period of time. ${ }^{23}$ Then $B=D-x_{m}\left(P_{m A}+P_{m E}\right)$. Substituting this in, the military's utility is given by:

$$
V\left(x_{m}, P_{m A}, P_{m E}\right)=\theta x_{m}^{\rho}+\left[D-x_{m}\left(P_{m A}+P_{m E}\right)\right]
$$

Note that this expression incorporates a diminishing value of aircraft as the quantity of aircraft of that type increases as well as a constant value of remaining funds which can be allocated to other purposes. Given an agreed-upon set of prices, the government will choose $x_{m}$ to maximize the value above. This yields,

$$
x_{m}=\left(P_{m A}+P_{m E}\right)^{\frac{1}{\rho-1}}(\rho \theta)^{\frac{1}{1-\rho}}
$$

Note that the quantity that the military is willing to purchase is falling in the price it must pay for the combination of airframes and engines.

It is worth pausing to highlight important features of the proposed demand system. First, we assume strong (Leontief) complementarity in the quantity of engines and airframes consumed. This is a natural reflection of the industry that we study. However, in a more general model the

\footnotetext{
${ }^{21}$ Note that this is similar to a limit case in a model such as Aghion et al. (2005) with no competition between leader and follower firms.

${ }^{22}$ The idea that the military only wanted to purchase the best available aircraft of each type is generally consistent with description of procurement offered in Holley (1964, p. 76). However, he notes that there were some exceptions. In particular, because Congress tended to judge the strength of the air wing based on the number of planes, there was some pressure to continue buying older and cheaper versions in order to hit the acquisition numbers that Congress expected. However, the military tried to avoid this whenever possible.

${ }^{23}$ Appendix B.4 provides a description of this process drawing on records of the Army Air Corps Procurement Planning Board obtained from the U.S. Archives. These records make it clear that military procurement authorities faced constraints consistent with our assumptions.
} 
degree of complementarity or substitutability between goods will be important for the results. ${ }^{24}$ Second, there is no complementarity or substitutability between the quality of airframes and engines in sector $m$. Making this assumption allows us to focus attention on the way that changes in market power caused by the introduction of IP protection affects innovation. If instead we allow for complementarity or substitutability in quality, how we model that interaction within the black box of the production function would end up driving the results obtained from the model. As we discuss below, it is not implausible that such effects existed in the empirical setting, and so we will confront them in the empirical portion of the analysis. Introducing these interactions into the theory, however, would only serve to obscure the key forces that our model is meant to illustrate.

\subsection{Supply}

There are $N_{E}$ engine firms and $N_{A}$ producers of airframes. At the beginning of the period there is one incumbent leading firm which has access to the best existing design. ${ }^{25}$ All firms then make decisions about how much to invest in innovation in each market segment $m$. The innovation investment of some firm $i$ of type $j$ is given by $I_{m j i}$. Given this investment, the firm innovates with probability $\phi\left(I_{m j i}\right)$, where $\phi(\cdot)$ is assumed to be a continuously differentiable function satisfying $\phi(0)=0, \phi^{\prime}\left(I_{m j i}\right)>0, \phi^{\prime \prime}\left(I_{m j i}\right)<0, \lim _{I_{m j i} \rightarrow \infty} \phi\left(I_{m j i}\right)=1$, and $\lim _{I_{m j i} \rightarrow 0} \phi^{\prime}\left(I_{m j i}\right) \rightarrow+\infty$.

The initial leading technology is observable by all market participants, a feature motivated by our empirical setting, so any new innovation represents an improvement over the current leading design rather than the best previous design of the innovating firm. Once innovation outcomes are realized there are three possible scenarios. If no firm successfully innovates in market segment $m$, then the initial technology leader in that segment remains the leader. If only one firm innovates, then that firm is the new technology leader. If multiple firms successfully innovate, then each firm has an equal probability that its innovation is superior, in which case it becomes the market leader.

To keep things simple, production costs are modeled as $T C_{m j i}=\gamma_{j} x_{m j i}$ where $x_{m j i}$ is firm output and $\gamma_{j}$ can be different for engine and airframe makers. We have also explored alternative production cost structures incorporating fixed costs as well as falling marginal costs reflecting learning-by-doing. ${ }^{26}$ These do not substantially change the key forces at work in the model, so we have opted for the simpler approach in our main analysis.

Firms make profits from two sources. Total profit $\pi_{m j}$ is the sum of profits from producing

\footnotetext{
${ }^{24}$ Lerner and Tirole (2004) show this for the case of patent pools.

${ }^{25}$ The reason we have an incumbent leader in the model is to ensure that, when IP protection is available, there is an incumbent firm that sell products (and extract rents) from the leading design even if no firm successfully innovates.

${ }^{26}$ For a discussion of learning in airframe production see Asher (1956) and, more recently, Benkard (2000).
} 
and selling products $\tilde{\pi}_{m j}$ plus a fixed fee $G$ paid to a firm if it produces the leading design in a product type and category.

\subsection{Solving the Model}

We solve the model under two alternative market structures. In the first, airframe manufacturers do not have property rights over their designs and instead compete for production orders on price. In the second, airframe firms that produce a new frontier design have property rights over that design. In both cases engine makers have property rights over the production of a design that they create. Comparing the outcomes in these two settings reveals the impact of a policy change that provides IP rights to airframe producers, such as the one featured in our empirical analysis. In this context, the empirical experiment that we study can be thought of as a decision by the government to pre-commit to one of these two market structures.

When manufacturers of a particular good do not have property rights over their new designs, designs are put up for competitive bidding based on price. We therefore model this market as Bertrand competition. If manufacturers do have property rights of their designs, we treat the firm with the best design as a monopolist. This monopolist firm then engages in direct bargaining with the monopsonist government purchaser. Naturally, these different market structures will have different implications for the profits of firms of type $j$ within each market segment $m$. To solve the model, we begin by taking $\pi_{m j}$ as given and deriving equilibrium innovation investment decisions. We then solve for profit levels under alternative market structures.

\subsection{Innovation Decisions}

We denote the innovation investment of the market leader $I_{m j L}$ and the investment of the follower firms as $I_{m j F}$. Note that all of the follower firms face a symmetric choice so they will all make the same innovation investment decision. The expected payoffs from a particular level of innovation, denoted $\Lambda_{L}\left(I_{m j L}\right)$ and $\Lambda_{F^{\prime}}\left(I_{m j F^{\prime}}\right)$ for leader and follower firms, respectively, depend on the innovation investments made by all other firms (see Appendix A.1 for the details). In Appendix A.3 we establish the following proposition regarding these innovation investment decisions.

Proposition 1: Taking $\pi_{m j}$ as given, there is a unique equilibrium innovation investment decision $I_{m j} F^{*}$ for follower firms and a unique equilibrium investment decision $I_{m j L} *$ for the initial leader firm in each sector $m$ and product type $j$.

Proof: See Appendix A.3.

Proposition 2: Equilibrium innovation investments for both leader and follower firms of type $j$ in sector $m$ are strictly increasing in $\pi_{m j}$.

Proof: See Appendix A.4. 
Corollary 1: When $\pi_{m j}>0, I_{m j i} *>0$ for all $i$ firms of type $j$ within sector $m$.

This follows directly from equations (6) and (7) together with the assumptions on $\phi(\cdot)$ and implies that as long as there is a fixed fee offered for new leading designs, there will be always be some innovation investment, even when profits from production are zero. ${ }^{27}$

\subsection{Profits with IP protection in airframes}

When both airframe and engine suppliers have IP protection, the government negotiates prices with the leading producers in each sector. We model this monopolist-monopsonist interaction as Nash-in-Nash price bargaining, following Horn and Wolinsky (1988) and Collard-Wexler, Gowrisankaran and Lee (2019), in which bargaining over the price of one input takes place taking as given the price of the other. If the government comes to an agreement with both suppliers then the government's surplus is $V\left(x_{m}, P_{m A}, P_{m E}\right)$. Without an agreement the government spends no money on aircraft of type $m$ and obtains surplus $V(0,0,0)=D$. For airframe producers, the surplus obtained from an agreement (production profit) is given by $\tilde{\pi}_{m A}=x_{m}\left(P_{m A}-\gamma_{A}\right)$ and a similar expression holds for engine makers. If no agreement is reached between the suppliers and the government then each supplier obtains zero profit.

Solving the Nash-in-Nash bargaining problem, the prices for airframes and engines are given by, ${ }^{28}$

$$
P_{m A}=\frac{\gamma_{A} 2 \rho+\gamma_{E}(1-\rho)}{3 \rho-1}, \quad \text { and, } \quad P_{m E}=\frac{\gamma_{E} 2 \rho+\gamma_{A}(1-\rho)}{3 \rho-1}
$$

To obtain positive prices requires $\rho>1 / 3$, a condition that we assume holds. ${ }^{29}$ Using these results, we obtain the following expression describing the profits of engine producers:

$$
\tilde{\pi}_{m E}^{I P}=\left(\gamma_{A}+\gamma_{E}\right)^{\frac{\rho}{\rho-1}}(1+\rho)^{\frac{1}{\rho-1}}(3 \rho-1)^{\frac{\rho}{1-\rho}}(\rho \theta)^{\frac{1}{1-\rho}}(1-\rho)
$$

A similar expression holds for the airframe producer.

\subsection{Profits without IP protection in airframes}

With no IP protection in airframes, the government is free to have any airframe firm produce its favored design. Thus, airframe producing firms compete on price, which is bid down to the marginal cost: $P_{m A}=\gamma_{A}$. Production profits are $\tilde{\pi}_{m A}=0$ and total profits for the firm that produced the leading design are $\pi_{m A}=G$.

The leading engine producer then engages in monopolist-monopsonist bargaining with the

\footnotetext{
${ }^{27}$ It is worth noting that follower firms will make larger investments in innovation (Arrow's replacement effect). This is because a follower firm benefits from innovating when no other firm innovates. The leader does not, since when no other firm innovates it remains the leader regardless of whether it innovates.

${ }^{28}$ See Appendix A. 2 for further details.

${ }^{29}$ See Appendix A. 2 for further details.
} 
government taking as given $P_{m A}=\gamma_{A}$. Under these circumstances, the negotiated price for engines is given by:

$$
P_{m E}=\frac{\gamma_{E}(1+\rho)+\gamma_{A}(1-\rho)}{2 \rho}
$$

and the "NO IP" production profit for the engine maker is,

$$
\tilde{\pi}_{m E}^{N O I P}=\left(\gamma_{E}+\gamma_{A}\right)^{\frac{\rho}{\rho-1}}(1+\rho)^{\frac{1}{\rho-1}}(1-\rho)(\rho \theta)^{\frac{1}{1-\rho}}(2 \rho)^{\frac{\rho}{1-\rho}}
$$

This leads us to the following proposition:

Proposition 3: In the absence of merger activity, granting IP protection to airframe producers increases innovation in airframes and decrease innovation in engines.

Proof: From Prop. 2 we know that innovation investments are increasing in profits. Taking the ratio of the production profits given in equation (2) to those from equation (3), we have

$$
\frac{\tilde{\pi}_{m E}^{I P}}{\tilde{\pi}_{m E}^{N O I P}}=\left(\frac{3 \rho-1}{2 \rho}\right)^{\frac{\rho}{1-\rho}}<1,
$$

which tells us that overall profits for engine makers are lower when airframe producers have access to IP protection.

\subsection{Predictions regarding merger activity}

The model also makes predictions about how granting IP protection to airframe producers affects the incentives for mergers between airframe and aero-engine producers. Initially, when airframe producers did not have access to IP protection, in order to obtain an order for airframes the firm must charge a price no greater than the marginal cost of the other airframe producers. Given this, even if an airframe producer has merged with an engine maker, the airframe division will be forced to set price equal to marginal cost and the payoffs for the combined firm will be the same as the payoffs of the two separate firms. Thus, without IP protection there is no incentive for airframe and engine producers to merge.

However, consider the incentives for vertical-complement mergers once IP protection is available in the airframe sector. If the leading engine and airframe producers merge, then the merged firm will engage in joint bargaining with the government over the total aircraft price $P_{m}$. Solving, the Nash-in-Nash bargaining problem yields the following production profit for the merged firm:

$$
\tilde{\pi}^{M E R G E D}=\left(\gamma_{A}+\gamma_{E}\right)^{\frac{\rho}{\rho-1}}(1+\rho)^{\frac{1}{\rho-1}}(2 \rho)^{\frac{\rho}{1-\rho}}(\rho \theta)^{\frac{1}{1-\rho}}(1-\rho)
$$


This leads us to the following proposition.

Proposition 4: The introduction of IP protection in the airframe industry generates incentives for mergers between airframe and engine producers for values of $\rho \in(1 / 3,1 / 2)$.

Proof: Taking the ratio of the production profits obtained when the firms remain independent to the profits obtained when the firms merge, we have:

$$
\frac{2 \pi^{I P}}{\pi^{M E R G E D}}=2\left(\frac{3 \rho-1}{2 \rho}\right)^{\frac{\rho}{1-\rho}}
$$

which is less than 1 for $\rho \in(1 / 3,1 / 2)$.

This shows that under certain circumstances the model predicts that granting IP protection will lead firms to undertake vertical-complement mergers. Note that, because this model does not predict that mergers will take place under all circumstances, the lack of merger activity cannot be used to reject the model (unless $\rho$ can be directly estimated, which is not possible in our setting). However, if we do observe firms undertaking vertical-complement mergers, that activity is consistent with the theory. ${ }^{30}$

\section{Data}

The main data used in the empirical analysis are drawn from detailed descriptions of aircraft designs and are available due in large part to the high level of general interest in aircraft-particularly military fighters and bombers. These data were compiled from several books describing airframe and aero-engine designs. The data include the near-universe of important military airframes which are matched with the corresponding aero-engine designs used between 1918 and 1935 in the United States and comparison countries. We choose this window to reflect the period of time after the end of World War I until the beginning of mobilization for World War II. In Appendix C, we provide further detail on these sources.

The aircraft in our data are divided into various categories (e.g., fighters and bombers), which are referred to as types or market segments in the theory. In the empirical analysis we focus primarily on fighters and bombers for two reasons. First, these were the most likely to see combat with other aircraft and, therefore, the segments where high-performance characteristics were most in demand. Since the measures we use to track innovation reflect high-performance (rather than low costs), these segments are the natural focus for our analysis. Second, fighters

\footnotetext{
${ }^{30}$ Additionally, the model makes predictions about which airframe and engine producers we would expect to merge. Specifically, the benefits of merging depend on the airframe producer and engine producer being leaders in the same market. Thus, we expect engine makers to merge with larger airframe producers with leadership positions in more of the markets in which the engine maker is also the leader. Moreover, once an engine and airframe producer have merged, we expect them to focus their innovation investments in the same aircraft types.
} 
(and to a lesser extent bombers) were the most distinct from civilian designs. ${ }^{31}$

Within each aircraft category we observe the introduction of completely new aircraft designs (e.g., Boeing's PW-9 fighter family) as well as new models of a particular design with different performance characteristics (e.g., the PW-9A and PW-9B versions of the PW-9 fighter). An observation in our airframe data is the introduction of a new model, including new versions of existing designs. For each model we typically observe the year of first delivery, producer, a variety of physical and performance characteristics, and the number of airframes delivered.

Our preferred measure of airframe performance is wing load, calculated as gross weight in pounds divided by wing area in square feet. This is a standard performance measure in the aircraft industry that reflects improvements through increasing lift and reducing drag. ${ }^{32}$ In addition, we also present results using maximum speed in miles per hour, as well as showing the relationship between wing load, maximum speed, and other performance measures. In general, these measures of performance are highly correlated (see Appendix Figure E1).

For engines, we consider three variables that measure different aspects of engine performance: horsepower divided by engine weight (in pounds), horsepower divided by engine displacement (in liters), which is related to the physical size of the engine, or horsepower divided by the frontal area of the engine (in square inches), which influences the aerodynamic properties of an aircraft. All three variables reflect factors that were of particular importance for highperformance military aircraft. ${ }^{33}$ We also discuss additional aspects of engine innovation that are more difficult to capture quantitatively.

It is worth highlighting that we focus on performance characteristics rather than the number of designs produced for several reasons. The first is that obtaining a single design with excellent performance, rather than many mediocre designs, was the objective of the military. Second, the number of designs may be endogenous to the performance of the current leading design; firms may be reluctant to invest in new designs if the current design has excellent performance. Finally, there is no objective criteria for what was considered a new design versus a modification of an existing design. Using performance characteristics as the outcome variable means our specification is less subject to bias associated with differences in these criteria across countries or data sources.

\footnotetext{
${ }^{31}$ There are no examples of the same model of aircraft being used by the military as a fighter and also sold for civil uses in substantial numbers. As discussed below, other designs, particularly bombers, did act as an important starting point for the development of new commercial designs.

${ }^{32}$ Phillips (1971) writes that, "Wing loading... is without question a direct measure of very important changes in airfoil technology. It probably is also an indirect or proxy indicator of parallel changes in the technology of other aspects of the airframe."

${ }^{33}$ This contrasts with features such as low operating and maintenance costs, which were more important for civil aircraft.
} 
Two types of data are not available for our analysis. Consistent data on airframe and aeroengine prices do not appear to be available, only a few scattered observations. Similarly, we would ideally like to have data on firm profits, which play an important role in our proposed mechanism. Unfortunately, such data are not available before the late 1920s. Even when profit data are reported, their usefulness is limited. ${ }^{34}$ For these reasons, we focus on airframe and aero-engine performance characteristics.

\section{Empirical Strategy and Results}

In this section we present our main results looking at the effect of the 1926 change in IP protection on innovation in the aircraft industry, including both airframe and aero-engine producers. ${ }^{35}$ We analyze both patterns observed in the United States over time as well as comparing the United States with the United Kingdom. Our main analysis focuses on fighters and bombers, and the engines used therein. In the appendix, we discuss the results for other market segments (e.g., reconnaissance). Following the main airframe and aero-engine results, we briefly discuss results looking at merger activity between airframe and aero-engine producers, another prediction that emerges from our theory. Finally, at the end of this section, we discuss a number of potential altenative theories and identification concerns.

\subsection{Airframes}

As a starting point, Figure 1 provides graphical evidence for comparing technological progress for fighters and bombers over time. In the United States, technological progress measured using wing load (Panel A, left side) and maximum speed (Panel B, left side) was slow before 1926 and increased afterward. The timing of this acceleration fits what we know about the time needed to develop new designs reasonably well; in Appendix D we show that it typically took between one and two years to produce a new original airframe design. The change for the United Kingdom is less pronounced, as shown in the right-hand panels, at least until rearmament accelerated in the late 1930s.

To quantify the patterns in Figure 1, we begin with a simple specification that uses only the United States. Specifically, we estimate the following regression,

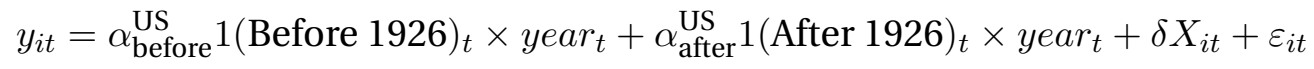

\footnotetext{
${ }^{34}$ For example, Vander Meulen (1991, p. 43) warns, "Profitability data remains scarce until most aircraft firms went public in the late 1920s. Even then it is difficult to use because of the standard practice of deferring large development charges against future earnings on expected production contracts that usually did not materialize."

${ }^{35}$ In the context of the model, this policy change should be viewed as the military buyer shifting from a pre-1926 regime in which it had pre-committed to purchasing airframes through open, competitive bidding, to a new post1926 regime in which the military committed to identifying the best available design and then conducting bilateral bargaining with the designing firm over the purchase price of each aircraft (with engines obtained through bilateral bargaining in both regimes).
} 
where the dependent variable, $y_{i t}$, is the log of wing load or maximum speed for airframe design $i$ in year $t$. The coefficients of interest quantify the pace of technological progress in the United States before $\left(\alpha_{\text {before }}^{\text {US }}\right)$ and after ( $\left.\alpha_{\text {after }}^{\text {US }}\right) 1926$ using a two-piece linear spline to allow the rate of innovation to change after 1926 while maintaining continuity in the overall level. In Appendix E, we consider alternative specifications that allow for a change in the levels of innovation and obtain similar results. $X_{i t}$ includes the constant term. Note that since an observation in our data is the introduction of a new airframe model there may be several observations in a given year. In robustness exercises, we also present results from alternative approaches.

The results for estimating equation (4) are presented in the first two columns of Table 1 . The estimated before- versus after-1926 trend in innovation for the United States is shown for the log of wing load (column 1) and the log of maximum speed (column 2). Improvements in fighter and bomber performance were between -0.1 and 1.3 percent before 1926 compared with 6.7 and 7.4 percent per year after 1926. Below the estimated coefficients we report the $F$-statistic and $p$ value for the equality of the coefficients, which confirms that in both cases we can reject the null hypothesis of equality. This suggests that increased innovation in airframes followed greater IP protection.

These results are consistent with increased technological progress following the 1926 policy change that provided greater IP protection. An important concern in this context is that technological progress attributed to IP protection is in fact due to unobserved factors the led to improvements in airframe design regardless of changes in the IP regime in the United States. For example, we may worry that there was some global breakthrough in airframe technology that took place around 1926 that is behind our results. If this were true, then we should expect to see similar accelerations in the pace of airframe performance in other countries.

To examine whether changes in the world technological frontier explain increased innovation we pool data for the United States and United Kingdom and compare using,

$$
y_{i t}=\beta_{\text {before }}^{\text {US }} 1(\text { Before 1926) })_{t} \times \text { year }_{t} \times U S_{i}+\beta_{\text {after }}^{\text {US }} 1(\text { After 1926 })_{t} \times y^{2} a r_{t} \times U S_{i}+\delta X_{i t}+\varepsilon_{i t}
$$

where the coefficients of interest are $\beta_{\text {before }}^{\mathrm{US}}$ and $\beta_{\text {after }}^{\mathrm{US}}$ corresponding to two-piece linear spline that measures the rate of innovation in the United States relative to the United Kingdom before and after 1926. ${ }^{36} X_{i t}$ includes a constant term, an indicator for the United States, a linear spline for comparison countries (i.e., the United Kingdom). In some specifications, we also include controls for the number and horsepower of engines used by airframes.

\footnotetext{
${ }^{36}$ In Appendix B.5, we add Japan as comparison country and obtain similar results.
} 


\section{Figure 1: Airframe Innovation}

A. Wing Load (in pounds per square foot)
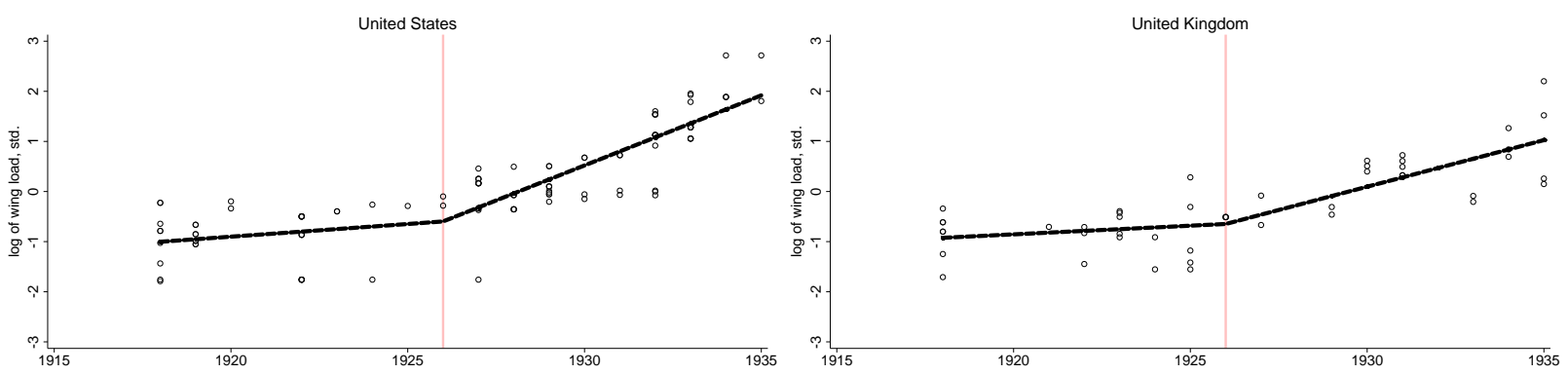

B. Maximum Speed (in miles per hour)
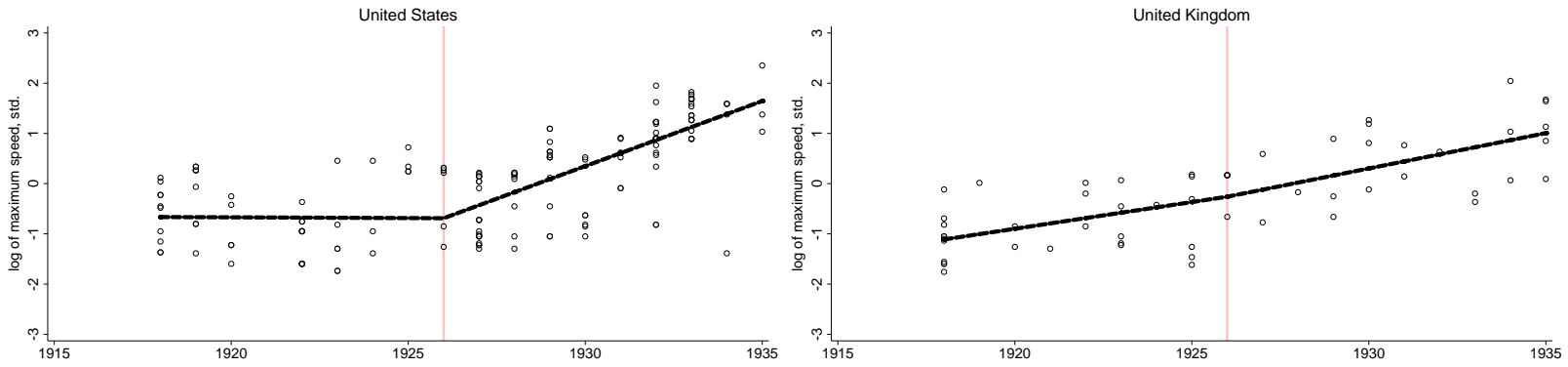

Notes: This figure shows different measures of innovation in military fighter and bomber airframes between 1918 and 1935. For the United States and United Kingdom, Panel A shows the log of weight (in pounds) divided by wing area (in square feet) and Panel B shows maximum speed (in miles per hour). Each measure is standardized by subtracting the mean and dividing by the standard deviation. The dashed black line is a linear spline with a different slope before and after 1926. 
Table 1: Results for Airframe Innovation Before and After 1926

\begin{tabular}{|c|c|c|c|c|c|c|}
\hline \multirow[b]{2}{*}{$\begin{array}{l}\text { Outcome } \\
\text { (in log) }\end{array}$} & \multicolumn{2}{|c|}{ United States Only: } & \multicolumn{4}{|c|}{ Comparison of US and UK: } \\
\hline & $\begin{array}{c}(1) \\
\text { Wing } \\
\text { Load }\end{array}$ & $\begin{array}{c}(2) \\
\text { Maximum } \\
\text { Speed }\end{array}$ & $\begin{array}{c}(3) \\
\text { Wing } \\
\text { Load }\end{array}$ & $\begin{array}{c}(4) \\
\text { Maximum } \\
\text { Speed }\end{array}$ & $\begin{array}{c}\text { (5) } \\
\text { Wing } \\
\text { Load }\end{array}$ & $\begin{array}{c}\text { (6) } \\
\text { Maximum } \\
\text { Speed }\end{array}$ \\
\hline Before $1926 \times$ year $\times$ US & $\begin{array}{c}0.013 \\
(0.006)\end{array}$ & $\begin{array}{l}-0.001 \\
(0.006)\end{array}$ & $\begin{array}{c}0.004 \\
(0.009)\end{array}$ & $\begin{array}{l}-0.028 \\
(0.009)\end{array}$ & $\begin{array}{l}-0.005 \\
(0.010)\end{array}$ & $\begin{array}{l}-0.031 \\
(0.009)\end{array}$ \\
\hline After $1926 \times$ year $\times$ US & $\begin{array}{c}0.074 \\
(0.006)\end{array}$ & $\begin{array}{c}0.067 \\
(0.006)\end{array}$ & $\begin{array}{c}0.025 \\
(0.010)\end{array}$ & $\begin{array}{c}0.031 \\
(0.010)\end{array}$ & $\begin{array}{c}0.023 \\
(0.010)\end{array}$ & $\begin{array}{c}0.024 \\
(0.009)\end{array}$ \\
\hline \multicolumn{7}{|l|}{ Control for: } \\
\hline $\begin{array}{l}\text { 1(\# of Engines }>1) \\
\text { Log of Engine Horsepower }\end{array}$ & $\begin{array}{l}\text { no } \\
\text { no }\end{array}$ & $\begin{array}{l}\text { no } \\
\text { no }\end{array}$ & $\begin{array}{l}\text { no } \\
\text { no }\end{array}$ & $\begin{array}{l}\text { no } \\
\text { no }\end{array}$ & $\begin{array}{l}\text { yes } \\
\text { yes }\end{array}$ & $\begin{array}{l}\text { yes } \\
\text { yes }\end{array}$ \\
\hline $\begin{array}{l}F \text {-statistic } \\
p \text {-value }\end{array}$ & $\begin{array}{c}34.7 \\
0.000\end{array}$ & $\begin{array}{c}37.6 \\
0.000\end{array}$ & $\begin{array}{c}1.5 \\
0.229\end{array}$ & $\begin{array}{c}11.4 \\
0.001\end{array}$ & $\begin{array}{c}2.5 \\
0.113\end{array}$ & $\begin{array}{c}13.3 \\
0.000\end{array}$ \\
\hline observations & 116 & 174 & 165 & 233 & 140 & 192 \\
\hline
\end{tabular}

Notes: This table shows regression results for US airframes (columns 1 and 2) and US and UK airframes (columns 3 through 6). The dependent variable is the log of the variable at the top of each column. In columns 1,3 , and 5 wing load is defined as airframe weight (in pounds) divided by wing area (in square feet); in columns 2 , 4 , and 6 maximum speed is measured in miles per hour. Columns 1 and 2 show results for the United States. Columns 3 and 4 show results comparing the United States to the United Kingdom. Columns 5 and 6 show results comparing the United States to the United Kingdom adding as controls an indicator if an airframe has more than one engine and the log of engine horsepower. A constant term is included in all columns. In addition, columns 3 through 6 include a linear spline for the United Kingdom and an indicator for the United States. Robust standard errors are shown in parentheses. 
The remaining columns of Table 1 show the results from estimating versions of equation (5) with the log of wing load or maximum speed as the dependent variable. Columns 3 and 4 compare the United States to the United Kingdom, while Columns 5 and 6 include additional controls for engine characteristics. The results show that technological progress in the United States was slower before 1926 relative to the United Kingdom and accelerated after 1926; the reported $F$-statistics (and $p$-values) confirm that we can reject the null hypothesis of equality of the coefficients in two of the four remaining columns. This provides evidence that the accelleration in performance is specific to the United States rather than the result of a global breakthrough. ${ }^{37}$

Note that the regressions in columns 3 through 6 may be affected by some spillover of design innovations across countries. Such spillovers will bias the estimated coefficients in those columns toward finding no effect. ${ }^{38}$ Because we are primarily interested in the direction of the observed effects, this bias is not a major concern for our analysis. However, the direction of this bias suggests that the magnitudes of our estimated effects may understate the true impact.

Additional results, in Appendix E.3, show that the patterns described in our main results are also found when including other comparison countries (Japan), to running weighted regressions, or to including data associated with other types of military aircraft (reconnaissance planes). In Appendix E.6 we examine the pattern of performance improvements for individual companies in the United States, specifically, Boeing, Curtiss, and Douglas. These results show that, even within company, we tend to see a similar pattern of increased performance in the years after 1926 relative to the years before. Finally, in Appendix E. 5 we present evidence on the timing of a change in technological progress that is consistent with the timing of the passage of the 1926 Act.

The technological progress shown in these results reflect the wide range of improvements introduced into airframes during this period. Wood gave way to metal in structural elements and fabric covering was replaced by monocoque designs where the stressed metal skin contributed to the plane's structural integrity. Cockpits were covered, wing shapes changed, flaps and slots were added, wing fairings were introduced to reduce interference between the fuselage and the wing root, new engine cowlings and cooling systems reduced engine drag, retractable landing

\footnotetext{
${ }^{37}$ It is worth noting that these regressions differ from a standard differences-in-differences analysis in that we do not have a simple treated versus control comparison. Other countries offered their airframe producers some level of IP protection before 1926, so we do not expect innovation in those locations to match pattern that we observe in the United States. In fact, we can see that innovation in the United States was outpaced by progress elsewhere before 1926. After 1926, the relative gains in the United States suggest that once the military committed to buying airframes from the firm that produced a design the U.S. innovation system became more effective. This suggests that a key benefit of comparing the United States to other countries is the ability to control for broad changes that might have caused airframe innovation rates to differ before versus after 1926.

${ }^{38}$ Naturally, if spillovers were perfect we would observe no effect, but the results suggest that this is not the case given that we observe substantial variation in performance measures across countries over time.
} 
gear were introduced, etc. And, whereas the United States was a technological laggard in the early 1920s, by the 1930s it had become a leader in both military and civilian airframe design.

It is useful to provide details tracing out the interplay between military and civil designs in this period. In the United States, the moribund rate of progress in military designs in the early to mid-1920s meant that many innovative designs were produced for the civil market. Emblematic of the importance of civil designs during period of military stagnation is the path-breaking Lockheed Vega of 1927, designed by Jack Northrop. The Vega was a single-engine high-wing monoplane with a wooden monocoque fuselage, wooden internally-braced wings, enclosed cockpit, and clean, aerodynamic lines.

However, by the early 1930s, military designs were pulling even with civilian models. At Boeing, the firm began production of an all-metal monoplane fighter, the XP-9, in 1928. While the XP-9 was not successful, its design was incorporated into a civil design, the Monomail (Boeing Model 200), which flew in 1930 (Bowers, 1989). ${ }^{39}$ The Monomail in turn provided inspiration for a new set of bomber designs, the B-9 family. The Boeing B-9 bomber family (first flown in 1931), followed closely by the Martin B-10 of 1932, represented an important turning point in the relationship between U.S. military aircraft design and the civil/commercial market. The designs of these new bombers clearly reflected the aerodynamic legacy of planes like the Monomail and the Vega, but at a much larger scale and with a two-engine design. These aircraft incorporated key advances, such as the installation of the two engines in-line with the wings, rather than slung below as in the Ford Trimotor. ${ }^{40}$

The designs for the B-9 and the Martin B-10 provided the template for modern commercial aircraft. When the Army ultimately favored Martin's B-10 over Boeing's B-9, Boeing took the lessons from the B-9 design and produced the Boeing Model 247. The Model 247, first flown in February 1933, was the world's first modern airliner, with a low-wing multi-engine all-metal monoplane design that would eventually become standard. It was soon followed by the Douglas DC-1, first flown in July 1933, which improved the basic template set by the Model 247 and laid the foundation for the DC-3 of 1935, the most successful commercial aircraft of the period.

This brief description highlights two distinct phases in the interplay between civilian or commercial and military aircraft design. In the first phase, from World War I up until the late 1920s, innovative civil aviation designs such as the Lockheed Vega led military designs. In the second phase, starting in the late 1920s, military designs incorporated the previous advances made into

\footnotetext{
${ }^{39}$ The Monomail actually flew before the XP-9, despite the fact that the XP-9 was designed first, because the more complex military design took longer to produce and required more modifications.

${ }^{40}$ Setting the engines well forward of the wing, there was less interference with the wing's lifting capacity, while putting the engines in-line rather than below the wing substantially reduced drag (Miller and Sawers, 1970, p. 67).
} 
civil aviation and pushed these advances into all-metal and larger multi-engine aircraft. This phase, epitomized by the Boeing B-9 and Martin B-10 bomber families, opened the door for the new commercial designs that followed.

In Appendix E.7 we provide empirical support for the patterns highlighted in the qualitative discussion above. We do this by comparing innovation rates after 1926 among producers focused heavily on the military market (Boeing, Curtiss, Douglas and Martin) to innovation by the largest firms focused primarily on the civil market (Fairchild and Lockheed) ${ }^{41}$ This comparison shows that indeed designs by firms focused on the civil market were more advanced in 1926, but that innovation was more rapid among military producers after 1926, so that by the mid-1930s the performance of military designs exceeded that of the best civil producers.

This helps explain why the first major advances toward modern commercial aircraft were made by companies-Boeing and Douglas-that previously focused on producing military designs. Both firms had gained experience in producing large multi-engine military aircraft, either for bombing or long-range observation, in the late 1920s and early 1930s, setting the stage for their success in the commercial market. For Boeing, in particular, there is a clear path leading from the B-9 bomber to the 247 airliner. It is useful to contrast this experience with Lockheed, a firm focused almost entirely on the civilian market. Lockheed had been the source of the most innovative designs in the mid-1920s, and Lockheed continued to produce excellent new designs in the early 1930s, such as the Altair and Orion, yet it remained focused on smaller single-engine aircraft. As a result, Lockheed was late in adopting the twin-engine design that would eventually dominate commercial aviation. ${ }^{42}$ These patterns reinforce the central role that military demand played in aircraft development during this period.

\subsection{Aero-Engines}

Next, we look at changes in aero-engine development in the United States after 1926. To begin, it is useful to provide an overview of the patterns of aero-engine innovation before and after the policy change we study. At the close of World War I, while the United States was a laggard in airframe innovation, it had become a leading aero-engine producer. By far the most important US engine produced during this period was the Liberty engine. The 12-cylinder liquid-cooled Liberty engine was designed in 1917 by engineers from the Packard and Hall-Scott companies under the direction of the federal Aircraft Production Board. This engine was so successful that it was rapidly adopted for use in European airframes, such as Britain's new DH9 bomber.

This pattern of US leadership in engine design continued up to the middle of the 1920s,

\footnotetext{
${ }^{41}$ This is possible after 1926 but not before, because we observe too few designs by civil producers in the earlier period.

${ }^{42}$ It entered this market in 1934, two years behind the 247, with the moderately-successful Electra.
} 
with US producers introducing pathbreaking new designs such as the Pratt \& Whitney Wasp and Wright Cyclone air-cooled radial engines. However, the evidence presented below suggests that progress slowed after 1926, particularly in the high-performance engine types that were most important for military applications. After that point, subsequent technological progress often involved more modest evolutions of existing designs (Taylor, 1971). American engine firms were innovative during the late 1920s and 1930s, but their attention was mainly focused on producing more durable designs with lower maintenance costs for the commercial market, rather than higher-performance designs for the military (Miller and Sawers, 1970, p. 86-7). ${ }^{43}$

The clearest example of the post-1926 slowdown in high-performance engine development in the United States was the almost complete abandonment of liquid-cooled designs. We can see this pattern in Table 2, which presents the share of liquid-cooled engine designs in total aeroengine designs, by country, before and after 1926. The sharp reduction in the share of designs of this type in the United States, compared the increase in the United Kingdom and Germany, is striking. This was not driven by an increase in other types of designs; in fact, after 1926, the United States produced fewer than half as many new liquid-cooled engines as either the United Kingdom or Germany.

Liquid-cooled designs were of particular importance to military purchasers because, while they were typically more expensive to operate and maintain, liquid cooling allowed a slimmer profile that was advantageous at high speeds. Reflecting this advantage, liquid-cooled designs powered every one of the aircraft that set a new speed record between 1921 and 1939 (Munson, 1978). ${ }^{44}$ Because of this feature, liquid-cooled engines were critical for top-of-the-line fighter aircraft throughout the 1930s. Thus, the abandonment of innovation in liquid-cooled aeroengines provides a concrete example of the contraction in aero-engine innovation that took place in the United States after 1926, particularly in those engine types that were most important for military applications.

Ultimately, the lack of innovation in liquid-cooled engines would turn out to be important in World War II, as liquid-cooled engines would prove dominant for top-line fighter designs in the first few years of the war, powering planes such as the British Hurricane and Spitfire, and the German Bf-109 (or Me-109). ${ }^{45}$ The P-51 Mustang provides a striking example of the consequences

\footnotetext{
${ }^{43}$ Commercial engine use differed from military use in important dimensions. Airlines flew much more often, but engines only had to operate at peak power for takeoff. Military combat aircraft flew less often, but peak power was demanded more often, not just at takeoff but also at altitude.

${ }^{44}$ This pattern is clear in our data on engine frontal area. A large frontal area was a particular drawback for radial engines, a feature that led to substantial effort in the development of cowlings, such as the famous NACA cowling of 1927, that aimed to mitigate this weakness.

${ }^{45}$ The drawbacks of radial engines for fighter applications were mitigated later in the war by designing radial engines with multiple rows of cylinders, such as the the BMW 801, which powered the FW-109, the main German fighter
} 
Table 2: Engine Type Before versus After 1926

\begin{tabular}{lcccc}
\hline & \multicolumn{4}{c}{ Fraction Liquid-Cooled: } \\
\cline { 2 - 5 } & United States & United Kingdom & Germany & Italy \\
Before 1926 & $(1)$ & $(2)$ & 0.2581 & (4) \\
After 1926 & 0.5366 & 0.4118 & 0.3125 & 0.7333 \\
\hline
\end{tabular}

Notes: The table shows the fraction of engines introduced before versus after 1926 that are liquid-cooled in the United States (column 1), United Kingdom (column 2), Germany (column 3), and Italy (column 4).

Table 3: Adoption Lag Before versus After 1926

\begin{tabular}{lcc}
\hline & US Only & Comparison of US and UK: \\
\cline { 2 - 3 } After 1926 & $(1)$ & $(2)$ \\
\hline \multirow{2}{*}{ United States } & 0.850 & -0.261 \\
& $(0.367)$ & $(0.529)$ \\
After 1926 $\times$ United States & & 0.263 \\
& & $(0.427)$ \\
observations & & 1.112 \\
& 205 & $0.645)$ \\
\hline
\end{tabular}

Notes: The table shows the results for the lag of engine adoption. The dependent variable is the year of introduction for an airframe minus the year of introduction for an engine. Column 1 shows results for the US only. Column 2 shows results comparing the United States to the United Kingdom. Column 1 includes a constant and an indicator if the airframe year is after 1926. Column 2 includes a constant, indicators if the airframe year is after 1926 and if an airframe is from the United States, and the interaction. Robust standard errors are shown in parentheses. 
of these changes. The P-51 was most effective high-performance fighter produced by the United States during World War II and, although designed in the United States, it only achieved its full potential when paired with the British-designed Rolls-Royce Merlin liquid-cooled engine. ${ }^{46}$ By the late-1930s, no US engine design could match the performance, particularly at altitude, of the Rolls-Royce Merlin engine family, or the German equivalents (Diamler-Benz 601/603/605 and Junkers Jumo 213 engines). Thus, by the onset of World War II, the United States was importing high-performance engine designs, a reversal of the pattern that existed at the end of WWI.

A second indicator of change in the pace of US engine development can bee seen by looking at the time lag between the vintage of engines and the vintage of the airframes they were used with. ${ }^{47}$ To examine this pattern, we run regressions where each observation represents a new airframe design, and the outcome variable is the lag between the year that design was introduced and the year of introduction of the primary engine used by that design. Regression results looking at how this lag changed in the United States after 1926 are presented in Table 3. Results in the first column, which use only data from the United States, indicate that the vintage lag in the United States increased by 0.85 years after 1926 relative to before. Of course, we may worry that this simply reflected underlying trends in the aircraft industry. To address this, in column 2, we compare patterns in the United States to those in the United Kingdom. Here we find evidence of an even larger increase in the vintage lag in the United States after 1926. These results are consistent with a relative slowdown in the pace of engine development in the United States after 1926.

A third way to study the pace of aero-engine development is to look at the rate of performance increase using direct measures of engine performance. We have three available performance measures to consider: horsepower divided by weight, horsepower relative to piston displacement (which is related to engine size), and horsepower relative to frontal area. Of these the first and third are the most relevant measures of engine performance, since weight and frontal area were two of the key dimensions that engineers sought to minimize.

Figure 2 presents the pattern of engine performance graphically for the United States (left panels) and United Kingdom (right panels). Consistent with our airframe analysis, we consider only engines used in fighter or bomber aircraft. At least along some dimensions, the evidence is consistent with a slowing of aero-engine performance in the United States after 1926.

The regression results in Table 4 quantify these patterns. In columns 1 through 3 , we focus on

used in the later years of WWII, and the Pratt \& Whitney Double Wasp, which powered the F6F Hellcat.

${ }^{46}$ Many of these were produced on-license in the United States.

${ }^{47}$ Looking at this time-lag is preferable to looking at the number of designs being produced since it is less reliant on the definition of what constitutes a new design. 


\section{Figure 2: Engine Innovation}
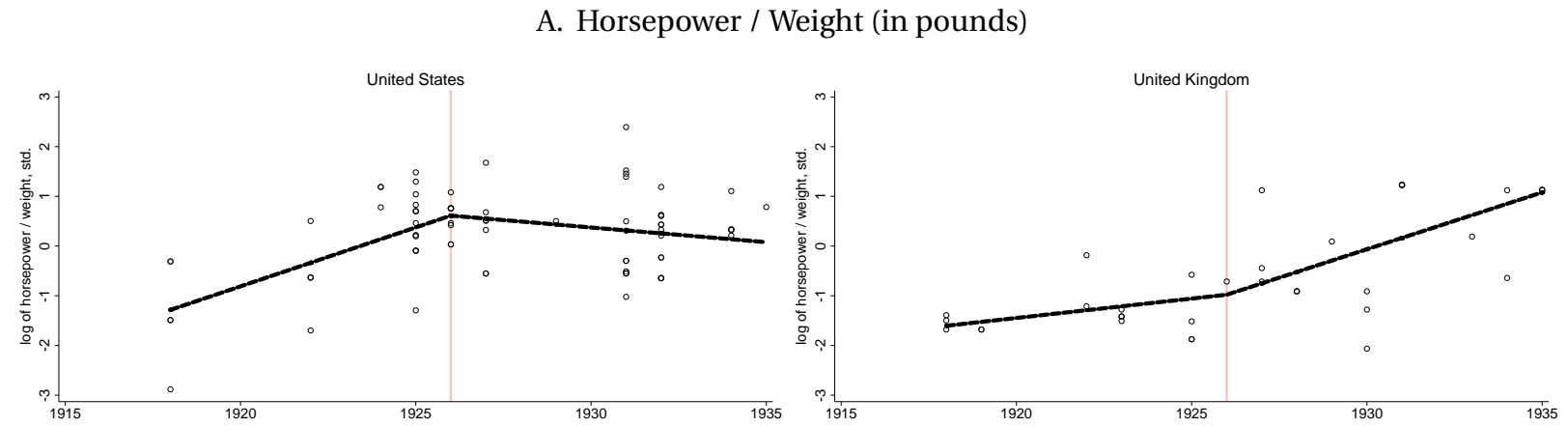

B. Horsepower / Displacement (in liters)
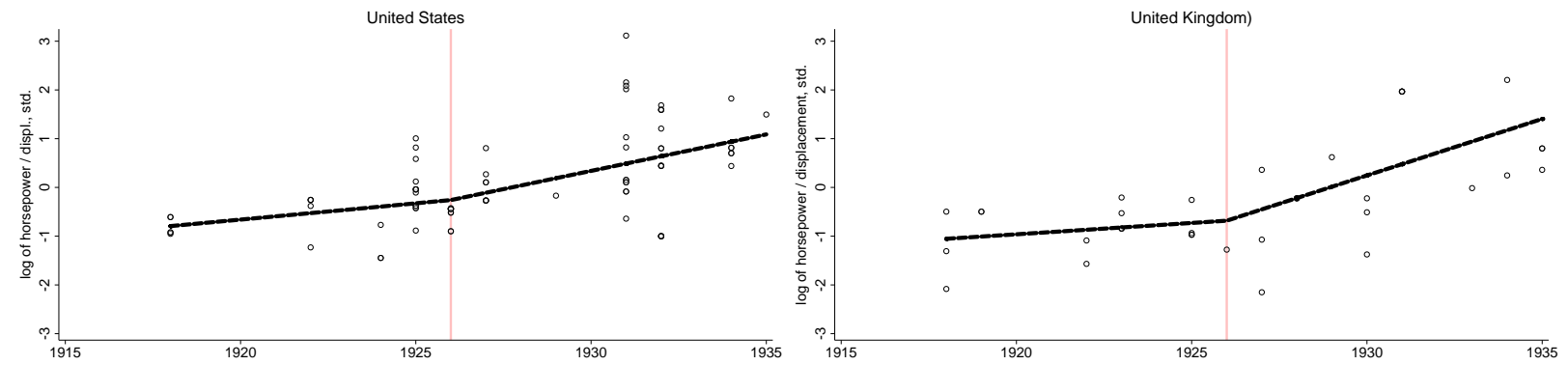

C. Horsepower / Frontal Area (in square inches)
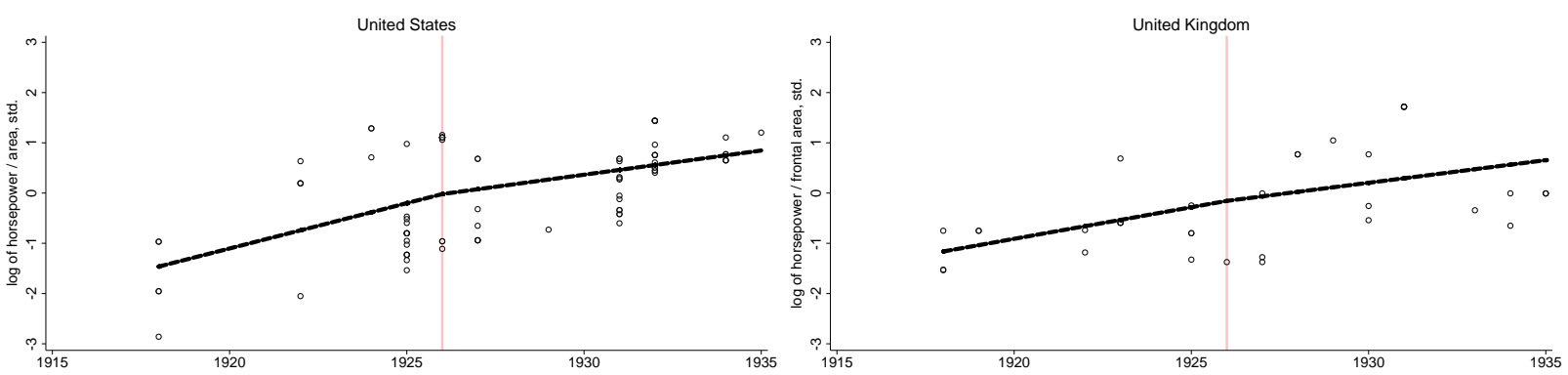

Notes: This figure shows different measures of innovation engines used by military fighters and bombers between 1918 and 1935. For the United States and United Kingdom, Panel A shows the log of horsepower divided engine weight (in pounds), Panel B shows the log of horsepower divided engine displacement (in liters), and Panel C shows the log of horsepower divided by an engine's frontal area (in square inches). Each measure is standardized by subtracting the mean and dividing by the standard deviation. The dashed black line is a linear spline with a different slope before and after 1926. 
Table 4: Results for Aero-Engine Innovation Before and After 1926

\begin{tabular}{|c|c|c|c|c|c|c|}
\hline \multirow[b]{2}{*}{$\begin{array}{l}\text { Outcome } \\
\text { (in log) }\end{array}$} & \multicolumn{3}{|c|}{ United States Only: } & \multicolumn{3}{|c|}{ Comparison of US and UK: } \\
\hline & $\begin{array}{c}(1) \\
\text { HP } \div \\
\text { Weight }\end{array}$ & $\begin{array}{c}(2) \\
\mathrm{HP} \div \\
\text { Disp }\end{array}$ & $\begin{array}{c}(3) \\
\mathrm{HP} \div \\
\text { Area }\end{array}$ & $\begin{array}{c}\text { (4) } \\
\text { HP } \div \\
\text { Weight }\end{array}$ & $\begin{array}{c}(5) \\
\text { HP } \div \\
\text { Disp }\end{array}$ & $\begin{array}{c}6) \\
\mathrm{HP} \div \\
\text { Area }\end{array}$ \\
\hline Before $1926 \times$ year $\times$ US & $\begin{array}{c}0.039 \\
(0.009)\end{array}$ & $\begin{array}{c}0.024 \\
(0.009)\end{array}$ & $\begin{array}{c}0.130 \\
(0.022)\end{array}$ & $\begin{array}{c}0.027 \\
(0.011)\end{array}$ & $\begin{array}{c}0.004 \\
(0.018)\end{array}$ & $\begin{array}{c}0.084 \\
(0.028)\end{array}$ \\
\hline After $1926 \times$ year $\times$ US & $\begin{array}{l}-0.010 \\
(0.005)\end{array}$ & $\begin{array}{c}0.043 \\
(0.005)\end{array}$ & $\begin{array}{c}0.072 \\
(0.008)\end{array}$ & $\begin{array}{l}-0.048 \\
(0.008)\end{array}$ & $\begin{array}{l}-0.018 \\
(0.011)\end{array}$ & $\begin{array}{c}0.009 \\
(0.017)\end{array}$ \\
\hline $\begin{array}{l}\text { Control for: } \\
\text { 1(Liquid-Cooled) }\end{array}$ & yes & yes & yes & yes & yes & yes \\
\hline $\begin{array}{l}F \text {-statistic } \\
p \text {-value }\end{array}$ & $\begin{array}{c}22.1 \\
0.000\end{array}$ & $\begin{array}{c}2.7 \\
0.105\end{array}$ & $\begin{array}{c}5.0 \\
0.028\end{array}$ & $\begin{array}{c}21.3 \\
0.000\end{array}$ & $\begin{array}{c}0.7 \\
0.402\end{array}$ & $\begin{array}{c}3.6 \\
0.061\end{array}$ \\
\hline observations & 85 & 85 & 85 & 123 & 123 & 123 \\
\hline
\end{tabular}

Notes: This table shows regression results for US aero-engines (columns 1 through 3 ) and US and UK aero-engines (columns 4 through 6). The dependent variable is the log of the variable at the top of each column. In columns 1 and 4 weight is measured in pounds; in columns 2 and 3 displacement is measured in liters; and in columns 3 and 6 frontal area is measured in square inches. Columns 1 through 3 show results for the United States only. Columns 4 through 6 show results comparing the United States to the United Kingdom. A constant term and an indicator for whether an engine is liquid-cooled are included in all columns. In addition, columns 4 through 6 include a linear spline for the United Kingdom and an indicator for the United States. Robust standard errors are shown in parentheses. 
the United States only using a specification similar to equation (4). These results indicate that performance slowed down in the United States for two of the three performance measures. In columns 4 through 6, we compare patterns in the United States to those in the Kingdom. ${ }^{48}$ For each outcome, the results indicate a relative slowdown in the rate of performance increase in United States, although the results are only statistically significant for two of the three measures. In Appendix E. 4 we examine the robustness of these results to alternative approaches.

Finally, it is worth addressing the potential concern that the aero-engine results are not due to the 1926 law change, but rather to changes in market structure associated with the entry of Pratt \& Whitney into the market in 1925. In Appendix B.7 we show that the entry of Pratt \& Whitney had relatively little impact on aero-engine market concentration in the years before 1929. This was because the Pratt \& Whitney entry was engineered by the Navy as a way to offset the merger of Wright and Lawrence, another important engine producer before 1925. Thus, the emergence of Pratt \& Whitney simply replaced Lawrence, resulting in a relatively similar market structure. However, that structure did become more concentrated following the mergers of 1929, as predicted by our theory.

\subsection{Mergers}

Our theory offers the additional prediction that, once airframe producers have access to IP protection, this may have generated incentives for mergers between airframe and aero-engine producers. Our empirical setting provides an excellent opportunity for studying this prediction. In particular, the type of active antitrust enforcement that may have slowed down or blocked merger activity in other settings was almost completely absent in the period we study. ${ }^{49}$

To track merger activity, we have constructed firm histories covering all of the important US producers of airframes and military engines. In addition, to provide a point of comparison we construct similar firm histories for British military airframe and engine manufacturers, as well as US manufacturers of civil airframes and aero engines. These firm histories are constructed using a wide variety of sources, most importantly, the Jane's yearbooks.

An analysis of these data, in Appendix F, shows that within three years of the 1926 law change, both of the major military aero-engine producers had merged with large military airframe pro-

\footnotetext{
${ }^{48}$ As with airframes, our cross-country comparison of aero-engine performance does not reflect a simple comparison of treated versus untreated locations. Each country had a different IP regime related to aero-engines during the study period, so we should not expect parallel trends in innovation before 1926. Given this, the cross-country comparison serves mainly to help us control for other broad factors that may have influenced aero-engine innovation. Similarly, any cross-country technology spillovers will bias the aero-engine results toward zero, so the estimates we obtain should be taken as a lower-bound on the true effect.

${ }^{49}$ Antitrust authorities were reluctant to oppose mergers in the 1920s after having suffered major defeats in their efforts to break up US Steel between 1915 and 1920 as well as in cases against United Shoe Company in 1918 and American Can Company in 1916 (Scherer and Ross, 1970, p. 457-8).
} 
ducers: Wright Aeronautical merged with Curtiss, the largest airframe producer, as well as what were previously Huff-Daland/Keystone, Loening, and Travel Air, to form the Curtiss-Wright Corporation, and Pratt \& Whitney merged with Boeing and what were previously Chance-Vought, Stearman, and Sikorski to form United Aircraft. ${ }^{50}$ This merger activity, taking place within just a few years of the 1926 law change, stands out relative to the period before 1926 or after 1930. Moreover, we do not observe any similar pattern of merger activity among US aero-engine and airframe producers focused on the civil market, nor do we observe any similar pattern among military aero-engine and airframe firms in the United Kingdom. These patterns of merger activity provide additional support for the theory in Section 3.

\subsection{Discussion}

Our main results show that the 1926 change in IP protection was associated with an increase in the rate at which airframe performance increased and a corresponding decrease in the rate at which aero-engine performance increased. We have also provided additional evidence, consistent with a third prediction of our theory, that airframe and aero-engine producers undertook mergers in the years just following the law change. All three of these patterns are found when looking only at the United States, or when comparing the United States to other countries.

In Section 3, we presented a theory that described one mechanism through which providing IP protection to airframe producers may increase innovation in airframes and simultaneously decrease innovation in aero-engines. This theory is attractive in part because, though it is simple and relies on straightforward economic (profit) incentives, it can match all three of the predictions documented in our empirical analysis. That said, it is not our intention to argue that other mechanisms did not also play a role in generating the changes in innovative activity documented in the previous sections.

In Appendix G, we discuss a number of potential alternative theories or possible identification concerns including: (1) airframes and engines could be substitutes in quality, (2) spillovers between the civil and military markets could be affecting our results, (3) our results could be due in part to changes in demand for military aircraft, (4) our results could be affected by other changes in procurement policies, and (5) that within-company learning could be influencing our results. These theories provide potential altenative explanations for some of the patterns we have documented. However, as we discuss, none of these provide a compelling alternative

\footnotetext{
${ }^{50}$ United Aircraft also included an airline, United, which originated as part of Boeing. In 1934, in response to charges of collusion from smaller airline operators, President Roosevelt revoked all private airmail contracts (Patillo, 1998, p. 87). Initially, the Army Air Corps filled in by flying the airmail routes. However, the Air Corps was ill-equipped to take on this job on such short notice. After a series of accidents resulted in the deaths of twelve pilots, air mail was returned to commercial operators under the Airmail Act of 1934. This legislation contained a provision which banned airmail carriers from also producing aircraft, and ultimately forced the breakup of United Aircraft.
} 
explanation for all three of the patterns documented in our main results.

\section{Conclusion}

The relationship between IP protection and innovation has important implications for economic growth and the development of industries. In this paper we show that the effects of IP protection can be both direct (i.e., IP increases the incentive to innovate in areas where IP is granted) and indirect (i.e., IP increases or decreases innovation in areas where technology is either substitute or complement). We use the setting of the interwar aircraft industry in the United States to show that both effects are quantitatively important. In particular, granting IP protection for airframes increased the rate of innovation for airframes and decreased the rate of innovation for complementary aero-engines. We also show that this led to mergers between airframe and aero-engine producers. Together, we interpret these results as support for an underlying mechanism that fundamentally connects innovation decisions and market structure.

Although our empirical evidence is derived from a particular setting, the mechanism we emphasize is general and relevant in other markets and time periods where products are linked as complements or substitutes. This has important implications for understanding how changes in IP protection affect innovation and market structure, the interaction with antitrust policy, and the potential consequences for economic growth. Our results are useful to researchers comparing similar goods in the context of difference-in-difference analysis to evaluate the efficacy of changes in IP: comparisons of goods that are complements (substitutes) will to tend to overstate (understate) estimated treatment effects. Our results also add to existing work suggesting that in some cases IP protection may provide property rights to too many agents, creating patent thickets (Shapiro, 2000) and an anticommons (Heller and Eisenberg, 1998). While we do not argue that property rights are too strong in our setting, we highlight a cost of providing IP protection to be weighed against potential benefits. 


\section{References}

Acemoglu, Daron and Joshua Linn, "Market Size in Innovation: Theory and Evidence from the Pharmaceutical Industry," Quarterly Journal of Economics, 2004, 119 (3), 1049-1090.

Aghion, Philippe and Peter Howitt, "A Model of Growth Through Creative Destruction," Econometrica, 1992, 60 (2), 323-351.

_ , Nick Bloom, Richard Blundell, Rachel Griffith, and Peter Howitt, "Competition and innovation: An inverted-U relationship,” The Quarterly Journal of Economics, 2005, 120 (2), 701-728.

_ , Richard Blundell, Rachel Griffith, Peter Howitt, and Susanne Prantl, "The effects of entry on incumbent innovation and productivity," The Review of Economics and Statistics, 2009, 91 (1), 20-32.

Arrow, Kenneth J., "The Economic Implications of Learning by Doing," The Review of Economic Studies, 1962, 29 (3), 155-173.

Asher, Harold, "Cost-Quantity Relationships in the Airframe Industry." PhD dissertation, The Ohio State University 1956.

Baten, Joerg, Nicola Bianchi, and Petra Moser, "Compulsory Licensing and Innovation Historical Evidence from Germany Patents After WWI," Journal of Development Economics, 2017, 126.

Benkard, C. Lanier, "Learning and Forgetting: The Dynamics of Aircraft Production," American Economic Review, 2000, 90 (4), 1034-1054.

Berkes, Enrico, “Comprehensive Universe of U.S. Patents (CUSP): Data and Facts," 2018.

Bilstein, Roger E., Orders of Magnitude: A History of the NACA and NASA, 1915-1990, Washington, DC: National Aeronautics and Space Administration, 1989.

Bittlingmayer, George, "Property Rights, Progress and the Aircraft Patent Agreement," Journal of Law \& Economics, 1988, 31 (1), 227-248.

Blundell, Richard, Rachel Griffith, and John Van Reenen, "Market share, market value and innovation in a panel of British manufacturing firms," The Review of Economic Studies, 1999, 66 (3), 529-554.

Bowers, Peter M., Curtiss Aircraft, 1907-1947, Naval Institute Press, 1987.

_ , Boeing Aircraft Since 1916, Annapolis, MD: Naval Institute Press, 1989.

Broadberry, Steve N., The Productivity Race: British Manufacturing in International Perspective, 1850-1990, Cambridge, UK: Cambridge University Press, 1997.

Bryan, Kevin, "Industrial Reversals of Fortune: The Meaning of Invention in the Early Airplane Industry," July 2016. Mimeo.

Buenstorf, Guido and Steven Klepper, "Heritage and Agglomeration: The Akron Tyre Cluster Revisited," Economic Journal, 2009, 119 (537), 705-733.

Chaudhuri, Shubham, Pinelopi K. Goldberg, and Panle Jia, "Estimating the Effects of Global Patent Protection in Pharmaceuticals: A Case Study of Quinolones in India," The American Economic Review, 2006, 96 (5), pp. 1477-1514.

Chen, Yongmin and David EM Sappington, "Innovation in vertically related markets," The Journal of Industrial Economics, 2010, 58 (2), 373-401.

Cohen, Wesley M., "Fifty years of empirical studies of innovative activity and performance," in "Handbook of the Economics of Innovation," Vol. 1, Elsevier, 2010, pp. 129-213.

Collard-Wexler, Allan, Gautam Gowrisankaran, and Robin S Lee, "Nash-in-Nash bargaining: a microfoundation for applied work," Journal of Political Economy, 2019, 127 (1), 163-195.

Duggan, Mark, Craig Garthwaite, and Aparajita Goyal, "The Market Impacts of Pharmaceutical Product Patents in Developing Countries: Evidence from India," American Economic Review, 2016, 106 (1), 99-135. 
Edgerton, David, England and The Aeroplane: Militarism, Modernity and Machines, second edition ed., London: Penguin Books, 2013.

Fearon, Peter, "The Formative Years of the British Aircraft Industry, 1913-1924," Business History Review, 1969, 43 (4), 476-495.

_ , "The British Airframe Industry and the State, 1918-35," Economic History Review, 1974, 27 (2), 236-251.

Finkelstein, Amy, "Static and Dynamic Effects of Health Policy: Evidence from the Vaccine Industry," Quarterly Journal of Economics, 2004, 119 (2), 527-564.

Francillon, Rene J., McDonnell Douglas Aircraft Since 1920, Vol. 1, Naval Institute Press, 1988.

Gilbert, Richard, "Looking for Mr. Schumpeter: Where Are We in the Competition-Innovation Debate?," Innovation policy and the economy, 2006, 6, 159-215.

Gilbert, Richard J., Collective Rights Organizations: A Guide to Benefits, Costs and Antitrust Safeguards Cambridge Law Handbooks, Cambridge University Press,

Gilchrist, Duncan S., "Patents as a Spur to Subsequent Innovation? Evidence from Pharmaceuticals," American Economic Journal: Applied Economics, 2016, 8 (4), 189-221.

Green, Jerry R. and Suzanne Scotchmer, "On the Division of Profit in Sequential Innovation," RAND Journal of Economics, 1995, 26 (1), 20-33.

Grossman, Gene and Elhanan Helpman, Innovation and Growth in the Global Economy, Cambridge, Massachusetts: The MIT Press, 1991.

Heller, Michael A. and Rebecca S. Eisenberg, "Can Patents Deter Innovation? The Anticommons in Biomedical Research," Science, 1998, 280 (5364), 698-701.

Holley, I.B., Buying Aircraft: Material Procurement for the Army Air Forces, Washington, DC: Office of the Chief of Military History, 1964.

Horn, Henrick and Asher Wolinsky, "Bilateral Monopolies and Incentives for Merger," The RAND Journal of Economics, 1988, pp. 408-419.

Jaworski, Taylor and Andrew Smyth, "Shakeout in the Early Commercial Airframe Industry," Economic History Review, 2016, 71 (2), 617-638.

Katznelson, Ron D. and Joh Howells, "The Myth of the Early Aviation Patent Hold-up - How a U.S. Government Monopsony Commandeered Pioneer Airplane Patents," Industrial and Corporate Change, 2014, 24 (1), 1-64.

Kelly, Paul, "Biplane to Monoplane: Twenty Years of Technological Development in British Fighter Aircraft, 1919-1939.” PhD dissertation, University of Edinburgh 2013.

Klepper, Steven, "Entry, Exit, Growth, and Innovation over the Product Life Cycle," American Economic Review, 1996, 86 (3), 562-583.

- and Kenneth L. Simons, "The Making of an Oligopoly: Firm Survival and Technological Change in the Evolution of the U.S. Tire Industry.," Journal of Political Economy, 2000, 108 (4), 728-760.

Koistinen, Paul A.C., Planning War, Pursuing Peace, University Press of Kansas, 1998.

Lampe, Ryan and Petra Moser, "Do Patent Pools Encourage Innovation? Evidence from the Nineteenth-Century Sewing Machine Industry.," Journal of Economic History, 2010, 70 (4), 898-920.

_ and _ , "Patent Pools and Innovation in Substitute Technologies - Evidence from the U.S. Sewing Machine Industry," RAND Journal of Economics, 2014, 44 (4), 757-778.

_ and _ , "Patent Pools, Competition and Innovation. Evidence from 20 Industries Under the New Deal.," Journal of Law, Economics \& Organization, 2016, 32, 1-36.

Lerner, Joshua and Jean Tirole, “Efficient Patent Pools," American Economic Review, 2004, 94 (3), 
691-711.

Loury, Glenn C., "Market Structure and Innovation,” The Quarterly Journal of Economics, 1979, 93 (3), 395-410.

Meulen, JA Vander, The Politics of Aircraft, Lawrence, Kansas: University of Kansas Press, 1991.

Miller, Ronald and David Sawers, The Technical Development of Modern Aviation, New York: Praeger Publishers, 1970.

Moscona, Jacob, "Patent Protection, Invention, and Productivity: Evidence from U.S. Agriculture,” December 2019. Working Paper.

Moser, Petra and Alessandra Voena, "Compulsory Licensing: Evidence from the Trading with the Enemy Act,” American Economic Review, 2012, 102 (1), 396-427.

Munson, Kenneth, Jane's Pocket Book of Record-Breaking Aircraft, New York: Collier Books, 1978.

National Advisory Committee for Aeronautics, Ninth Annual Report of the National Advisory Committee for Aeronautics 1923.

Patillo, Donald M., Pushing the Envelope, Ann Arbor: University of Michigan Press, 1998.

Phillips, A, Technology and Market Structure, Heath Lexington Books, 1971.

Rae, John B, Climb to Greatness, Cambridge, MA: The MIT Press, 1968.

Romer, Paul M., "Endogenous Technological Change," Journal of Political Economy, 1990, 98 (5, Part 2), S71-S102.

Rowland, Alex, Model Research: The National Advisory Committee for Aeronautics, 1915-1958, Washington, DC: National Air and Space Administration, 1985.

Sampat, B and HL Williams, "How Do Patents Affect Follow-On Innovation? Evidence from the Human Genome," American Economic Review, 2019, 109 (1), 203-236.

Sanyal, Paroma and Suman Ghosh, "Product market competition and upstream innovation: evidence from the US electricity market deregulation," Review of Economics and Statistics, 2013, 95 (1), 237-254.

Scherer, FM and DR Ross, Industrial Market Structure and Economic Performance, Rand McNally \& Co., 1970.

Schmookler, Jacob, Invention and Economic Growth, Cambridge, MA: Harvard University Press, 1966.

Schumpeter, Joseph A., Capitalism, Socialism, and Democracy, New York, NY: Harper, 1942.

Shapiro, Carl, "Navigating the Patent Thicket: Cross licenses, Patent Pools, and Standard Setting," Innovation policy and the economy, 2000, 1, 119-150.

_ , The Rate and Direction of Inventive Activity Revisited, University of Chicago Press,

Taylor, C. Fayette, Aircraft Propulsion. A Review of the Evolution of Aircraft Piston Engines., Washington, DC: Smithsonian Institution Press, 1971.

Vives, Xavier, "Innovation and competitive pressure," Journal of Industrial Economics, 2008, 56 (3), 419-469.

Williams, Heidi L., "Intellectual Property Rights and Innovation: Evidence from the Human Genome," Journal of Political Economy, 2013, 121 (1), 1-27.

_ , "How Do Patents Affect Research Investments?," Annual Review of Economics, 2017, 9, 441469. 
Appendix 


\section{A. Theory Appendix}

\section{A.1 The innovation investment optimization problem}

The expected payoff of innovation for the market leader is given by,

$$
\begin{aligned}
\Lambda_{L}\left(I_{m j L}\right) & =\pi_{m j}\left[1-\phi\left(I_{m j F}\right)\right]^{N-1} \\
& +\phi\left(I_{m j L}\right) \pi_{m j} \sum_{n=1}^{N-1}\left(\frac{1}{n+1}\right)\left(\begin{array}{c}
N-1 \\
n
\end{array}\right) \phi\left(I_{m j F}\right)^{n}\left[1-\phi\left(I_{m j F}\right)\right]^{N-n-1} \\
& -I_{m j L} .
\end{aligned}
$$

The top row on the right-hand side of this expression reflects the return if no other firm innovates, in which case the market leader retains leadership regardless of whether or not it successfully innovates. The second row is the expected payoff if the leader innovates but other firms do so as well. In this case the chance that the current leader's innovation is chosen for production by the government is $1 /(n+1)$ where $n+1$ is the total number of innovating firms. The last term reflects the cost of innovation.

The expected payoff for a follower firm $F^{\prime}$ given investment $I_{m F^{\prime}}$ is,

$$
\begin{aligned}
\Lambda_{F^{\prime}}\left(I_{m j F^{\prime}}\right)= & \phi\left(I_{m k F^{\prime}}\right) \pi_{m j}\left[\sum_{n=0}^{N-2}\left(\frac{1-\phi\left(I_{m j L}\right)}{n+1}+\frac{\phi\left(I_{m j L}\right)}{n+2}\right)\right. \\
& \left.\left(\begin{array}{c}
N-2 \\
n
\end{array}\right) \phi\left(I_{m j F}\right)^{n}\left[1-\phi\left(I_{m j F}\right)\right]^{N-n-2}\right]-I_{m j F^{\prime}}
\end{aligned}
$$

Leader and follower firms choose their level of innovation investment to maximize the expected payoff from innovation, shown in Eqs. 6 and 7 respectively. Taking first order conditions, the leader sets $I_{m j L}$ such that,

$$
\phi^{\prime}\left(I_{m j L}\right)=\left[\pi_{m j} \sum_{n=1}^{N-1}\left(\frac{1}{n+1}\right)\left(\begin{array}{c}
N-1 \\
n
\end{array}\right) \phi\left(I_{m j F}\right)^{n}\left[1-\phi\left(I_{m j F}\right)\right]^{N-n-1}\right]^{-1}
$$

The follower $F^{\prime}$ sets $I_{m j F^{\prime}}$ such that,

$$
\phi^{\prime}\left(I_{m j F^{\prime}}\right)=\left[\pi_{m j} \sum_{n=0}^{N-2}\left(\frac{1-\phi\left(I_{m j L}\right)}{n+1}+\frac{\phi\left(I_{m j L}\right)}{n+2}\right)\left(\begin{array}{c}
N-2 \\
n
\end{array}\right) \phi\left(I_{m j F}\right)^{n}\left[1-\phi\left(I_{m j F}\right)\right]^{N-n-2}\right]^{-1}
$$

Given the assumption that $\phi^{\prime \prime}(\cdot)<0$, the the first order conditions obtained from the maximization of Eqs. 6 and 7 with respect to the level of innovation investment constitute optimal 
solutions to the leader's and the follower's problems taking as given the investments of all other firms. In equilibrium it must be the case that $I_{m j F^{\prime}}=I_{m j F}$ for all follower firms. Proving equilibrium existence therefore involves showing that the first order conditions obtained from Eqs. 6 and 7 can be satisfied under this condition. Proof of equilibrium existence is provided in Appendix A.3.

\section{A.2 Nash-in-Nash bargaining with IP protection in airframes}

When airframe producers have IP protection, under Nash-in-Nash bargaining the airframe price is given by,

$$
P_{m A}=\arg \max _{P_{m A}}\left[\theta x_{m}^{\rho}+D-x_{m}\left(P_{m A}+P_{m E}\right)-D\right]\left[x_{m}\left(P_{m A}-\gamma_{A}\right)\right]
$$

taking as given that the government reaches an agreement with the engine maker with negotiated price $P_{m E}$. Substituting in for $x_{m}$ using Eq. 1 and rearranging we obtain,

$$
P_{m A}=\arg \max _{P_{m A}} \quad C\left(P_{m A}+P_{m E}\right)^{\frac{\rho+1}{\rho-1}}\left(P_{m A}-\gamma_{A}\right)
$$

where, $C=\left[\theta^{\frac{2}{1-\rho}} \rho^{\frac{\rho+1}{1-\rho}}-\theta^{\frac{2}{1-\rho}} \rho^{\frac{2}{1-\rho}}\right]>0$.

The first order condition for this maximization yields,

$$
P_{m A}-\gamma_{a}=\left(P_{m A}+P_{m E}\right)\left(\frac{1-\rho}{1+\rho}\right) .
$$

A similar expression holds for the price of engines. These expressions implicitly define the equilibrium prices negotiated between the government and each type of supplier. Simplifying, we have,

$$
P_{m A}=\frac{\gamma_{A}(1+\rho)+P_{m E}(1-\rho)}{2 \rho} \quad \text { and } \quad P_{m E}=\frac{\gamma_{E}(1+\rho)+P_{m A}(1-\rho)}{2 \rho}
$$

Note that these expressions can be used to show that the difference between the prices of engines and airframes is driven entirely by differences in the underlying costs, i.e., $P_{m A}=P_{m E}+$ $\left(\gamma_{A}-\gamma_{E}\right)$.

Solving these expressions, we obtain,

$$
P_{m A}=\frac{\gamma_{A} 2 \rho+\gamma_{E}(1-\rho)}{3 \rho-1}
$$

and a corresponding expression for $P_{m E}$. We can see from this expression that to obtain a positive finite price we need $\rho>1 / 3$. Henceforth we assume that this condition is satisfied. The total 
price for an aircraft under these conditions is then,

$$
P_{m}=P_{m A}+P_{m E}=\frac{\left(\gamma_{A}+\gamma_{E}\right)(1+\rho)}{3 \rho-1}
$$

Given these prices, the production profit for the engine producer when the airframe producer has access to IP protection is given by,

$$
\tilde{\pi}_{m E}^{I P}=\left(\gamma_{A}+\gamma_{E}\right)^{\frac{\rho}{\rho-1}}(1+\rho)^{\frac{1}{\rho-1}}(3 \rho-1)^{\frac{\rho}{1-\rho}}(\rho \theta)^{\frac{1}{1-\rho}}(1-\rho)
$$

A similar expression holds for the airframe producer.

\section{A.3 Proof of equilibrium existence and uniqueness}

To prove equilibrium existence we need to show that there exists a $I_{m j f}$ such that equation (9) is satisfied when $I_{m j F^{\prime}}=I_{m j F}$. Given our assumptions on $\phi(\cdot)$ we know that the left-hand side of equation (9) is strictly decreasing in $I_{m j F}$, that $\lim \phi^{\prime}\left(I_{m j F}\right) \rightarrow+\infty$ as $I_{m j F} \rightarrow 0$, and that $\lim \phi^{\prime}\left(I_{m j F}\right) \rightarrow 0$ as $I_{m j F} \rightarrow+\infty$. It remains for us to study how the right-hand side of equation (9) evolves as $I_{m j F}$ changes. To simplify the notation, define $z=\phi\left(I_{m j F}\right)$, which is a strictly increasing function of $I_{m j}$.

Focusing only on the terms behind the summation operator in equation (9), we can expand this term to obtain,

$$
\begin{array}{cc}
\frac{(N-2) !}{0 !(N-2) !} & \left(\frac{1-\phi\left(I_{m j L}\right)}{1}+\frac{\phi\left(I_{m j L}\right)}{2}\right) z^{0}(1-z)^{N-2} \\
\frac{(N-2) !}{1 !(N-3) !} & \left(\frac{1-\phi\left(I_{m j L}\right)}{2}+\frac{\phi\left(I_{m j L}\right)}{3}\right) z^{1}(1-z)^{N-3} \\
\frac{(N-2) !}{2 !(N-4) !} & \left(\frac{1-\phi\left(I_{m j L}\right)}{3}+\frac{\phi\left(I_{m j L}\right)}{4}\right) z^{2}(1-z)^{N-4} \\
\vdots & \\
\frac{(N-2) !}{(N-4) ! 2 !} & \left(\frac{1-\phi\left(I_{m j L}\right)}{N-3}+\frac{\phi\left(I_{m j L}\right)}{N-2}\right) z^{N-4}(1-z)^{2} \\
\frac{(N-2) !}{(N-3) ! 1 !} & \left(\frac{1-\phi\left(I_{m j L}\right)}{N-2}+\frac{\phi\left(I_{m j L}\right)}{N-1}\right) z^{N-3}(1-z)^{1} \\
\frac{(N-2) !}{(N-2) ! 0 !} & \left(\frac{1-\phi\left(I_{m j L}\right)}{N-1}+\frac{\phi\left(I_{m j L}\right)}{N}\right) z^{N-2}(1-z)^{0}
\end{array}
$$

To see how this term changes as $z$ changes, we take the derivative with respect to $z$ to obtain: 


$$
\begin{aligned}
& -(N-2) \frac{(N-2) !}{0 !(N-2) !}\left(\frac{1-\phi\left(I_{m j L}\right)}{1}+\frac{\phi\left(I_{m j L}\right)}{2}\right)(1-z)^{N-3} \\
& \frac{(N-2) !}{1 !(N-3) !}\left(\frac{1-\phi\left(I_{m j L}\right)}{2}+\frac{\phi\left(I_{m j L}\right)}{3}\right)(1-z)^{N-3}-(N-3) \frac{(N-2) !}{1 !(N-3) !}\left(\frac{1-\phi\left(I_{m j L}\right)}{2}+\frac{\phi\left(I_{m j L}\right)}{3}\right) z(1-z)^{N-4} \\
& 2 \frac{(N-2) !}{2 !(N-4) !}\left(\frac{1-\phi\left(I_{m j L}\right)}{3}+\frac{\phi\left(I_{m j L}\right)}{4}\right) z(1-z)^{N-4}-(N-4) \frac{(N-2) !}{2 !(N-4) !}\left(\frac{1-\phi\left(I_{m j L}\right)}{3}+\frac{\phi\left(I_{m j L}\right)}{4}\right) z^{2}(1-z)^{N-5} \\
& \vdots \\
& (N-4) \frac{(N-2) !}{(N-4) ! 2 !}\left(\frac{1-\phi\left(I_{m j L}\right)}{N-3}+\frac{\phi\left(I_{m j L}\right)}{N-2}\right) z^{N-5}(1-z)^{2}-2 \frac{(N-2) !}{(N-4) ! 2 !}\left(\frac{1-\phi\left(I_{m j L}\right)}{N-3}+\frac{\phi\left(I_{m j L}\right)}{N-2}\right) z^{N-4}(1-z) \\
& (N-3) \frac{(N-2) !}{(N-3) ! 1 !}\left(\frac{1-\phi\left(I_{m j L}\right)}{N-2}+\frac{\phi\left(I_{m j L}\right)}{N-1}\right) z^{N-4}(1-z)-\frac{(N-2) !}{(N-3) ! 1 !}\left(\frac{1-\phi\left(I_{m j L}\right)}{N-2}+\frac{\phi\left(I_{m j L}\right)}{N-1}\right) z^{N-3} \\
& (N-2) \frac{(N-2) !}{(N-2) ! 0 !}\left(\frac{1-\phi\left(I_{m j L}\right)}{N-1}+\frac{\phi\left(I_{m j L}\right)}{N}\right) z^{N-3}
\end{aligned}
$$

Next, we reorganize to obtain,

$$
\begin{array}{r}
(1-z)^{N-3}\left[\frac{1-\phi\left(I_{m j L}\right)}{2}+\frac{\phi\left(I_{m j L}\right)}{3}-\frac{1-\phi\left(I_{m j L}\right)}{1}-\frac{\phi\left(I_{m j L}\right)}{2}\right] \frac{(N-2) !}{0 !(N-3) !} \\
+z(1-z)^{N-4}\left[\frac{1-\phi\left(I_{m j L}\right)}{3}+\frac{\phi\left(I_{m j L}\right)}{4}-\frac{1-\phi\left(I_{m j L}\right)}{2}-\frac{\phi\left(I_{m j L}\right)}{3}\right] \frac{(N-2) !}{1 !(N-4) !} \\
-z^{2}(1-z)^{N-5}\left[\frac{1-\phi\left(I_{m j L}\right)}{3}+\frac{\phi\left(I_{m j L}\right)}{4}\right] \frac{(N-2) !}{2 !(N-5) !} \\
-z^{N-5}(1-z)^{2}\left[\frac{1-\phi\left(I_{m j L}\right)}{N-3}+\frac{\phi\left(I_{m j L}\right)}{N-2}\right] \frac{(N-2) !}{2 !(N-5) !} \\
+z^{N-4}(1-z)\left[\frac{1-\phi\left(I_{m j L}\right)}{N-2}+\frac{\phi\left(I_{m j L}\right)}{N-1}-\frac{1-\phi\left(I_{m j L}\right)}{N-3}-\frac{\phi\left(I_{m j L}\right)}{N-2}\right] \frac{(N-2) !}{1 !(N-4) !} \\
+z^{N-3}\left[\frac{1-\phi\left(I_{m j L}\right)}{N-1}+\frac{\phi\left(I_{m j L}\right)}{N}-\frac{1-\phi\left(I_{m j L}\right)}{N-2}-\frac{\phi\left(I_{m j L}\right)}{N-1}\right] \frac{(N-2) !}{0 !(N-3) !}
\end{array}
$$

In the first two term and last two terms of this expression, the value within the square brackets will always be negative. The remaining issue is what happens to the two terms in the middle. Note that the two middle terms will be unmatched only of there are no terms between them, which in the case of the expressions above will occur when $N=7$. However, when $N=7$, the two middle terms can be rewritten together as,

$$
z^{2}(1-z)^{2}\left[\frac{1-\phi\left(I_{m j L}\right)}{4}+\frac{\phi\left(I_{m j L}\right)}{5}-\frac{1-\phi\left(I_{m j L}\right)}{3}-\frac{\phi\left(I_{m j L}\right)}{4}\right] \frac{(N-2) !}{1 !(N-5) !}
$$

which is also less than zero. We have now shown that the quantity inside the summation opera- 
tor in equation (9) is a strictly decreasing function of $x=\phi\left(I_{m j F}\right)$ and therefore also a decreasing function of $I_{m j F}$. This tells us that the right-hand side of equation (9) is an increasing function of $I_{m j F}$. It remains to show the location of the endpoints of this function at $I_{m j F}=0$ and as $I_{m j F} \rightarrow+\infty$.

First consider the case in which $I_{m j F}=0$, at which point $x=\phi\left(I_{m j F}\right)=0$. At this point, the right-hand side of equation (9) simplifies to,

$$
\left[\pi_{m j} \frac{(N-2) !}{0 !(N-2) !}\left(\frac{1-\phi\left(I_{m j L}\right)}{1}+\frac{\phi\left(I_{m j L)}\right)}{2}\right)\right]^{-1}
$$

which is a finite positive number. When $I_{m j F} \rightarrow+\infty$ the right-hand side of equation (9) approaches,

$$
\left[\pi_{m j} \frac{(N-2) !}{0 !(N-2) !}\left(\frac{1-\phi\left(I_{m j L)}\right.}{N-1}+\frac{\phi\left(I_{m j L}\right)}{N-2}\right)\right]^{-1}
$$

which is also a finite positive number. Thus, we have shown that the right-hand side of equation (9) is strictly increasing function of $I_{m j F}$ which begins with a positive value at $I_{m j F}=0$ and asymptotes to a larger finite positive value as $I_{m j} \rightarrow+\infty$. Since the left-hand side of equation (9) is strictly decreasing function of $I_{m j F^{\prime}}$, approaches $+\infty$ as $I_{m j F^{\prime}} \rightarrow 0$ and approaches 0 as $I_{m j F^{\prime}} \rightarrow+\infty$, there must be a single unique equilibrium $I_{m j F}$ that satisfies this equation when $I_{m j F^{\prime}}=I_{m j F}$ conditional on $I_{m L}$. The left panel of Figure Al provides a graphical representation of these two curves.

Next, we need to show that there is a unique equilibrium combination of $I_{m j L}$ and $I_{m j F}$. This is defined by equations (8) and (9) where $I_{m j F^{\prime}}=I_{m j F}$. Using an approach similar to the one applied to equation (9) above, it can be shown that the $I_{m j L}$ that satisfies equation (8) is a decreasing function of $I_{m j F}$ that takes a positive finite value when $I_{m j F}=0$ and approaches a smaller positive value as $I_{m j F} \rightarrow+\infty$. Similarly, the $I_{m j F}$ that satisfies equation (9) is a decreasing function of $I_{m j L}$ which takes a finite positive value at $I_{m j L}=0$ and approaches a smaller positive value as $I_{m j L} \rightarrow+\infty$. Thus, these curves take the form described in the right panel of Figure A1 with a unique equilibrium.

\section{A.4 Proof that innovation investment is increasing in profits}

An increase in profits will cause the right-hand side of equation (9) to decrease. In terms of the left panel of Figure A1, this will cause the RHS line to move downward, resulting in a higher equilibrium $I_{m j F}$ given $I_{m j L}$. In the right panel of Figure A1, an increase in profits will cause an upward shift in both curves, implying higher equilibrium innovation investments for both the leader and the follower firms. 


\section{Figure A1: Illustration of the Theory}
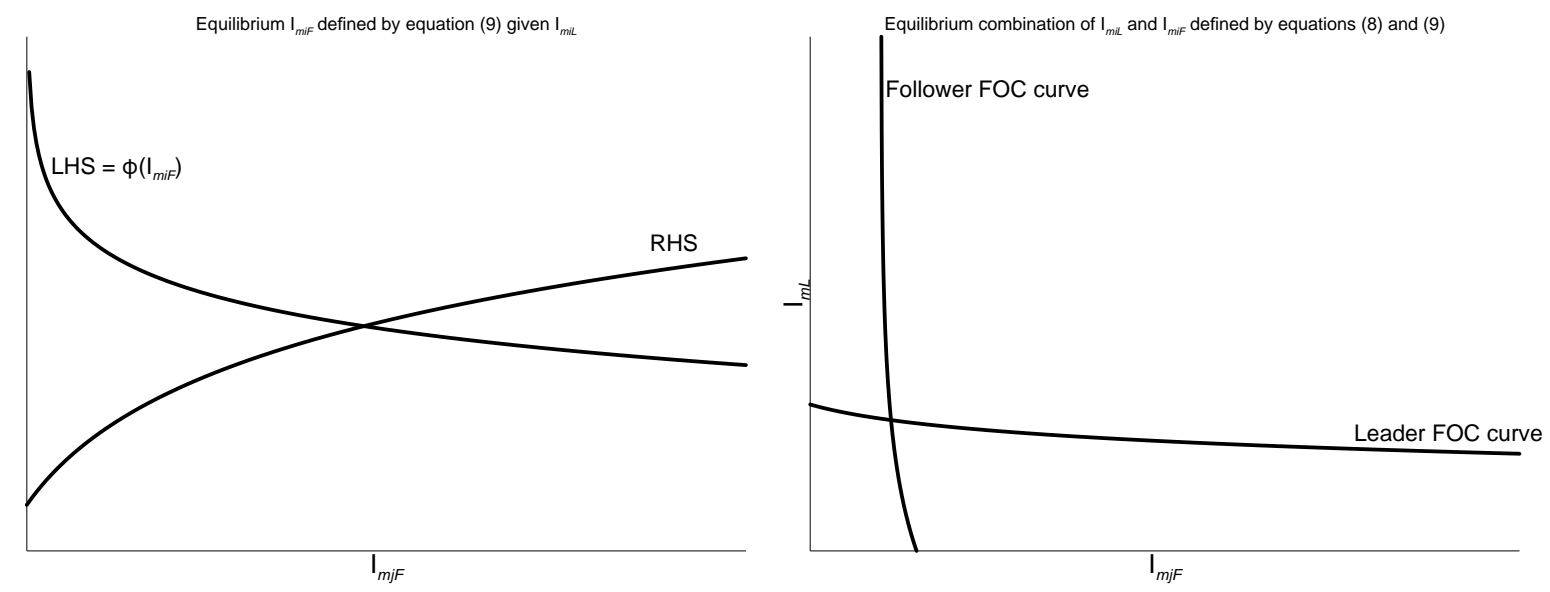


\section{B. Empirical Setting Appendix}

\section{B.1 The political economy of the 1926 Air Corps Act}

This appendix section provides some additional historical detail on the process leading up the the 1926 Act that provides the variation that we focus on. The starting point for this discussion is the end of WWI. Following the end of the war, the National Defense Act of 1920 set limits on military strength allocated across branches. According the Holley (1964) (p. 44) the Air Service ceiling was set at 16,000 men and 1,514 officers, but the actual strength depended on the funds made available through piecemeal appropriations.

Concerns about the readiness and capacity of the Air Service led to the appointment of the Lassiter Board in 1923. This board, composed of military officers, reviewed the current state of the Air Service and recommended a peacetime size of 2,500 aircraft. However, tight budgets leading to cutbacks in military spending, similar to those that occurred across all of the major WWI combatants, meant that this size was not achieved.

Further concerns about readiness led to the appointment of a congressional committee chaired by Representative Florian Lampert of Wisconsin (Holley, 1964, p. 46) in 1925. The Lampert commission followed the Lassiter board in terms of the size of the air arm, recommending a stable five-year appropriation program to achieve that. However, the board had no actual power and their recommendations were not implemented.

At around the same time, the court-martial of Brig. General Billy Mitchell drew public attention to the issue of air power. Mitchell had risen to fame flying in Europe during WWI, where he became Chief of the Air Service. Upon his return following the War, he became the preeminent advocate of air power in the U.S. In the early 1920s, he put on a series of demonstrations during which ex-German warships were bombed by various Army and Navy planes. The results were widely publicized and vividly illustrated the potential of air power, to the chagrin of the Navy. In 1925, Mitchell criticized his superior officers' management of the air arm following the crash of the airship Shenandoah. He was court-martialed by a panel of military judges and suspended from active duty. The whole affair drew substantial public attention to the issue.

As a result of growing concern and public attention, a third board, the Morrow Board, was appointed by the President at the request of the Secretaries of War and of the Navy in 1925. The Morrow Board report agreed with many of the conclusions of the previous committees, but differed in that they believed that the actual number of aircraft should be left up to the War Department.

Following these three separate reports, the House Military Affairs Committee put together what would become the Air Corps Bill of 1926. This bill provided for a five-year procurement 
plan aimed at raising over time the number of available aircraft to 1,800 with a limitation on orders of 400 per year. However, as noted by Holley (1964), p. 49-50, allowing only 400 new aircraft to be purchased a year made it impossible to achieve a service strength of 1,000 in five years given the rate at which aircraft needed to be replaced. The solution that the Air Corps found was to extend the service life of aircraft from five to seven years, in order to reduce the replacement rate, though this led to more accidents and meant that aircraft that were not technically obsolete were in fact far below the world technological frontier. However, the Air Corps ultimately faced further problems in growing the number of available aircraft, because Congress failed to appropriate any funds for the Air Corps in 1926 and cut funding arbitrarily in future years (Holley, 1964, p. 65). Koistinen (1998) writes (p. 183) that "Both the Calvin Coolidge and Herbert Hoover administrations used their discretionary powers to delay and then to retard the implementation of the five-year program." Thus, the five-year plan still left procurement officers, and aircraft manufacturers, with substantial year-to-year uncertainty, similar to the uncertainty that existed in the years before 1926 .

The most important part of the 1926 Acts for our purposes are those provisions related to procurement policy. As discussed in the main text, these were subtly altered in a way that allowed procurement officers to largely avoid competitive bidding. What forces were behind these changes? Koistinen (1998) describes how,

Air Corps officers, most experts on air power, and nearly all aircraft manufacturers and their trade associations insisted that the high technology of airplanes made competitive bidding virtually impossible... If, when the production stage was reached, the contract did not in whole or in part go to the designing and developing firm, the company could not recoup costs and was discouraged from future effort. Moreover, low bidders might be inexperienced, incompetent or corrupt. Even if thoroughly qualified and adequately financed, a contractor other than the developer would have to adapt the new design to the firm's manufacturing methods, which took time and modified the end product.

This quite nicely sums up the agreement between military officials and industry representatives on the destructive nature of the competitive bidding system of aircraft procurement. It was this combined influence that convinced Congress to build in a loophole that allowed procurement officers to get around the requirement that competitive bidding be used.

\section{B.2 Further discussion of patenting and the patent pool}

The aircraft patent pool was formed in 1917 to overcome a dispute between the Wright (later Wright-Martin) and Curtiss companies over key patents used for aircraft control (ailerons) to allow for increased wartime production. Wright held the most important patent and resisted the formation of the pool, but was ultimately forced to join by the government (Bittlingmayer, 1988; 
Katznelson and Howells, 2014). In order to compel Wright-Martin to join the pool the government used its position as the main buyer of aircraft. In addition, Congress passed legislation that would have condemned the patents, which gave government negotiators even more leverage.

Pool members paid royalties to Wright and Curtiss (Bittlingmayer, 1988). These two companies were to receive up to $\$ 2$ million in royalties, later revised to $\$ 1$ million. Members had unlimited access to all patents in the pool (Patillo, 1998, pp. 35-36). When firms created new patents that were covered by the pool, they could receive some payments through an arbitration process. However, of the 750 patents covered by the pool, only 159 had been brought into arbitration by 1935. Of those, only 51 received cash awards, and the total awards for patents added after the formation of the pool was very small. Of the $\$ 4,360,000$ paid by the pool by 1933 , only $\$ 360,000$ were paid for patents other than the original Wright and Curtiss patents.

The result of the patent pool was to essentially eliminate patent protection as an option for airframe producers. In fact, when the pool was eventually challenged in 1972, the government argued that the pool was anti-competitive mainly because it hampered competition in research and development (Bittlingmayer, 1988). This feature was also echoed at the time by key participants. For example, an internal document produced by the Curtiss company in May of 1923 argues in favor of maintaining the pool after the expiration of the initial patents. The document offers a number of arguments in favor of maintaining the pool, including that "The continuance of the Cross-License Agreement places all subscriber manufacturers on an equal footing competitively; promotes friendly intercourse; draws the manufacturing interests together; encourages cooperative spirit; and is in all respects a course strictly in accord with modern business practice."

One way to provide direct evidence supporting these points is to look at patent data during the study period. This is done in Figure B1, which plots the number of patents in the airframe and aero-engine technology categories from 1911-1935. These patents are broken down by whether they were assigned to a major military airframe or aero-engine producing firm (the firms in our data), some other "non-military" firm, or whether they remained unassigned. The striking feature in this graph is that a very small share of patents were associated with those firms that were actually producing high-performance airframes and aero-engines. This feature would be surprising were it not for existing historical evidence, such as that reviewed above, indicating that patent protection played relatively little role in aircraft innovation during this period because of the existence of the patent pool. 


\section{Figure B1: Patents Related to Airframes and Aero-Engines}
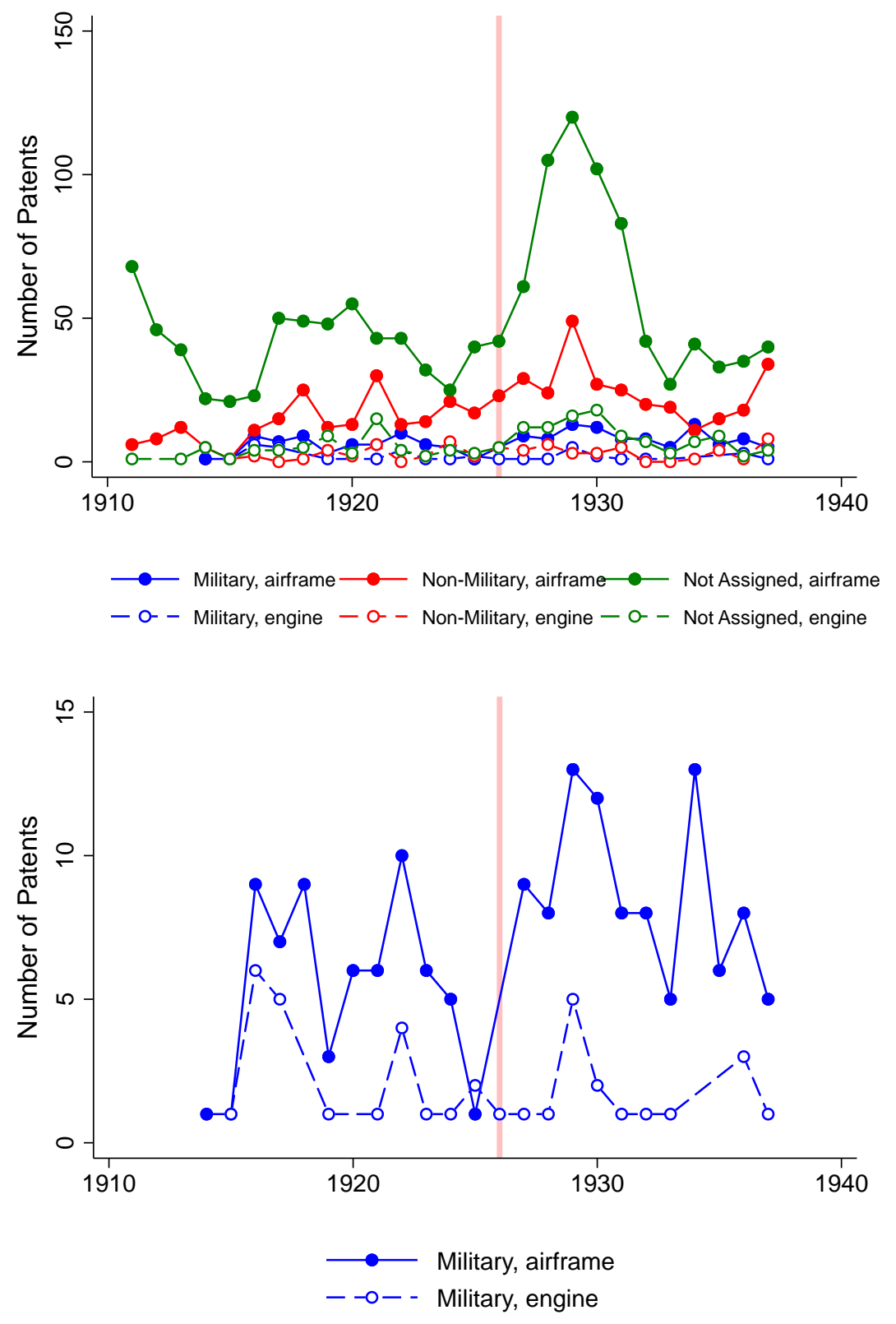

Notes: This figure plots the time series of patent counts in the United States related to airframes and aero-engines. Within the US Patent and Trademark Office classification 244 ("Aeronautics and Astronautics"), airframe-related patents are identified by the subclasses for "Aircraft Structure" and "Aircraft Sustentation" (solid lines) and enginerelated patents are identified by the subclasses for "Aircraft Steering Propulsion" and "Aircraft Power Plants" (dashed lines). Assignees that appear in our data as producers of airframes and engines purchased by the US military are identified as "military" producers in the figure (in blue) and the remaining assigned patents are identified as "nonmilitary" (in red). The final group are patents with no assignee (in green). The top panel shows all groups together and the bottom panel shows only "military" patents. The data are drawn from Berkes (2018). 


\section{Figure B2: Unit Costs for Military and Civil Aircraft}

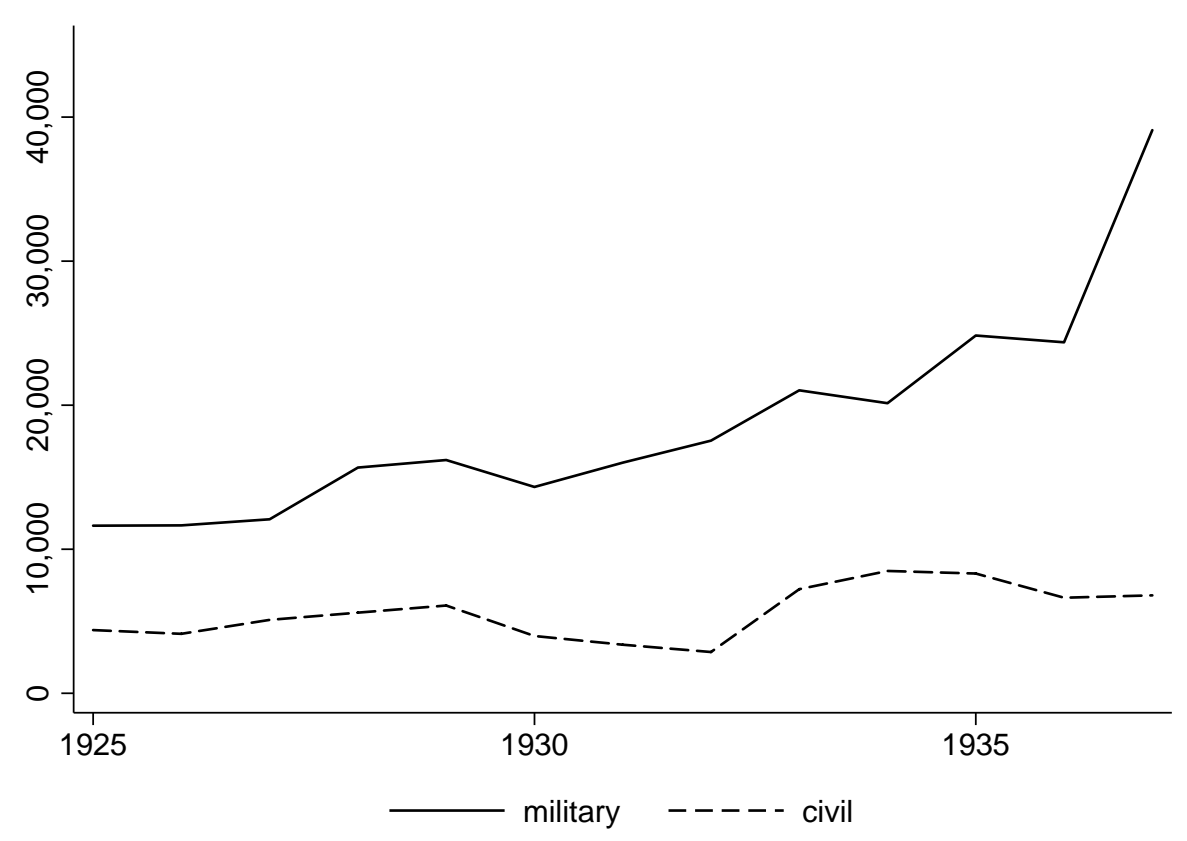

Notes: Data from the Aircraft Yearbooks published by the Aeronautical Chamber of Commerce and generously shared by Paul Rhode. 


\section{B.3 Unit values of military vs. civil aircraft}

Figure B2 shows average unit costs for military and civilian aircraft across the study period. Clearly military aircraft were more expensive than civil aircraft.

\section{B.4 Military aircraft procurement in the United States}

This section presents some additional details on U.S. military aircraft procurement practices based primarily on the records of the U.S. Army Air Corps Procurement Board collected from the U.S. Government Archives. Most of these records start in 1926, with just a few available in 1925. The procurement board met regularly during the year, and thus the records of these meetings allow us to gain some understanding of how the procurement process unfolded.

Procurement planning for a year began early the year before with a discussion of the expected needs of the military for the following year. Starting with the budget allocated by Congress, and subtracting out the costs of any ongoing contracts from the prior year, the Board would then make a preliminary allocation of expenditures based on estimated prices.

The Board would then continue to meet on roughly a monthly basis to update and adjust the allocation. The following quote from the minutes of the Board's meeting on February 4, 1926 gives a sense of how this process worked:

In connection with the price submitted by the Douglas Company in the amount of $\$ 17,800.00$ per unit for $C-1$ Transports, which would exceed the total amount allocated for 10 of this Type in the sum of \$150,000, the advisability of the procurement or [sic] 10 transports was considered...In view of the foregoing, motion was unanimously adopted by the Board... that procurement be effected of (7) Transports...

A second example from the minutes of the Procurement Board's meeting on January 20, 1927 illustrates similar trade-offs:

Recommendations were submitted by the Chief, Material Division...for the procurement of (6) Pratt \& Whitney Wasp Engines. The Board recommended approval of six (6) of these engines at a total estimated cost of $\$ 60,000.00$. This item, however, will not be carried on the Procurement Program until another item or items are cancelled in order to provide sufficient funds for the item...

A third example of this tension appears in the minutes of the February 12, 1930 Procurement Board meeting:

The question of the procurement of 14 Amphibian airplanes, in the amount of $\$ 681,380$, set up and approved under 1930 funds, was presented. After discussion the Board, without objections, recommends that approximately 17 of the Loening Amphibians with "Wasp" engines be procured immediately from the funds set up. However, the exact number that can be procured from these funds will be determined after negotiations have been concluded. 
These and numerous other similar discussions illustrate the extent to which the military procurement boards faced fixed budgets that induced trade-offs between various budget items. Increases in the cost of one item came either at the cost of a reduction in the quantity of that item, or a reduction somewhere else in the budget. The demand system used in our theory is meant to reflect, in a stylized way, these features.

The Procurement Board meeting minutes also reveal the extent to which the military had to negotiate prices with individual airframe manufacturers after the 1926 law changes (unfortunately very few records survive for the period before 1926). This feature shows up in the discussion of the Loening Amphibians discussed above. Another example, from the minutes of the Board's April 11, 1927 meeting describe how,

The question of procurement of 87 primary training planes, PT-1's for the Air Corps requirement was discussed, and the Board recommended contracts be placed with the Consolidated Aircraft Corporation, but not until such time that a satisfactory price could be obtained that would materially reduce unit cost.

Some military oversite was exercised to limit the potential profits that manufacturers could extract from an accepted design. A discussion of the purchase of Amphibious aircraft from Loening in the Board minutes of December 8, 1926, for example, describe how,

Prices for the Loening Amphibians are understood to be subject to negotiation, as to date the Loening Aeronautical Engineering Corporation have not submitted figures justifying the price quoted of $\$ 23,500$ per plane.

Together these and other similar quotes suggest that, in the period after 1926, the military was clearly forced to negotiate with manufacturers over the prices of the aircraft produced under their designs. This monopolist-monopsonist bargaining is incorporated into our theory.

\section{B.5 The aircraft industry in comparison countries}

This appendix discusses the state of the airframe and aero-engine industries in the various comparison countries considered in our analysis. We begin with a brief overview of the comparison countries, before turning to a more detailed discussion of the United Kingdom, our main point of comparison.

The United Kingdom was the most similar comparison country to the United States. The UK industry was composed of a large number of airframe producers and a smaller number of engine makers. Military orders made up the majority of the market, as they did in all countries during this period. While the government played an active role in the industry, there were no major policy changes around the time of the US policy change that we study that would affect our ability to use the British industry as a counterfactual. 
For airframes, Japan also provides a useful comparison country. The airframe sector in Japan was somewhat more concentrated than in the United States or United Kingdom, and the industry was younger. As in other countries, the government was the primary source of demand, but, importantly, we have not identified any major policy changes that would cause problems for our study. The engine sector in Japan was not sufficiently developed to provide a valid comparison for that analysis.

We also use data from Germany and Italy in our analysis of engine technology. However, for airframes, restrictions imposed on Germany by the Treaty of Versailles limited production, so Germany is not included in the airframe analysis. We also considered including Italy and the Soviet Union in our analysis of airframe technologies, but in both cases there were too few designs in the early 1920s for these to serve as useful comparison countries.

We also collected data for France, an important aircraft producer during this period. However, in 1928 the French government made a substantial policy change aimed at spurring the introduction of new aircraft prototypes. Since this "prototype policy" corresponds fairly closely to the timing of the policy change in the United States that we study, France will not provide a clean comparison for our main analysis.

\section{B.5.1 The aircraft industry in the United Kingdom}

This appendix section describes the developments in the UK aircraft industry during the interwar period. The discussion below draws on Fearon (1969, 1974), Broadberry (1997), Edgerton (2013), and Kelly (2013).

The UK aircraft industry had a slow start. Private aviation was limited and the main source of demand prior to World War I. With the outbreak of war, production efforts shifted to military uses and, ultimately, the founding of the Air Ministry and Royal Air Force in 1917. By the end of the war, the UK was among the world leaders, if not in the lead, in terms of airpower (Fearon, 1974). After the war, the industry experienced a prolonged period of low demand, as it did elsewhere.

Disagreement exists over the dynamisms of the British aircraft industry in the inter-war period. Fearon (1974) suggests that the British industry was somewhat backward technologically during the inter-war period and only began delivering world-class aircraft under the pressures of rearmament. Edgerton (2013) disagrees and provides evidence that in fact the British industry was strongly supported by military demand and continued to produce innovative aircraft throughout the interwar period. Broadberry (1997) provides a useful review of this debate. The performance measures recorded in our data appear to be more in line with Edgerton's more positive view of the British industry during the inter-war period than the more pessimistic view of Fearon. 
There is little debate over the central role that military demand played in the British industry. In the early 1920s, to maintain the industry, which was deemed vital to the national defense, the Air Ministry established a "ring system" of airframe (and aircraft engine) producers to fill a stream of procurement orders throughout the interwar period. The effect was to concentrate orders among a few firms and would remain financially viable.

In terms of industry structure, the UK industry shared many similarities to the US industry. The industry was relatively unconcentrated, particularly airframe manufacturers. In 1920 the census records 13 active firms in the industry. This had risen to 38 by the 1930 census, but most of the production was concentrated in 16 large firms. These larger firms produced essentially all of the military orders.

Like the United States, British government institutions were active in aeronautical research. The two main centers were the National Physical Laboratory (NPL) at Teddington and the Royal Aeronautical Establishment (RAE) at Farnborough. The NPL operated a wind tunnel and was active in aerodynamic testing, while the RAE was more focused on testing components such as engines and propellers.

\section{B.6 NACA}

This section presents additional background information on the National Advisory Committee on Aeronautics (NACA), which relies on Bilstein (1989). NACA was founded in 1915, during WWI, by an act of Congress. NACA was modeled after aeronautical research centers in Europe, particularly those in France and Britain. Its focus was on basic research, while the more applied problems of testing and improving aircraft were left to the Army and Navy.

In the early 1920s NACA employed a number of research engineers working at the Langley airfield in Virginia. Bilstein (1989) reports that 100 workers were employed in 1925. At Langley, NACA constructed a small variable density wind tunnel that began operations in 1922. By 1925, the Langley operation also included an experimental engine laboratory a well as 19 aircraft dedicated to test flights. A propeller research tunnel went into service in 1927, followed by a full-scale wind tunnel in 1931.

Figure B3 describes the NACA budget across the study period using data collected from the NACA Annual Reports from 1922 to 1936. The budget grew fairly slowly across the early 1920s and then increased substantially starting in 1930. The high level of expenditure in 1930-31 reflects the cost of constructing the new wind tunnel that opened in 1931. Given these patterns, increased spending on research by NACA seems unlikely to explain the change in the rate of airframe performance increase that we observe starting in 1926. This is not to say that NACA did not generate important inventions. It did, including the NACA cowling for reducing the drag on 
Figure B3: NACA budget during the study period

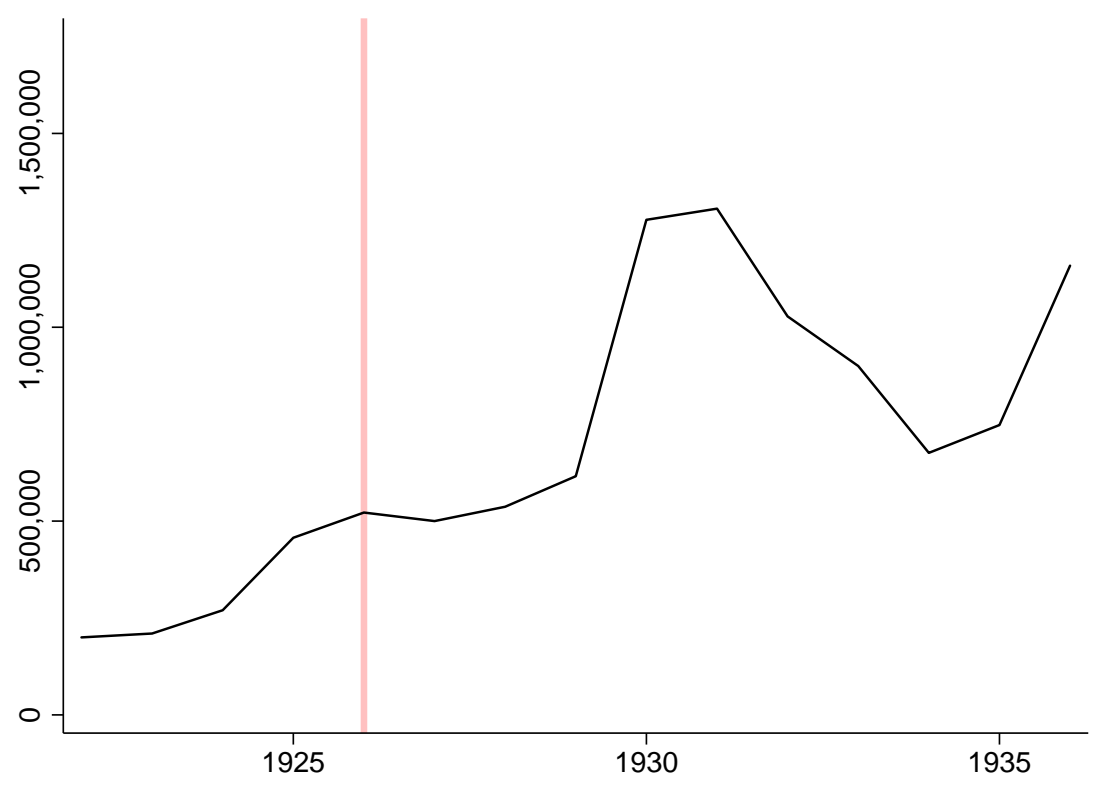


air-cooled engines, introduced in 1928, and a system of airfoil classifications. However, these innovations were publicly available for use by both U.S. and foreign airframe producers. For example, the new cowling developed by NACA in the late 1920s was both described in a published technical note as well as in an article in Aviation magazine (Rowland, 1985). Moreover, similar research was being undertaken by NACA's foreign counterparts.

\section{B.7 Market shares of engine producers}

This appendix provides evidence on the level of concentration in the market for aero-engines in the U.S. Of particular interest is how this was affected by the entry of Pratt \& Whitney in 1925 as well as the impact of the wave of mergers that took place after 1929. A first view of the data is provided in Figure B1, which shows the market share of different military engines producers between 1919 and 1939. Panels A and B show the share of total output in terms of the number of engines and the share of total horsepower, respectively. One notable feature of these graphs is that when Pratt \& Whitney entered in 1925, the main impact was to replace Lawrence, which had just been purchased by Wright. As a result, the entry of Pratt \& Whitney had a relatively modest effect on overall concentration in the market.

Further evidence on this point is provided in Figure B2 which plots Herfindahl-Hirschman Index (HHI) values calculated across all producers based on either the number of engines produced (top panel) or the number of horsepower produced (bottom panel). Note that concentration levels here are volatile because quantities are assigned to the year in which an order was placed, rather than the year of delivery. To provide a more realistic view of concentration, we have also included three-year moving averages in the graph.

In both the top and bottom panels of Figure B2, we do not see a substantial change in HHI values from 1925 to 1929 despite the entry of Pratt \& Whitney. Thus, it does not appear that the entry of Pratt \& Whitney substantially altered the market structure. Rather, that entry mainly offset the exit of Lawrence through the merger with Wright. However, after the merger wave of 1929 we see a substantially elevated level of market concentration. This is what we would expect from the theory given that mergers between aero-engine and airframe makers provided the merged companies with advantages not available to their non-merged competitors. 
Figure B1: Military Engine Producer Market Share
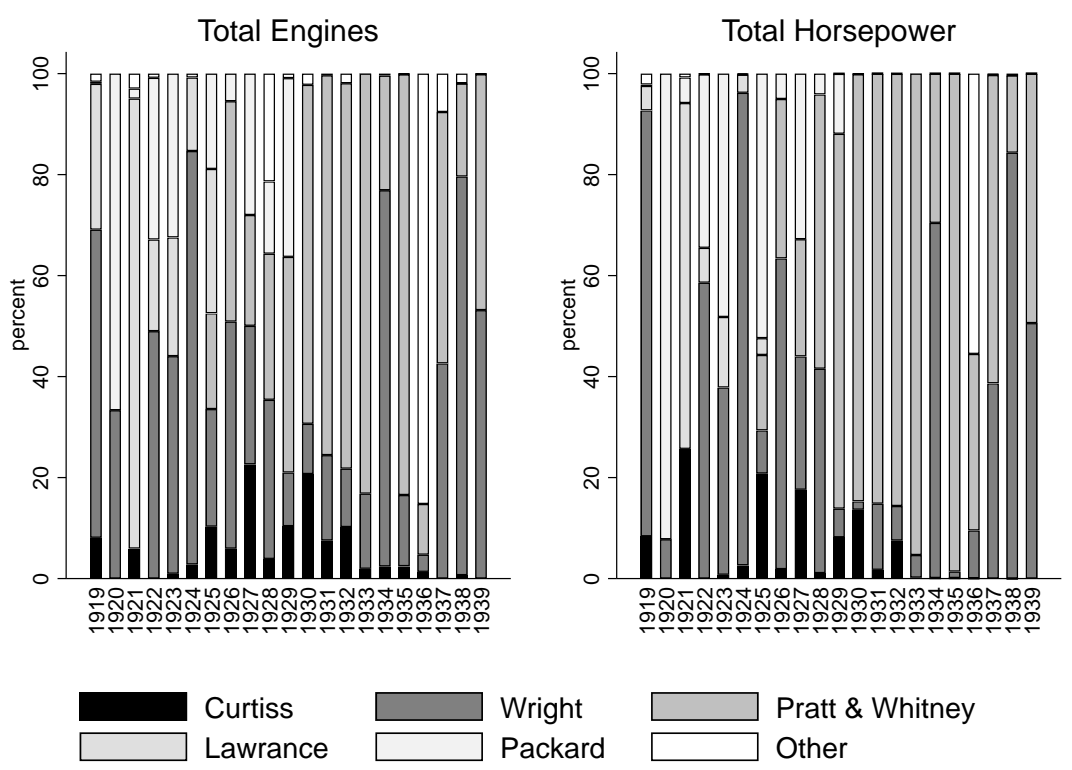
Figure B2: HHI Values in the Market for Military Aero-engines

HHI based on number of engines produced

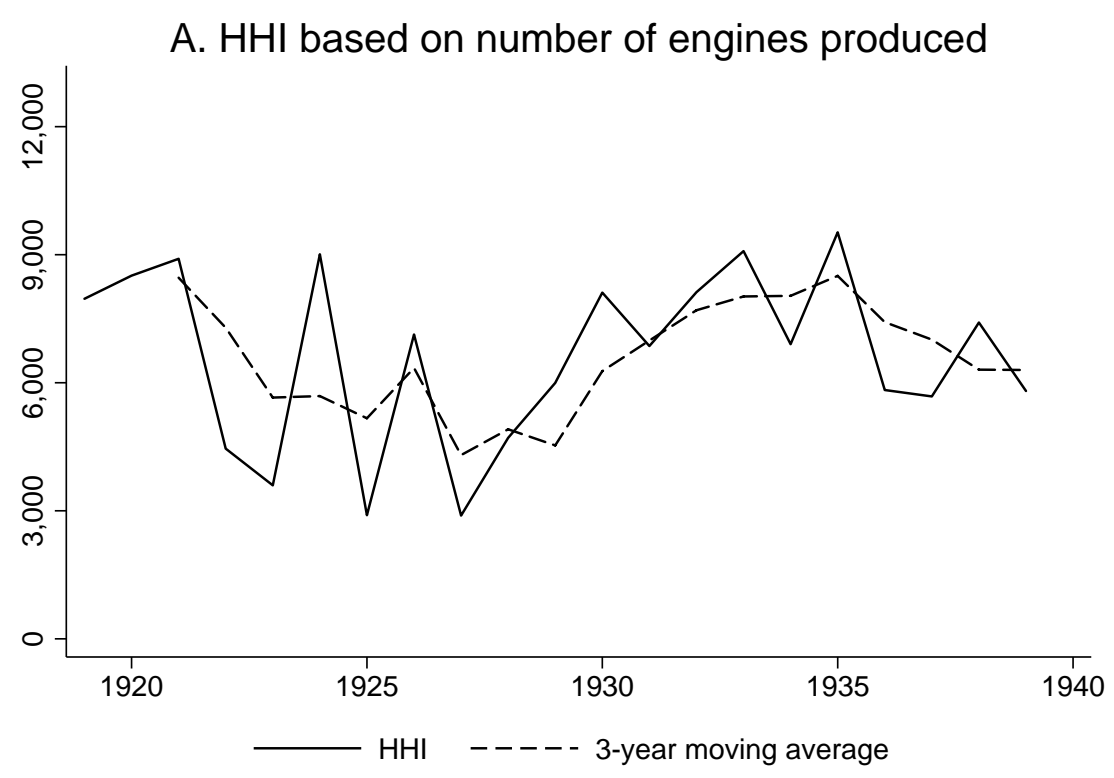

HHI based on number of horsepower produced

B. $\mathrm{HHI}$ based on number of horsepower produced

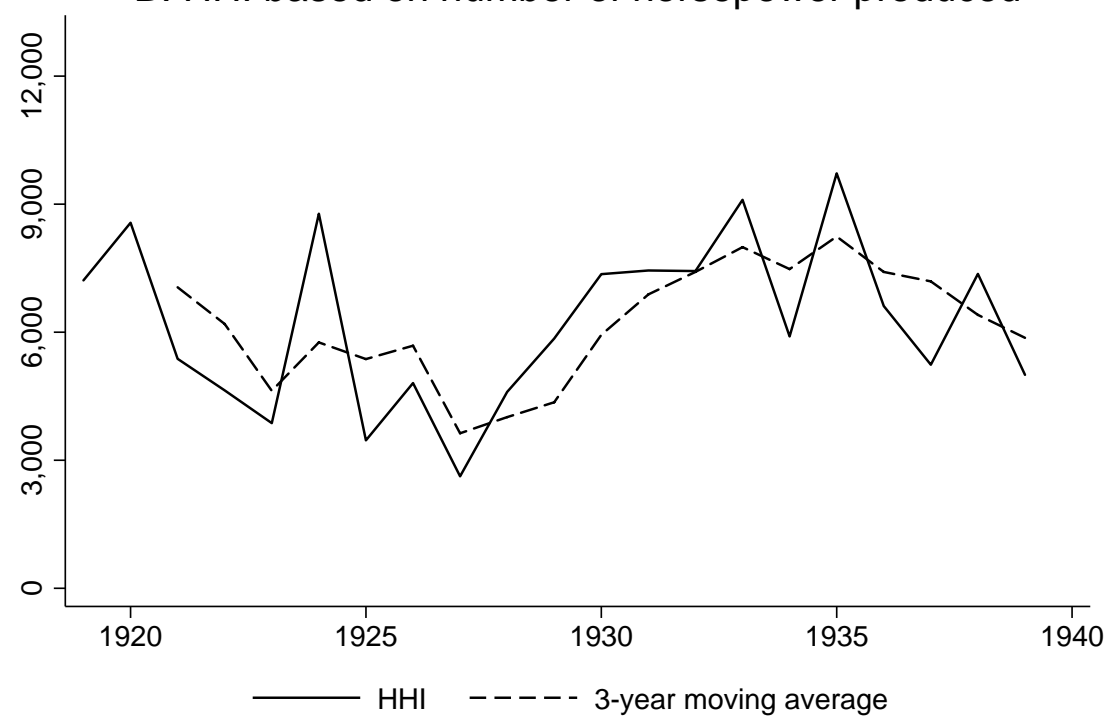




\section{Data Appendix}

This appendix provides additional details about the data used in the analysis. It is worth noting that there is no single consistent source for all of the data we used. Instead, it was necessary to pull together information from a variety of different sources. In doing so, we have tried to generate series that are as consistent as possible. Different sources may report performance characteristics from different tests, so when multiple sources of data are available we test the robustness of our results to alternative underlying data.

\section{U.S. military aircraft data}

Our U.S. military airframe data come from two sources:

Swanborough, Gordon and Bowers, Peter M. (1963). United States Military Aircraft Since 1908. London: Putnam \& Company Ltd.

Swanborough, Gordon and Bowers, Peter M. (1968). United States Navy Aircraft Since 1911. New York: Funk \& Wagnalls.

Together, these provide a full listing of military aircraft, including individual variants of all important types and even many experimental or one-off designs. For most designs, and all of those produced in quantity, the data provide details such as first year of production, quantity produced, type of aircraft (fighter, bomber, trainer, etc.), wing area, empty weight, gross weight, maximum speed, cruising speed, service ceiling, and in some cases range, endurance and bomb load. It is worth noting that details are not available for every variant listed, but for most aircraft, and for essentially all aircraft produced in quantity, most of these details are available. We also supplement these main data sources with some additional information provided by:

Fahey, James C. (1946). U.S. Army Aircraft 1908-1946. First edition. New York: Ships and Aircraft.

\section{U.K. military aircraft data}

For U.K. aircraft, our data source is a similar pair of volumes from Putnam publishing covering military aircraft:

Thetford, Owen. (1988). Aircraft of the Royal Air Force Since 1918. Eighth edition. London: Guild Publishing.

Thetford, Owen. (1991). British Naval Aircraft Since 1912. Sixth revised edition. Annapolis: Naval Institute Press.

The data provided in these volumes is similar to those provided in the U.S. volumes.

\section{Japanese military aircraft data}

The Japanese military aircraft data come from another Putnam volume with a format that is 
similar to the volumes available for the U.S. and U.K.:

Mikesh, RC and Abe, S. (1990). Japanese Aircraft 1910-1941. London: Putnam Aeronautical Books.

This volume provides data for each aircraft similar to those available for the U.S. and U.K.

\section{Additional airframe data notes}

Our airframe data covers each military airframe design as well as individual variants of those designs. While we use data describing the performance of each variant of a design, not all performance details are available for all variants of a design, so our analysis relies on those variants for which performance details are available. Given that variants of a design typically have very similar performance characteristics, the fact that not all details are available for all variants is unlikely to create issues for our analysis.

The key performance details in the airframe analysis are wing area and gross weight. These details are reported for most design variants and there appears to be relatively little variation in how they were reported. In robustness tests, we also use additional details such as maximum speed and service ceiling. There is more variation in the measurement of maximum speed, since that can be different at different altitudes for an particular design variant. In our analysis, if different maximum speeds are reported at different altitudes, we use the highest value.

There is some question in our data about the timing of the introduction of new aircraft models. This is because there is a lag between the timing of, say, the first flight of a new model and when the first version is delivered. In our airframe data, new models are typically assigned the year in which the first version was delivered.

\section{U.S. aero-engine data}

There are two main sources available for U.S. aero-engine data. The first source is the Jane's, which have a separate section describing the aero-engines produced by each country:

Jane, Frederick. All the World Aircraft. 1919-1920, 1922-1929. London: Sampson Low, Marson \& Co. (not published in 1921)

Jane's All the World Aircraft. 1930-1938. London: Sampson Low, Marston \& Co.

For each engine type, Jane's typically provides information on the displacement (or bore and stroke), number of cylinders, coolant type (air or liquid), weight, "normal" horsepower (typically the rated horsepower), revolutions per minute corresponding to the horsepower measure, the physical height and width of the engine, or the radius for radial engines, and in some cases additional details such as fuel usage per hour. For engines, such as the Pratt \& Whitney Wasp, which were produced in a number of versions as the engine was modified or improved over time, 
the Jane's data typically provides details for each variation. It is worth noting that the Jane's data do not provide information on the number of engines produced or the year that they first come into service. To infer the year of entry into service, we use the first year that the engine appears in Jane's.

The Jane's data do not identify whether engines were used primarily for military or for civil purposes, nor do they tell us the type of military aircraft an engine might have been used for. However, in order to focus on engines used by the military, it is useful to have this information. In order to identify the types of military aircraft that US aero-engines were used with, we manually match the engines listed in the Jane's engine data to the engines listed in the US airframe data provided above. This matching allows us to combine information on the type of aircraft an engine was used with, from the airframe data, with the detailed information on engine performance provided by the Jane's data. The result allows us to select for analysis only those engines used by the military, or only those engines used in particular types of military aircraft such as fighters and bombers. Doing so allows us to provide an analysis of aero-engines that is consistent with our analysis of airframes.

We also have an alternative source for U.S. aero-engines used by the Army Air Corps:

Fahey, James C. (1946). U.S. Army Aircraft 1908-1946. First edition. New York: Ships and Aircraft.

The "Fahey data" provide details similar to those available from Jane's, but only for Army Air Corps aircraft. According to the author, these data were compiled from government sources and an effort was made to generate data that were consistent over time. However, an important drawback in the Fahey data is that they provide details only for broad engine types, such as the Wasp, but not separate information for each of the many versions of the Wasp produced. Thus, these data are less detailed than the Jane's data, which is why we prefer to rely on the Jane's data in our main analysis. However, we still check the robustness of our results to using this alternative data source.

\section{U.K. aero-engine data}

Aero-engine data for the United Kingdom is provided from a single and extremely detailed source:

Lumsden, Alec (1994). British Piston Aero-Engine and their Aircraft. Shrewsbury, U.K.: Airlife Publishing Ltd.

These "Lumsden data" provide performance details for all UK aero-engines, including both military and civilian varieties. The data are extremely detailed and provide information for a large number of variants of each engine type, all of which typically have very similar performance 
characteristics. These data also provide the year in which each engine variant was introduced.

In addition, the Lumsden data provide, for each engine variant, a listing of the airframes that the engine was used with. Using these listings, it is possible to merge the engine performance details from Lumsden with information on the type of airframe each engine was used with from the United Kingdom airframe data described above. Doing so allows us to generate a sample including those engines purchased by the military, as well as a sample including only those engines used with fighter or bomber aircraft. This allows us to generate a sample that is consistent with our airframe analysis and comparable to the sample of engines used with fighter or bomber aircraft constructed for the United States.

\section{German and Italian aero-engine data}

The data on German and Italian aero-engines used in our analysis are also drawn from the Jane's directories, and so the details available for engines from those countries are similar those available for US engines. However, we do not have airframe data to match these aero-engine data to, so it is not possible to isolate those engines used by the military, or those used in fighter or bomber aircraft. This is particularly true in Germany, where there were limitations on the production of military aircraft imposed by the Treaty of Versailles.

\section{Supplementary aero-engine data}

In addition to the sources described above, the following sources have been used to fill in some details missing from the other sources:

Gunston, Bill (1995). World Encyclopedia of Aero Engines. Third edition. Sparkford, U.K.: Patrick Stephens Limited.

\section{Additional aero-engine data notes}

Just as with the airframe data, our aero-engine data covers each aero-engine design as well as individual variants of those designs. While we use data describing the performance of each variant of a design, not all performance details are available for all variants of a design, so our analysis relies on those variants for which performance details are available. Given that variants of a design typically have very similar performance characteristics, the fact that not all details are available for all variants is unlikely to create issues for our analysis.

The key performance details in the aero-engine analysis are displacement (calculated from the swept volume of the engine cylinders), horsepower, weight, revolutions per minute, and the frontal area of the engine, which is calculated based either on the diameter of the engine (for radial engines) or the height and width (for all other types). Displacement data is consistently provided for almost every engine. Measuring horsepower is more difficult and may depend on the exact parameters under which the engine is tested. Many of our sources provide multiple 
horsepower measurements. In our analysis, we rely on horsepower at sea level, which is typically reported as normal or takeoff horsepower. In some sources only rated horsepower is available. However, within each source, the way that horsepower is reported tends to be consistent, which is an important feature for our analysis. Horsepower can also be affected by the revolutions per minute at which the engine was evaluated. As a result, horsepower is typically accompanied by information revolutions per minute.

For consistency, we collect the revolutions per minute information that corresponds to the horsepower measure used in our analysis. Engine weight can also vary depending on how weight was measured. In our analysis we rely on dry weight, the most common value reported in our sources. However, even dry weight may vary depending on what engine components or accessories are included. Thus, engine weight is likely to be noisier than engine displacement, but it also provides a more direct reflection of one of the engine features that was of paramount importance to engineers. The frontal area reflects another key feature that engineers sought to minimize. This feature was particularly important for high-speed single-engine fighter aircraft, where the size of an engine's frontal area was the key determinant of the overall frontal area, of the aircraft fuselage, a key component in determining the aircraft's drag. 


\section{Innovation timing and funding type for key designs}

This appendix provides some supporting information for statements made in the main text about how the development of new designs were funded and how long it took for new designs to be developed. We focus on the most important US fighter and bomber designs produced during the study period using data from Gordon Swanborough and Peter M. Bowers (1963) United States Military Aircraft Since 1908., London: Putnam \& Company Ltd. and Gordon Swanborough and Peter M. Bowers (1968) United States Navy Aircraft Since 1911., New York: Funk \& Wagnalls. These sources often describe the way that new designs were funded (e.g., private venture, joint project, government contract). In addition, they also provide information on when the project was started, when the design first flew, and when the first production contract was issued. These dates are useful for thinking about the kind of delays we might expect in the innovation process.

Table D1 reports the data. Note that this list is smaller than the list of new designs used in our main analysis. To keep things manageable, we have included only major original designs in this table. The table does not include less important designs nor does it include the many evolutionary improvements that were made in newer versions of existing designs. The information on funding shows that a large number of the key designs produced during the interwar period were private ventures, particularly designs intended for the Army Air Corp. The Navy was much more likely to issue contracts for the development of prototypes. There is no evidence that the form of funding changed substantially across the study period. The information on timing suggests that most new designs were produced within one to two years, and that production contracts usually came within 2 to 3 years of project initiation. This suggests that the timing of the response indicated in our main analysis is reasonable. 


\section{Table D1: Information on key U.S. fighter and bomber designs}

\begin{tabular}{|c|c|c|c|c|c|c|}
\hline & Aircraft & Type & Development type & Began & First flown & $\begin{array}{c}\text { Production version } \\
\text { ordered }\end{array}$ \\
\hline \multicolumn{7}{|l|}{ Boeing } \\
\hline & PW-9/FB & Fighter & Private venture & ? & April, 1923 & September, 1924 \\
\hline & $\mathrm{F} 2 \mathrm{~B}$ & Fighter & Private venture & $?$ & Nov., 1926 & March, 1927 \\
\hline & $\mathrm{P}-12 / \mathrm{F} 4 \mathrm{~B}$ & Fighter & Private venture & 1928 & June, 1928 & June, 1929 \\
\hline & P-26 & Fighter & Joint with Army & 1931 & March, 1932 & January, 1933 \\
\hline & B-9 & Bomber & Private venture & 1930 & April, 1931 & Not ordered \\
\hline & B-17 & Bomber & Army competition & 1934 & July, 1935 & June, 1939 \\
\hline \multicolumn{7}{|c|}{ Brewster } \\
\hline & $\mathrm{F} 2 \mathrm{~A}$ & Fighter & Navy contract & 1936 & Dec., 1937 & June, 1938 \\
\hline \multicolumn{7}{|l|}{ Curtiss } \\
\hline & $18-\mathrm{T}$ & Fighter & Navy contract & 1918 & July, 1918 & Not ordered \\
\hline & CS & Bomber* & ? & & 1923 & $?$ \\
\hline & PW-8 & Fighter & Private venture & 1922 & May, 1923 & September, 1923 \\
\hline & P-1/F6C & Fighter & & & & March, 1925 \\
\hline & $\mathrm{F} 8 \mathrm{C}$ & Fighter & Army competition & 1924 & & June, 1927 \\
\hline & F11C & Fighter & Navy contract & 1932 & June, 1932 & October, 1932 \\
\hline & P-36 & Fighter & Privately financed & 1934 & Nov., 1934 & July, 1937 \\
\hline \multicolumn{7}{|c|}{ Douglas } \\
\hline & DT & Bomber & ? & 1921 & & 1921 \\
\hline & B-18 & Bomber & Privately financed & 1934 & $?$ & January, 1936 \\
\hline & TBD & Bomber & Navy contract & 1934 & April, 1935 & February, 1936 \\
\hline \multicolumn{7}{|c|}{ Great Lakes } \\
\hline & BG-1 & Bomber & Navy contract & 1932 & 1933 & November, 1933 \\
\hline \multicolumn{7}{|c|}{ Grumman } \\
\hline & $\mathrm{FF} / \mathrm{SF}$ & Fighter & Navy contract & ? & 1931 & $?$ \\
\hline & $\mathrm{F} 2 \mathrm{~F}$ & Fighter & Navy contract & 1932 & October, 1933 & $?$ \\
\hline & $\mathrm{F} 4 \mathrm{~F}$ & Fighter & Navy competition & 1935 & September, 1937 & June, 1938 \\
\hline \multicolumn{7}{|c|}{ Huff-Daland/Keystone } \\
\hline & LBS & Bomber & ? & 1923 & 1923 & 1927 \\
\hline \multicolumn{7}{|l|}{ Martin } \\
\hline & MB-2 & Bomber & ? & ? & $?$ & 1920 \\
\hline & BM & Bomber & Navy contract & 1928 & 1930 & April, 1931 \\
\hline & B-10 & Bomber & Private venture & & March, 1932 & January, 1933 \\
\hline \multicolumn{7}{|c|}{ Nothrop } \\
\hline & BT/A-17 & Bomber & From civil design & ? & 1935 & $?$ \\
\hline \multicolumn{7}{|c|}{ Seversky } \\
\hline & P-35 & Fighter & Private venture & ? & 1935 & 1936 \\
\hline \multicolumn{7}{|c|}{ Thomas-Morse } \\
\hline & MB-3 & Bomber & Army contract & 1918 & February, 1919 & 1919 \\
\hline \multicolumn{7}{|c|}{ Vought } \\
\hline & VE-7 & Fighter & ? & ? & 1918 & ? \\
\hline & SBU & Bomber & Navy contract & 1932 & May, 1933 & January, 1935 \\
\hline & SB2U & Bomber & Navy contract & 1934 & January, 1936 & October, 1936 \\
\hline & $\mathrm{F} 4 \mathrm{U}$ & Fighter & Navy contract & 1938 & May, 1940 & June, 1941 \\
\hline
\end{tabular}

* Torpedo bomber 


\section{E. Results Appendix}

\section{E.1 Relationship between airframe performance measures}

While our main analysis of airframe innovation focuses on two performance measures, wing load and maximum speed, other performance measures may have mattered. In this section we provide evidence showing that alternative performance indicators, such as altitude ceiling, range, and cruising speed, are highly correlated with the two performance measures used in our main analysis. Specifically, the Figure E1 illustrates the relationship between wing load and alternative measures of airframe performance. In general, the correlation between wing load and the alternative measures are quite strong with the exception of power load in the final panel.

\section{E.2 Relationship between aero-engine performance sources}

Our main analysis of aero-engine innovation uses data drawn from Jane's for the performance characteristics of engines matched to military airframes. In this section we provide a comparison between the reporting for aero-engine performance characteristics in Jane's and reporting based on airworthiness certification. The latter data is only available after 1928. Figure E2 shows there is close correspondence between two of our measures of engine performance constructed from Jane's and airworthiness certification.

\section{E.3 Additional results for airframes}

In this section we present robustness results for airframes, in Table E1. These results show that our main airframe results are robust to including Japan as an additional comparison country (columns 1 and 2). We obtain the same pattern of coefficients-slower innovation before 1926 and faster innovation after 1926-when our specifications is weighted (columns 3 and 4). The results for the reconnaissance market segment are qualitatively similar to those presented in the main text but not statistically significant (columns 5 and 6). This is not surprising since we expect a focus on fighters and bombers to reflect the most desirable airframe performance characteristics.

In Table E2 we present additional results where we allow for a level shift in the outcome variable in the United States after 1926, in addition to the change in the rate of innovation that is our main focus. These results show that allowing a level shift in addition to the change in slope does not alter our main conclusion.

\section{E.4 Additional results for aero-engines}

Table E3 shows that our aero-engine results are similar to those reported in the main text comparing only the United States with the United Kingdom when observations are weighted (columns 1 and 2). In addition, results are similar when Germany and Italy as comparison countries and 
without weighting (columns 3 and 4 ) and using an alternative source for data on military engine purchases (columns 5 and 6, also unweighted).

In Table E4 we present additional results where we allow for a level shift in the outcome variable in the United States after 1926, in addition to the change in the rate of innovation that is our main focus. These results show that allowing a level shift in addition to the change in slope yields similar results to those in the main text. 


\section{Figure E1: Correlation between Alternative Airframe Performance Measures}
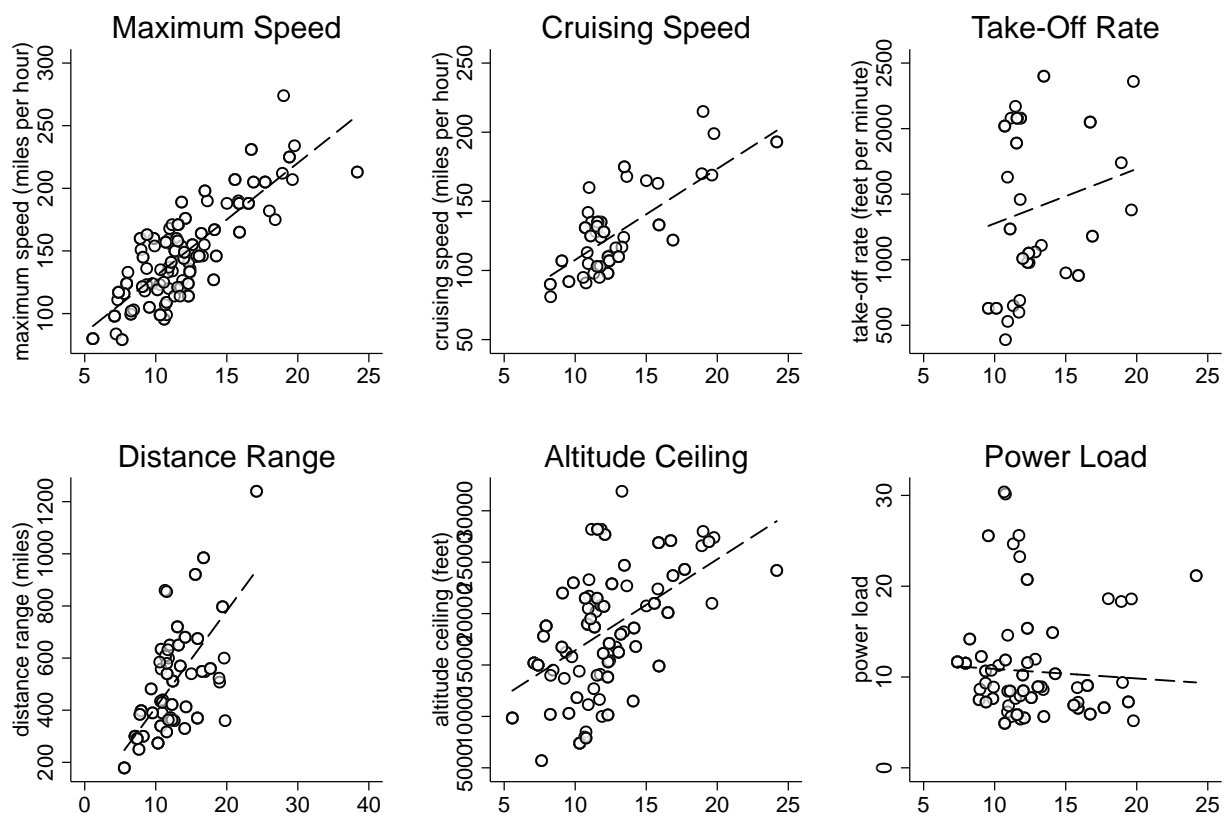

Wing Load (gross weight (in pounds) divided by wing area (in square feet)

Notes: Each panel shows the relationship between wing load and the given alternative measure of airframe performance for the US airframe industry. Power load is defined as gross weight (in lbs) per horsepower.

\section{Figure E2: Correlation between Aero-Engine Performance from Alternative Sources}
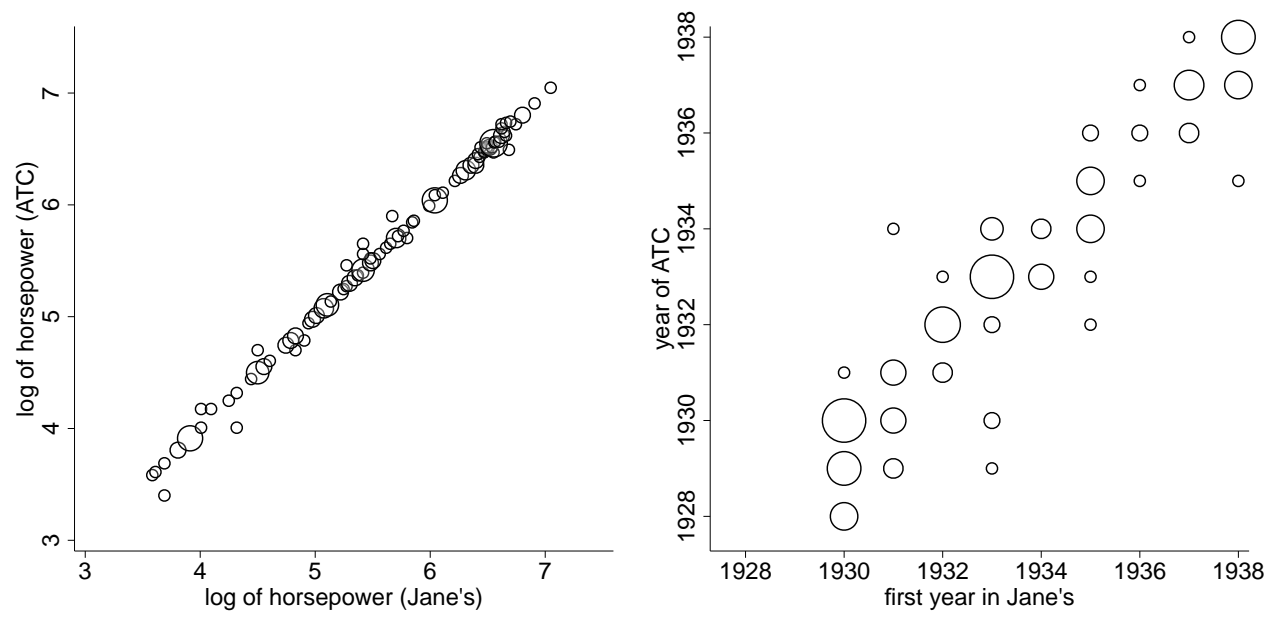

Notes: The figure shows the relationship between aero-engine performance measures from Jane's and airworthiness certification. The left panel shows this relationship for the horsepower divided by displacement (in liters) and revolutions per minute. The right panel shows this relationship for the horsepower divided by displacement (in liters). The size of the dot in each panel reflects the number of observations with the horsepower or year combination across the different sources. 
Table E1: Robustness Results for Airframe Innovation

\begin{tabular}{|c|c|c|c|c|c|c|}
\hline \multirow[b]{2}{*}{$\begin{array}{l}\text { Outcome } \\
\text { (in log) }\end{array}$} & \multicolumn{2}{|c|}{ Add Japan } & \multicolumn{2}{|c|}{ Weighted } & \multicolumn{2}{|c|}{ Reconnaissance } \\
\hline & $\begin{array}{c}(1) \\
\text { Wing } \\
\text { Load }\end{array}$ & $\begin{array}{c}(2) \\
\text { Maximum } \\
\text { Speed }\end{array}$ & $\begin{array}{c}(3) \\
\text { Wing } \\
\text { Load }\end{array}$ & $\begin{array}{c}(4) \\
\text { Maximum } \\
\text { Speed }\end{array}$ & $\begin{array}{c}(5) \\
\text { Wing } \\
\text { Load }\end{array}$ & $\begin{array}{c}6) \\
\text { Maximum } \\
\text { Speed }\end{array}$ \\
\hline Before $1926 \times$ year $\times$ US & $\begin{array}{l}-0.013 \\
(0.009)\end{array}$ & $\begin{array}{l}-0.028 \\
(0.009)\end{array}$ & $\begin{array}{l}-0.049 \\
(0.008)\end{array}$ & $\begin{array}{l}-0.038 \\
(0.009)\end{array}$ & $\begin{array}{c}0.006 \\
(0.010)\end{array}$ & $\begin{array}{l}-0.005 \\
(0.016)\end{array}$ \\
\hline After $1926 \times$ year $\times$ US & $\begin{array}{c}0.022 \\
(0.007)\end{array}$ & $\begin{array}{c}0.032 \\
(0.008)\end{array}$ & $\begin{array}{c}0.047 \\
(0.010)\end{array}$ & $\begin{array}{c}0.036 \\
(0.012)\end{array}$ & $\begin{array}{c}-0.018 \\
(0.018)\end{array}$ & $\begin{array}{l}-0.020 \\
(0.011)\end{array}$ \\
\hline $\begin{array}{l}F \text {-statistic } \\
p \text {-value }\end{array}$ & $\begin{array}{c}5.6 \\
0.019\end{array}$ & $\begin{array}{c}14.5 \\
0.000\end{array}$ & $\begin{array}{c}35.0 \\
0.000\end{array}$ & $\begin{array}{c}15.1 \\
0.000\end{array}$ & $\begin{array}{c}0.8 \\
0.371\end{array}$ & $\begin{array}{c}0.4 \\
0.510\end{array}$ \\
\hline observations & 200 & 252 & 140 & 192 & 31 & 58 \\
\hline
\end{tabular}

Notes: This table shows regression results for versions of equation (5) comparing the United States, United Kingdom, and Japan (columns 1 and 2) and alternative specifications comparing the United States and United Kingdom (columns 3 through 6). The dependent variable is the log of the variable at the top of each column. Columns 1 and 2 present results adding Japan as a comparison country, columns 3 and 4 show results without weighting by units purchased, and columns 5 and 6 shows results for the reconnaissance market segment. All specifications include a constant term, an indicator for the United States, an indicator if an airframe has more than one engine, and the log of engine horsepower. Robust standard errors are shown in parentheses. 
Table E2: Airframe Results using an Alternative Estimation Strategy

\begin{tabular}{|c|c|c|c|c|c|c|}
\hline \multirow[b]{2}{*}{$\begin{array}{l}\text { Outcome } \\
\text { (in log) }\end{array}$} & \multicolumn{2}{|c|}{ United States Only: } & \multicolumn{4}{|c|}{ Comparison of US and UK: } \\
\hline & $\begin{array}{c}(1) \\
\text { Wing } \\
\text { Load }\end{array}$ & $\begin{array}{c}(2) \\
\text { Maximum } \\
\text { Speed }\end{array}$ & $\begin{array}{c}(3) \\
\text { Wing } \\
\text { Load }\end{array}$ & $\begin{array}{c}(4) \\
\text { Maximum } \\
\text { Speed }\end{array}$ & $\begin{array}{c}(5) \\
\text { Wing } \\
\text { Load }\end{array}$ & $\begin{array}{c}(6) \\
\text { Maximum } \\
\text { Speed }\end{array}$ \\
\hline Before $1926 \times$ year $\times$ US & $\begin{array}{c}0.003 \\
(0.012)\end{array}$ & $\begin{array}{l}-0.007 \\
(0.013)\end{array}$ & $\begin{array}{c}0.002 \\
(0.016)\end{array}$ & $\begin{array}{l}-0.023 \\
(0.017)\end{array}$ & $\begin{array}{c}0.015 \\
(0.015)\end{array}$ & $\begin{array}{l}-0.009 \\
(0.014)\end{array}$ \\
\hline After $1926 \times$ year $\times$ US & $\begin{array}{c}0.071 \\
(0.006)\end{array}$ & $\begin{array}{c}0.065 \\
(0.006)\end{array}$ & $\begin{array}{c}0.028 \\
(0.011)\end{array}$ & $\begin{array}{c}0.036 \\
(0.011)\end{array}$ & $\begin{array}{c}0.033 \\
(0.010)\end{array}$ & $\begin{array}{c}0.034 \\
(0.009)\end{array}$ \\
\hline After $1926 \times$ year & & & $\begin{array}{c}0.001 \\
(0.011)\end{array}$ & $\begin{array}{c}0.016 \\
(0.010)\end{array}$ & $\begin{array}{l}-0.018 \\
(0.012)\end{array}$ & $\begin{array}{c}0.006 \\
(0.008)\end{array}$ \\
\hline Before $1926 \times$ year & & & $\begin{array}{c}0.043 \\
(0.009)\end{array}$ & $\begin{array}{c}0.029 \\
(0.009)\end{array}$ & $\begin{array}{c}0.025 \\
(0.008)\end{array}$ & $\begin{array}{c}0.034 \\
(0.007)\end{array}$ \\
\hline After $1926 \times$ US & & & $\begin{array}{l}-0.009 \\
(0.103)\end{array}$ & $\begin{array}{l}-0.077 \\
(0.113)\end{array}$ & $\begin{array}{l}-0.166 \\
(0.092)\end{array}$ & $\begin{array}{l}-0.199 \\
(0.091)\end{array}$ \\
\hline After 1926 & $\begin{array}{c}0.082 \\
(0.078)\end{array}$ & $\begin{array}{c}0.045 \\
(0.084)\end{array}$ & $\begin{array}{c}0.091 \\
(0.066)\end{array}$ & $\begin{array}{c}0.122 \\
(0.075)\end{array}$ & $\begin{array}{c}0.185 \\
(0.059)\end{array}$ & $\begin{array}{c}0.133 \\
(0.053)\end{array}$ \\
\hline United States & & & $\begin{array}{c}-4.303 \\
(30.990)\end{array}$ & $\begin{array}{c}44.322 \\
(32.704)\end{array}$ & $\begin{array}{l}-28.917 \\
(27.977)\end{array}$ & $\begin{array}{c}16.417 \\
(27.130)\end{array}$ \\
\hline $\begin{array}{l}\text { Control for: } \\
\text { 1(\# of Engines }>1 \text { ) } \\
\text { Log of Engine Horsepower }\end{array}$ & $\begin{array}{l}\text { no } \\
\text { no }\end{array}$ & $\begin{array}{l}\text { no } \\
\text { no }\end{array}$ & $\begin{array}{l}\text { no } \\
\text { no }\end{array}$ & $\begin{array}{l}\text { no } \\
\text { no }\end{array}$ & $\begin{array}{l}\text { yes } \\
\text { yes }\end{array}$ & $\begin{array}{l}\text { yes } \\
\text { yes }\end{array}$ \\
\hline $\begin{array}{l}F \text {-statistic } \\
p \text {-value }\end{array}$ & $\begin{array}{c}27.0 \\
0.000\end{array}$ & $\begin{array}{c}23.8 \\
0.000\end{array}$ & $\begin{array}{c}1.8 \\
0.187\end{array}$ & $\begin{array}{c}8.7 \\
0.003\end{array}$ & $\begin{array}{c}1.1 \\
0.295\end{array}$ & $\begin{array}{c}6.2 \\
0.013\end{array}$ \\
\hline observations & 116 & 174 & 165 & 233 & 140 & 192 \\
\hline
\end{tabular}

Notes: This table shows regression results for US airframes (columns 1 and 2) and US and UK airframes (columns 3 through 6). The dependent variable is the log of the variable at the top of each column. In columns 1,3 , and 5 wing load is defined as airframe weight (in pounds) divided by wing area (in square feet); in columns 2, 4, and 6 maximum speed is measured in miles per hour. Columns 1 and 2 show results for the United States while also allowing for a change in level of innovation before versus after 1926. Columns 3 and 4 show results comparing the United States to the United Kingdom. Columns 5 and 6 show results comparing the United States to the United Kingdom and controls for an indicator if an airframe has more than one engine and the log of engine horsepower. A constant term is included in all columns. Robust standard errors are shown in parentheses. 
Table E3: Robustness Results for Aero-Engine Innovation

\begin{tabular}{|c|c|c|c|c|c|c|}
\hline \multirow[b]{2}{*}{$\begin{array}{l}\text { Outcome } \\
\text { (in log) }\end{array}$} & \multicolumn{2}{|c|}{ Weighted } & \multicolumn{2}{|c|}{ Add Ger. and Italy } & \multicolumn{2}{|c|}{ Data from Fahey (1946) } \\
\hline & $\begin{array}{c}\text { (1) } \\
\text { HP } \div \\
\text { Weight }\end{array}$ & $\begin{array}{c}(2) \\
\mathrm{HP} \div \\
\text { Disp }\end{array}$ & $\begin{array}{c}\text { (3) } \\
\mathrm{HP} \div \\
\text { Weight }\end{array}$ & $\begin{array}{c}(4) \\
\text { HP } \div \\
\text { Disp }\end{array}$ & $\begin{array}{c}\text { (5) } \\
\mathrm{HP} \div \\
\text { Weight }\end{array}$ & $\begin{array}{c}(6) \\
\text { HP } \div \\
\text { Disp }\end{array}$ \\
\hline Before $1926 \times$ year $\times$ US & $\begin{array}{c}0.038 \\
(0.022)\end{array}$ & $\begin{array}{l}-0.035 \\
(0.030)\end{array}$ & $\begin{array}{c}0.043 \\
(0.017)\end{array}$ & $\begin{array}{c}0.004 \\
(0.018)\end{array}$ & $\begin{array}{c}0.038 \\
(0.013)\end{array}$ & $\begin{array}{c}0.015 \\
(0.017)\end{array}$ \\
\hline After $1926 \times$ year $\times$ US & $\begin{array}{l}-0.028 \\
(0.016)\end{array}$ & $\begin{array}{c}0.010 \\
(0.022)\end{array}$ & $\begin{array}{l}-0.040 \\
(0.010)\end{array}$ & $\begin{array}{l}-0.018 \\
(0.011)\end{array}$ & $\begin{array}{l}-0.054 \\
(0.016)\end{array}$ & $\begin{array}{l}-0.055 \\
(0.015)\end{array}$ \\
\hline $\begin{array}{l}F \text {-statistic } \\
p \text {-value }\end{array}$ & $\begin{array}{c}3.6 \\
0.061\end{array}$ & $\begin{array}{c}0.9 \\
0.354\end{array}$ & $\begin{array}{c}12.2 \\
0.001\end{array}$ & $\begin{array}{c}0.7 \\
0.402\end{array}$ & $\begin{array}{c}12.4 \\
0.001\end{array}$ & $\begin{array}{c}6.0 \\
0.017\end{array}$ \\
\hline observations & 123 & 123 & 266 & 123 & 93 & 94 \\
\hline
\end{tabular}

Notes: This table shows regression results for versions of equation (5) comparing the United States, United Kingdom, Germany, and Italy. Columns 1 and 2 compares the United States and United Kingdom weighting the by the numer of units purchase, columns 3 and 4 add Germany and Italy to the comparison group, and columns 5 and 6 shows results using an alternative source for military engine purchases (Fahey, 1946). All specifications include a constant term, an indicator for the United States, and control for an indicator if an aero-engine is liquid-cooled. Robust standard errors are shown in parentheses. 
Table E4: Aero-Engine Results using an Alternative Estimation Strategy

\begin{tabular}{|c|c|c|c|c|c|c|}
\hline \multirow[b]{2}{*}{$\begin{array}{l}\text { Outcome } \\
\text { (in log) }\end{array}$} & \multicolumn{3}{|c|}{ United States Only: } & \multicolumn{3}{|c|}{ Comparison of US and UK: } \\
\hline & $\begin{array}{c}(1) \\
\text { HP } \div \\
\text { Weight }\end{array}$ & $\begin{array}{c}(2) \\
\mathrm{HP} \div \\
\text { Disp }\end{array}$ & $\begin{array}{c}(3) \\
\mathrm{HP} \div \\
\text { Area }\end{array}$ & $\begin{array}{c}(4) \\
\mathrm{HP} \div \\
\text { Weight }\end{array}$ & $\begin{array}{c}\text { (5) } \\
\mathrm{HP} \div \\
\text { Disp }\end{array}$ & $\begin{array}{c}6) \\
\text { HP } \div \\
\text { Area }\end{array}$ \\
\hline Before $1926 \times$ year $\times$ US & $\begin{array}{c}0.045 \\
(0.012)\end{array}$ & $\begin{array}{c}0.030 \\
(0.012)\end{array}$ & $\begin{array}{c}0.141 \\
(0.029)\end{array}$ & $\begin{array}{c}0.042 \\
(0.013)\end{array}$ & $\begin{array}{c}0.021 \\
(0.021)\end{array}$ & $\begin{array}{c}0.103 \\
(0.040)\end{array}$ \\
\hline After $1926 \times$ year $\times$ US & $\begin{array}{l}-0.007 \\
(0.005)\end{array}$ & $\begin{array}{c}0.046 \\
(0.006)\end{array}$ & $\begin{array}{c}0.078 \\
(0.010)\end{array}$ & $\begin{array}{l}-0.039 \\
(0.010)\end{array}$ & $\begin{array}{l}-0.007 \\
(0.014)\end{array}$ & $\begin{array}{c}0.021 \\
(0.017)\end{array}$ \\
\hline After $1926 \times$ year & & & & $\begin{array}{c}0.004 \\
(0.006)\end{array}$ & $\begin{array}{c}0.020 \\
(0.016)\end{array}$ & $\begin{array}{c}0.031 \\
(0.029)\end{array}$ \\
\hline Before $1926 \times$ year & & & & $\begin{array}{c}0.032 \\
(0.009)\end{array}$ & $\begin{array}{c}0.060 \\
(0.014)\end{array}$ & $\begin{array}{c}0.054 \\
(0.015)\end{array}$ \\
\hline After $1926 \times$ US & & & & $\begin{array}{l}-0.137 \\
(0.078)\end{array}$ & $\begin{array}{l}-0.153 \\
(0.106)\end{array}$ & $\begin{array}{l}-0.178 \\
(0.205)\end{array}$ \\
\hline After 1926 & $\begin{array}{l}-0.043 \\
(0.044)\end{array}$ & $\begin{array}{l}-0.046 \\
(0.051)\end{array}$ & $\begin{array}{l}-0.086 \\
(0.089)\end{array}$ & $\begin{array}{c}0.092 \\
(0.069)\end{array}$ & $\begin{array}{c}0.069 \\
(0.097)\end{array}$ & $\begin{array}{c}0.116 \\
(0.192)\end{array}$ \\
\hline United States & & & & $\begin{array}{l}-80.124 \\
(25.716)\end{array}$ & $\begin{array}{l}-41.046 \\
(40.350)\end{array}$ & $\begin{array}{l}-198.813 \\
(76.376)\end{array}$ \\
\hline $\begin{array}{l}\text { Control for: } \\
\text { 1(Liquid-Cooled) }\end{array}$ & yes & yes & yes & yes & yes & yes \\
\hline $\begin{array}{l}F \text {-statistic } \\
p \text {-value }\end{array}$ & $\begin{array}{c}19.3 \\
0.000\end{array}$ & $\begin{array}{c}1.6 \\
0.203\end{array}$ & $\begin{array}{c}5.0 \\
0.028\end{array}$ & $\begin{array}{c}24.3 \\
0.000\end{array}$ & $\begin{array}{c}1.2 \\
0.269\end{array}$ & $\begin{array}{c}3.7 \\
0.058\end{array}$ \\
\hline $\begin{array}{l}\text { observations } \\
\text { obse }\end{array}$ & 85 & 85 & 85 & 123 & 123 & 123 \\
\hline
\end{tabular}

Notes: This table shows regression results for US aero-engines (columns 1 through 3) and US and UK aero-engines (columns 4 through 6). The dependent variable is the log of the variable at the top of each column. In columns 1 and 3 weight is measured in pounds; in columns 2 and 4 displacement is measured in liters; and in columns 3 and 6 frontal area is measured in square inches. Columns 1 through 3 show results for the United States only while also allowing for a change in level of innovation before versus after 1926. Columns 4 through 6 show results comparing the United States to the United Kingdom while also allowing for a change in level of innovation before versus after 1926 for both countries together. A constant term and an indicator if an engine is liquid cooled are included in all columns. Robust standard errors are shown in parentheses. 


\section{E.5 Timing of changes in airframe and aero-engine innovation}

In our main empirical analysis, we impose a change in policy in 1926 and then quantify differences before and after this year. However, it is useful to consider an alternative approach that allows for a single break year that best explains the data. Figure E3 plots the results from a specification similar to equation (4), but where the break in the linear spline is chosen to best fit the data. In each panel, the paths of innovation is similar to the results reported in the main text. For airframes, there is period of slow progress followed by an increase (Panel A); for engines, there is a period of more rapid progress and then a slowdown (Panel B). The "optimal" year after 1926 for airframes and aero-engines, which is consistent with results presented in the main text as well as evidence presented in Appendix D.

\section{E.6 Additional results for individual firms}

This subsection presents performance patterns at the level of individual producers for three of the most important airframe firms during this period, Boeing, Curtiss and Douglas. These graphs cover all of the aircraft produced for the military by each of these three firms during the study period. The data come from different sources than those used in the main analysis, so these results also provide a check on our main data. ${ }^{51}$

These figures indicate that the same pattern of accelerated innovation after 1926 documented in the main analysis also appear when we look at performance measures by company. The only exception here is for the maximum speed of Curtiss aircraft. It is worth noting that these figures include all types of military aircraft, so the changes in performance may also be influenced by shifts in the mix of aircraft being produced. Because of this, we view these as somewhat less indicative of overall performance improvements than the results shown in the main text, which focus on specific aircraft types. Nevertheless, the fact that we view similar patterns within companies provides further support for the results presented in the main text.

\section{E.7 Comparing innovation in military and civil designs}

In this appendix we compare innovation patterns in the U.S. for firms focused on the military market and those focused instead on the civil/commercial market. This is a useful comparison because it can shed light on which of these two sides of the market appears to have been driving innovation forward in the period after 1926. If the key force at work after 1926 was changes in the attractiveness of the civil/commercial market due to policy changes such as the Air Commerce Act, then we should expect firms focused entirely on that market to innovate at least as fast, if not faster, after 1926, than firms focused mainly on selling to the military. In contrast, if the change

\footnotetext{
${ }^{51}$ The data for Boeing come from Bowers (1989). The Curtiss data are from Bowers (1987). The Douglas data are from Francillon (1988).
} 
in military procurement policy that we highlight was more important, then we should expect faster innovation among producers focused on the military market.

For airframe producers, we study all designs from the six largest U.S. airframe producers. We focus in particular on a comparison between those producers focused primarily on the military market (Boeing, Curtiss, Douglas and Martin) and those focused primarily on the civil/commercial market (Fairchild and Lockheed). ${ }^{52}$ There are two important points to note about the airframe analysis. First, we focus on whether firms were focused on the military or civil market here, rather than whether particular designs were intended for military or civil use, because we expect there to be some spillovers between military and civil designs within a firm. Second, we study patterns only after 1926. This is because we observe too few designs from the major civil producers before 1926 to conduct a pre/post analysis.

For aero-engines, we focus on the designs produced by all firms, comparing the main producers of military engines (Wright, Curtiss and Pratt \& Whitney) to all other firms. These data come from volumes of Jane's All the Worlds Aircraft and cover all major new engine designs. Since these data cover all firms, we do have enough civil designs to study relative patterns both before and after 1926.

Table E5 presents regression results quantifying the difference between the military and civilian markets for airframes and engines. Columns 1 and 2 estimate the difference in slopes based on two different measures of airframe performance. Columns 3 through 5 show relative performance of military and civilian after 1926. This suggests limited scope for the results presented in Section 5 to be driven by changes in the civilian market rather than the change in IP protection that is the main focus of this paper.

\footnotetext{
${ }^{52}$ See Appendix E.6 for details on these data.
} 


\section{Figure E3: Timing for Airframe and Aero-Engine Innovation}

A. Airframes
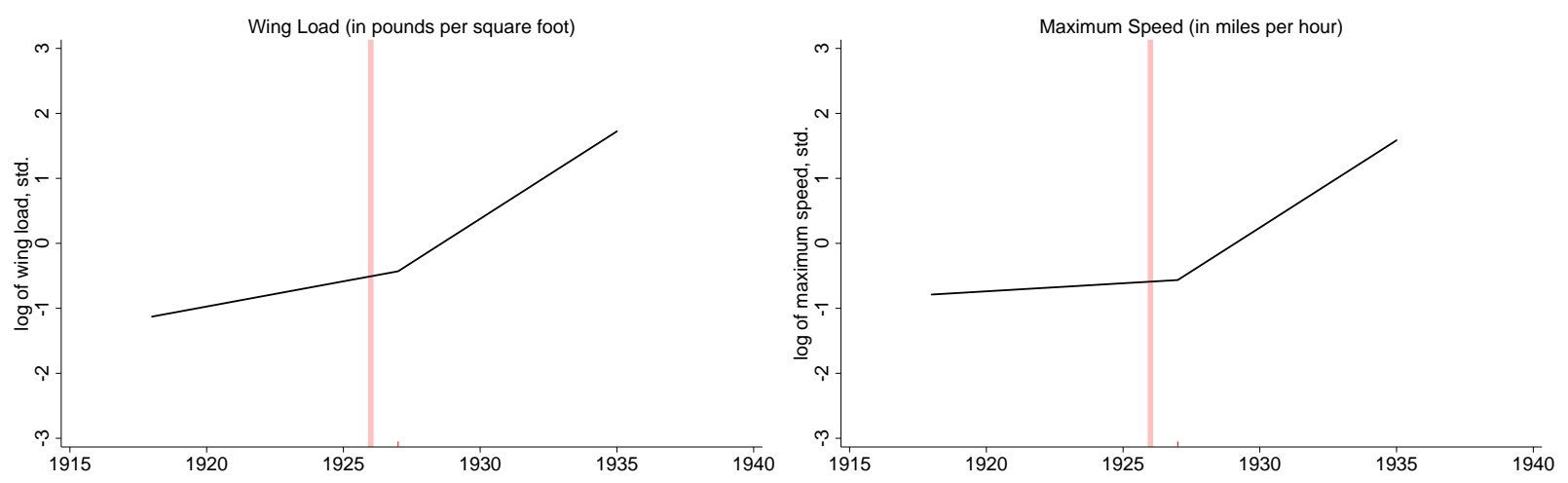

B. Aero-Engines
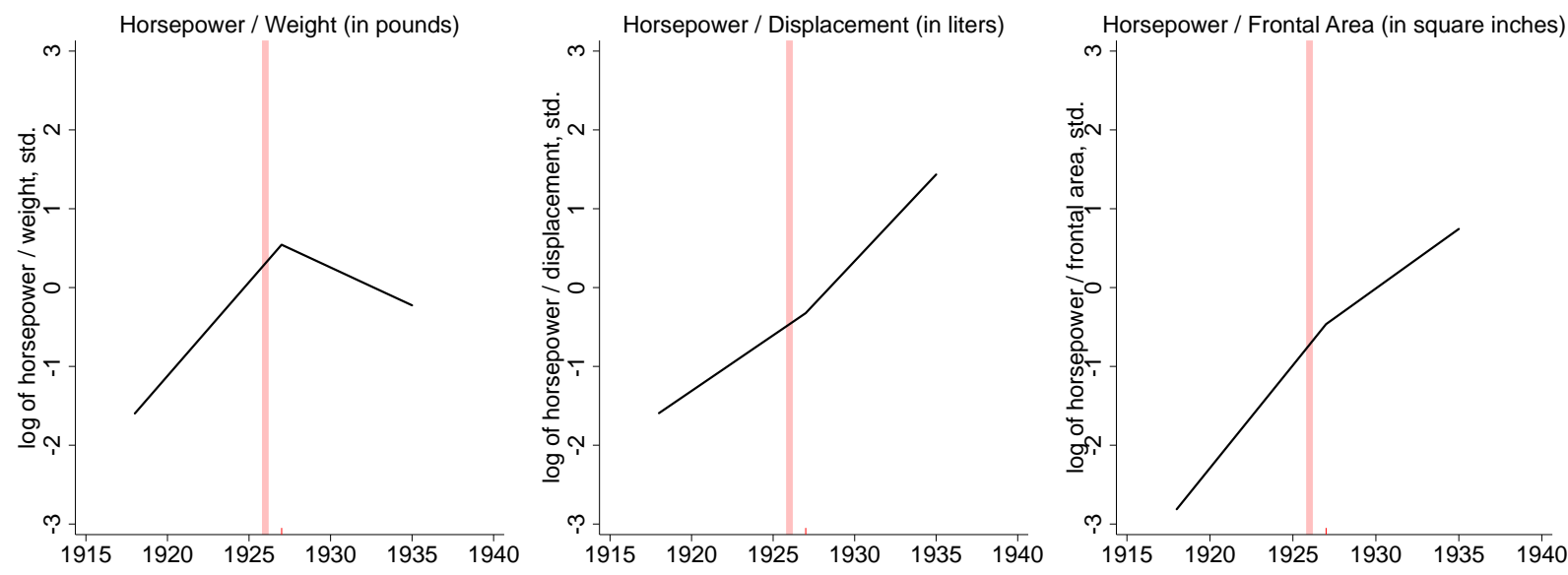

Notes: The figure shows the results of estimating a specification similar to equation (4). For airframes, the break year for the linear spline the best fits the data is 1929 (Panel A). For aero-engines, the break year for the linear spline the best fits the data is 1926 (Panel B). 


\section{Figure E4: Evolution of aircraft performance by company}
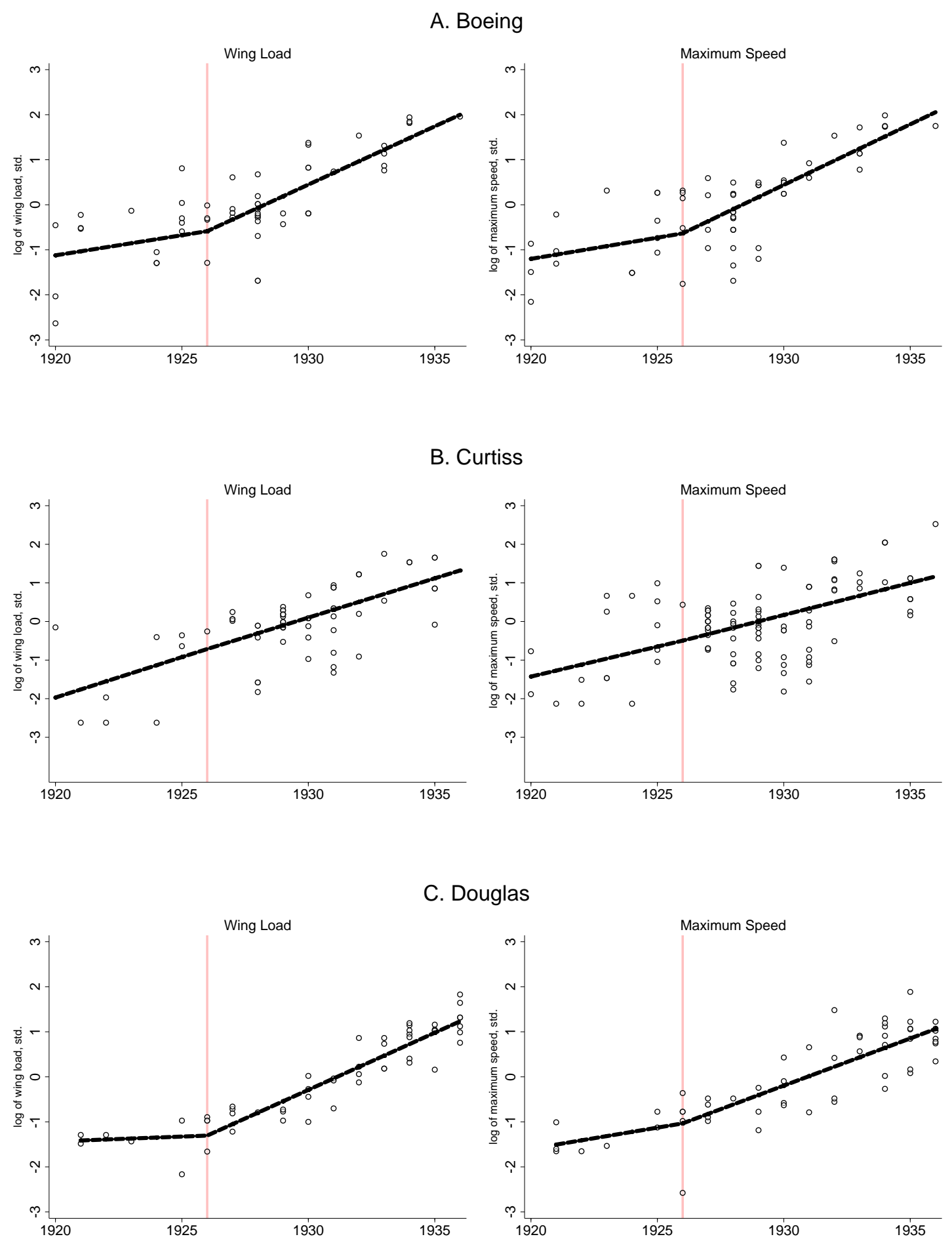
Table E5: Comparing Military versus Civil Airframe and Engine Producers

\begin{tabular}{|c|c|c|c|c|c|}
\hline & (1) & (2) & (3) & (4) & (5) \\
\hline Outcome & Wing & Maximum & $\mathrm{HP} \div$ & $\mathrm{HP} \div$ & $\mathrm{HP} \div$ \\
\hline (in log) & Load & Speed & Weight & Disp & Area \\
\hline \multirow[t]{2}{*}{ Military $\times$ year } & 0.038 & 0.028 & 0.005 & 0.041 & 0.016 \\
\hline & $(0.010)$ & $(0.007)$ & $(0.011)$ & $(0.011)$ & $(0.021)$ \\
\hline firm fixed effects & yes & yes & yes & yes & yes \\
\hline year fixed effects & yes & yes & yes & yes & yes \\
\hline observations & 225 & 261 & 265 & 137 & 244 \\
\hline
\end{tabular}




\section{F. Merger Appendix}

Figure F1 describes the pattern of merger activity among US firms active in military airframe or engine production from 1920-1934, the year in which Roosevelt's administration intervened in the industry to break up United Aircraft. At the top we have the two major US military aeroengine producers after 1926, Wright Aeronautical and Pratt \& Whitney. Curtiss also produced some military aero-engines during this period, though the firm was primarily focused on airframes. Contemporary sources indicate that these were essentially the only firms capable of producing the high-performance aero-engines demanded by the military.

Figure F2 describes the pattern of entry, exit and merger activity among all US aero-engine producers, including both civil and military. These producers can be roughly divided into integrated aero-engine and airframe firms (such as Aeromarine, Curtiss, Kinner), firms affiliated with major automotive manufactures (Allison, Continental, Lycoming, Packard), independent firms, and the major military engine producers (Wright and Pratt \& Whitney). Lawrence, which also made military aircraft engines, was absorbed by Wright early in the 1920s. This loss of an independent producer was part of the impetus for the Navy to encourage the founding of Pratt \& Whitney by former Wright employees, which aimed at maintaining some competition in the market. Curtiss really belongs among both the integrated firms and the military engine producers, since it produced military engines before the merger with Wright. Subsequent to the merger, engine production activities were concentrated in the Wright division of Curtiss-Wright. It is worth noting that two of the integrated firms, Kinner and Aeronca, do not appear in Figure F1 because they primarily produced small light planes for the civil market.

These data show that the only substantial vertical-complement merger activity between 1920 and 1934 occurred among the military engine producers. All of the integrated firms remained integrated during the study period, while all of the other firms remained focused only on engine production.

The next set of data, described in Figure F3, shows merger patterns among British airframe and aero-engine producers. We can see that British firms did not undertake the same type of merger activity between airframe and aero-engine producers in the late 1920s observed in the U.S. The only substantial merger during this period was the purchase of the airframe producer Avro by the integrated group that already included Armstrong-Whitworth Aircraft together with Armstrong-Siddeley Engines. This grouping was itself a byproduct of the mega-merger between two enormous armament firms, Vickers and Armstrong Whitworth, which took place in 1927. That merger resulted in the spin-off of the aircraft and aero-engine holdings of Armstrong Whitworth as two separate companies both under the direction of Sir John Siddeley, who then used 
the opportunity to purchase Avro. The impetus behind this activity was thus driven by forces outside of the aircraft industry, which was of relatively little importance to the larger Armstrong or Vickers conglomerates.

Most importantly, we see no evidence that leading military aero-engine makers, such as Rolls-Royce, engaged in merger activity similar to what we have observed among U.S. aeroengine producers. Overall the pattern observed in Britain indicates that the pattern observed among U.S. producers were not being driven by broader industry trends, such as changes in technologies or production methods.

Finally, in Table F1, we describe the pattern of matching between products produced by the different airframe and aero-engine firms before and after 1926. Each cell in this table describes the share of each airframe producer's output that was used together with engines from a particular aero-engine firm. Prior to 1926, we see that Boeing airframes were relatively more likely to be used with Pratt \& Whitney engines, while Curtiss airframes were more likely to use Wright engines. Given this, the fact that Boeing subsequently merged with Pratt \& Whitney while Curtiss merged with Wright matches what our theory would predict. In addition, after 1928, we see that these matching patterns were even stronger, a pattern that is also consistent with what the theory would lead us to expect (though it is not unexpected and may be explained in a variety of other ways).

Table F1: Engines Used By Airframe Producers Before and After 1929

\begin{tabular}{|c|c|c|c|c|c|c|}
\hline \multirow[b]{3}{*}{ Airframe } & \multicolumn{6}{|c|}{ Engine Producers: } \\
\hline & \multicolumn{2}{|c|}{ Pratt \& Whitney } & \multicolumn{2}{|c|}{ Wright } & \multicolumn{2}{|c|}{ Other Engine } \\
\hline & (1) & (2) & (3) & (4) & (5) & (6) \\
\hline Producers: & Pre-1929 & Post-1929 & Pre-1929 & Post-1929 & Pre-1929 & Post-1929 \\
\hline Boeing & 0.2917 & 0.9375 & 0.3750 & 0.0312 & 0.3333 & 0.0312 \\
\hline Curtiss & 0.2571 & 0.4815 & 0.4571 & 0.5185 & 0.2857 & 0.0000 \\
\hline Other & 0.1667 & 0.4098 & 0.1389 & 0.5082 & 0.6944 & 0.0820 \\
\hline
\end{tabular}

Notes: The table shows the fraction of output by Boeing, Curtiss, and "other" airframe producers that use Pratt \& Whitney, Wright, and "other" engines before and after 1929. 
Figure F1: Entry, Exit, and Mergers of Airframe and Engine Producers

Engine producers

Wright Aeronautical

Pratt \& Whitney

Airframe producers:

Curtiss

Huff-Daland/Keystone

Loening

Travel Air

Boeing:

Chance-Vought

Stearman

Sikorski

Consolidated

Thomas Morse

Fleet

Glenn L. Martin Co.

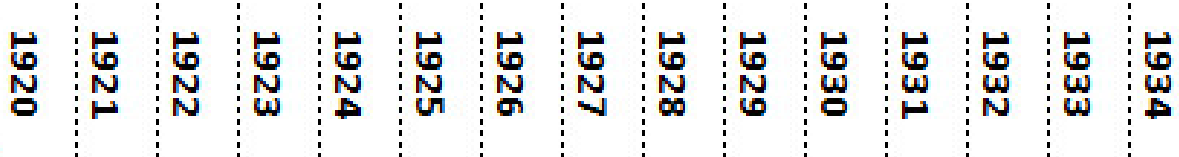

Lockheed

Douglas (Northrup)

Fairchild

Grumman

Cox-Klemin

Aeromarine-Klemm

Waco

New Standard

Atl./Fokker/Nor. Am.

Berliner Joyce:

Bellanca

Seversky/Republic:

Lowe Willard Fowler

Stout/Ford Motor:

Hall:
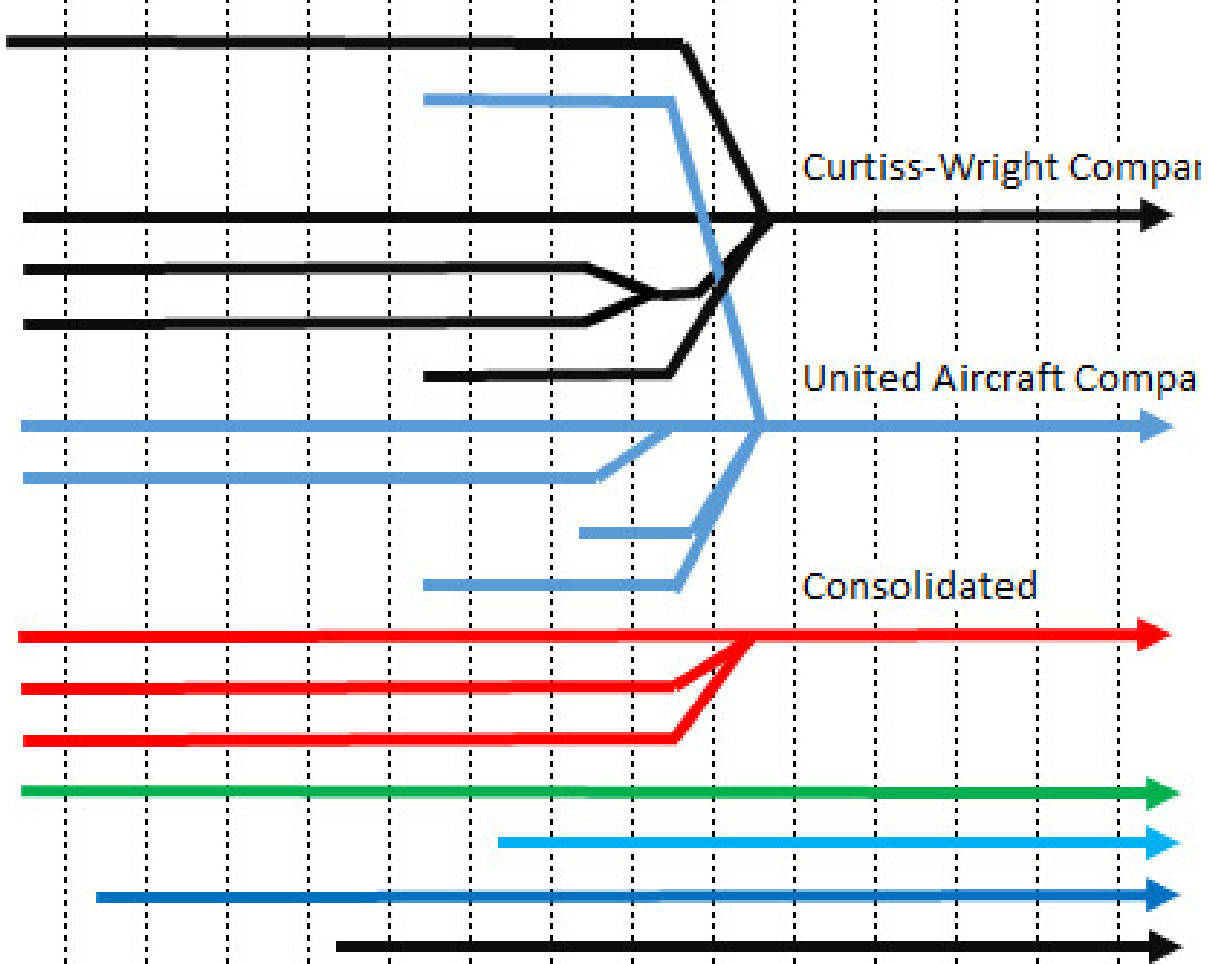

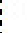

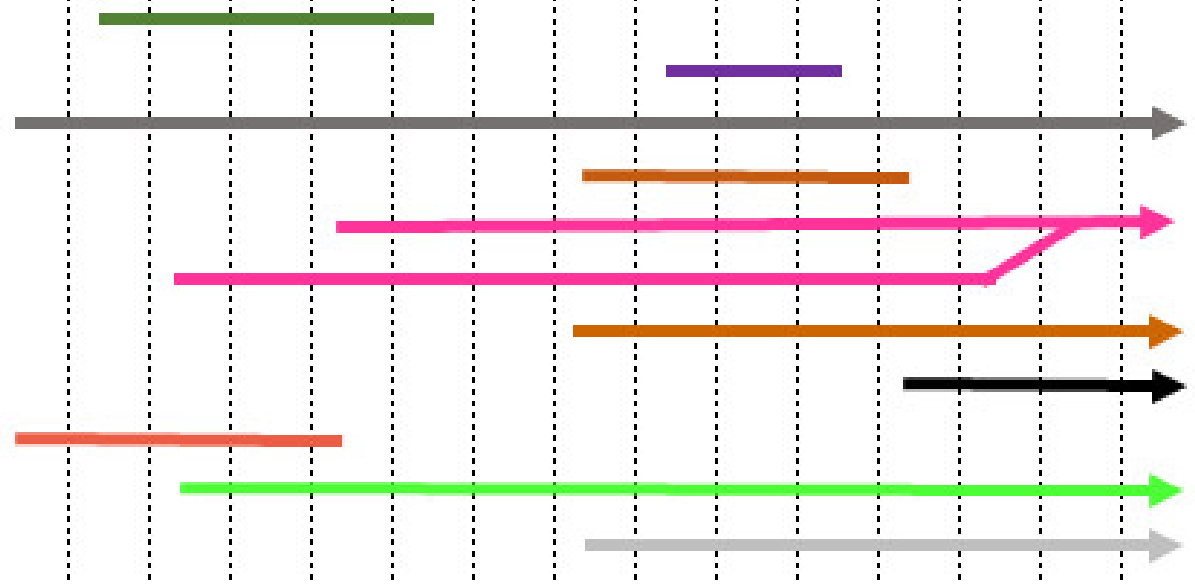


Figure F2: Entry, Exit, and Mergers, Among U.S. Aero-Engine Producers

Main military aero-engine manufacturers

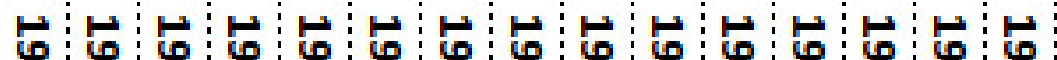

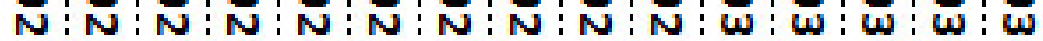

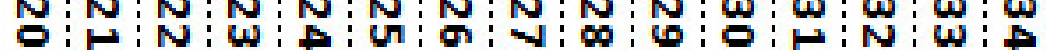

Pratt \& Whitney/United:

Wright/Curtiss-Wright

Lawrence

Integrated firms

Aero-marine

Aeronca

Curtiss

Kinner

Ranger (Fairchild)

Affiliates of auto companies

Allison (GM)

Continental

Packard

Lycoming

Unaffiliated firms

Detroit

Le Blond

Guiberson

Hall-Scott

Jacobs

Menasco

Szekeley

Warner

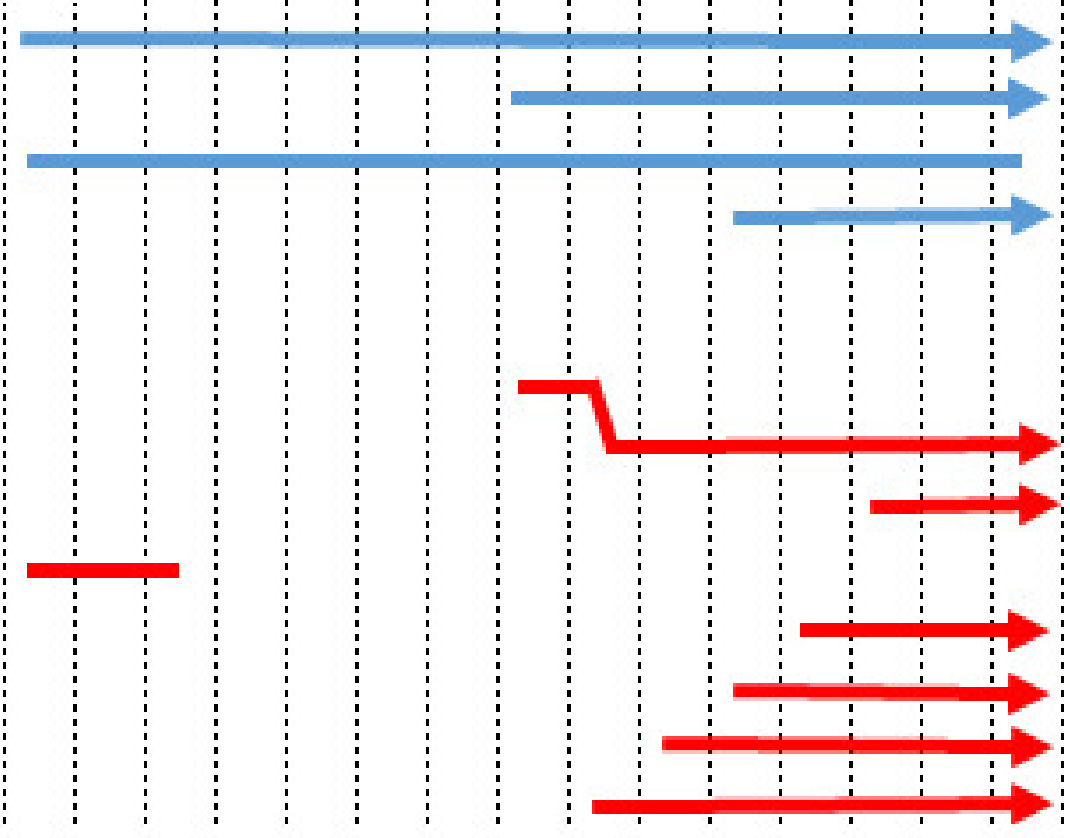


Figure F3: Entry, Exit, and Mergers, Among British Firms

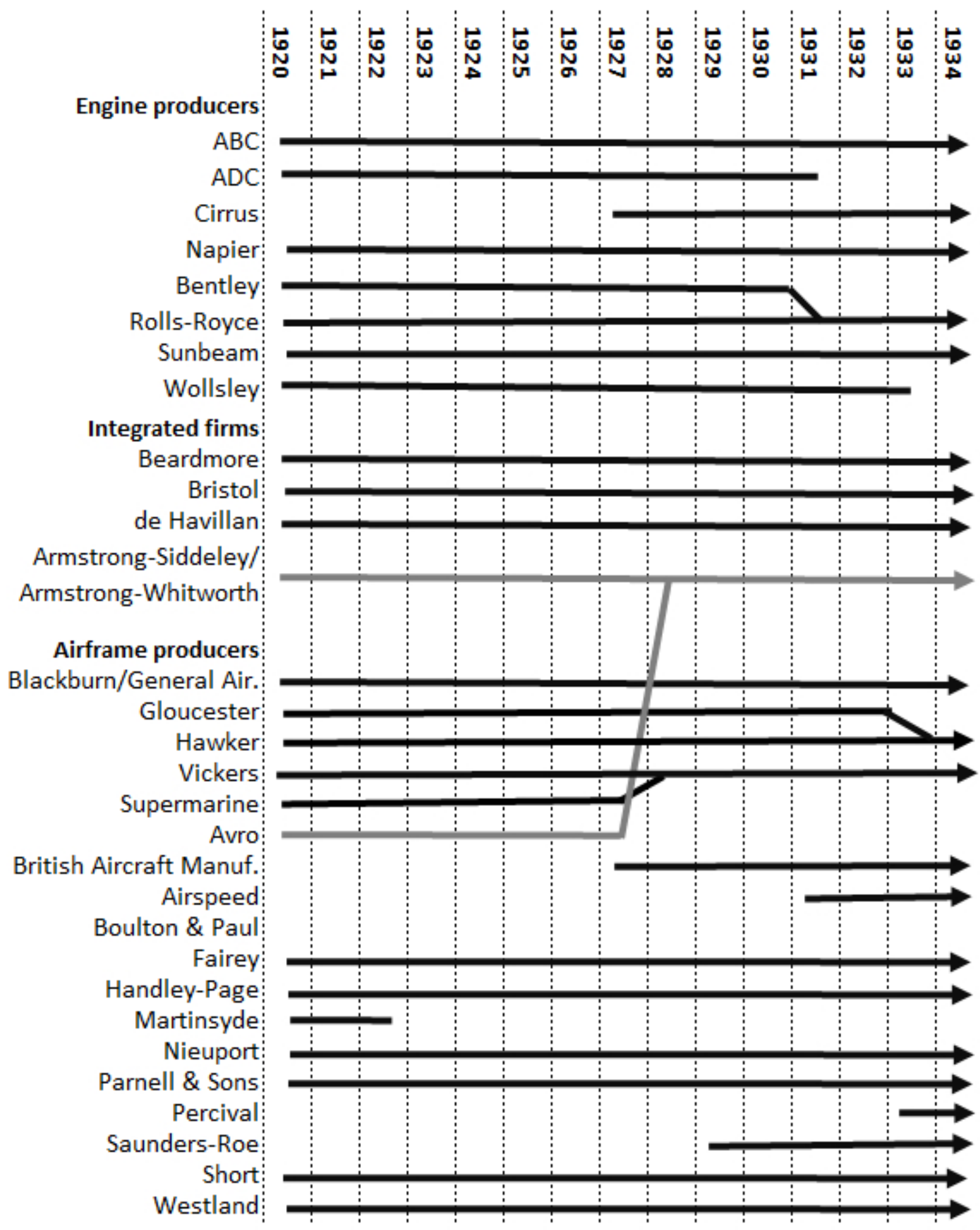




\section{G. Discussion of Alternative Explanations}

Our main analysis shows three patterns. First, the rate of airframe innovation increased after 1926. Second, the rate of aero-engine innovation diminished after 1926. Third, within three years of the 1926 Act, the most important aero-engine firms had merged with the most important airframe producers. Our theory provides a simple mechanisms that describes how providing IP protection to airframe producers may have generated all three of these outcomes. This theory is attractive in part because it is simple and relies on straightforward economic (profit) incentives. Below we discuss potential alternative explanations for the patterns we have observed.

Quality substitutes: One alternative explanation for our findings is that the quality of airframes and the quality of aero-engines are substitutes. In this theory, faster improvement in airframes could reduce the incentive for innovation in aero-engines. However, our study of the aircraft industry during this period suggests that airframe and engine performance were more likely to be complements than substitutes. For example, better engines could make planes faster, but with faster speeds poor aerodynamics became costlier in terms of lost efficiency and increased stress on the airframe. Conversely, better aerodynamic performance made airframes more efficient, but these efficiency gains were even greater at the higher speeds that more powerful engines could achieve. We view this explanation as unlikely, although we cannot not rule out some level of substitutability or complementarity in quality between airframe and engine technology.

Spillovers from civil/commercial market: Another potential concern is that the change in innovation patterns may have been driven by policy changes affecting the civil and commercial aviation market, such as the Air Commerce Act. As discussed in Section 2, the fact that we focus on a high-performance segment of the market where the military was the dominant buyer suggests that this is unlikely. Further evidence against this explanation is offered in Appendix E.7. After 1926, it was firms focused on the military rather than the civilian/commercial market that drove innovation in both airframes and aero-engines. Not only did firms selling mainly to the military innovate more rapidly after 1926, but within these firms the civil designs they did produce tended to follow rather than lead the performance of military designs. These patterns are not consistent with our main results being driven by changes occurring in the civil/commercial market.

Increase in demand: Another potential alternative theory is that the patterns we document were due to changes in the overall government demand for military aircraft after 1926. Greater demand could explain the acceleration in airframe performance. However, this story is difficult to reconcile with the slow-down in engine performance. Thus, while the increase in demand was 
likely to affect military aircraft market during this period, this explanation is not consistent with our key empirical findings.

Change in procurement: Alternatively, innovation activity observed around 1926 could have been due to changes in procurement practices, rather than property rights. However, the records of the Air Corps Procurement Board do not indicate other significant changes in procurement practices beyond the shift from competitive bidding to negotiated contracts. In addition, the fact that a number of the important designs produced after 1926 were private ventures rather than the result of government contracts for experimental aircraft or clearly-defined design competitions suggests this channel is unlikely to be driving our results (see Appendix D for further details).

Within-company learning: Finally, airframe producers may have experienced learning that allowed for the production of better designs over time. As with the explanation emphasizing increased government demand, this explanation is not consistent with the slowdown in engine performance nor does it explain relative differences between the United States and foreign airframe producers. 